Portland State University

PDXScholar

\title{
Development of a Liquid Contacting Method for Investigating Photovoltaic Properties of PbS Quantum Dot Solids
}

Vitalii Alekseevich Dereviankin

Portland State University

Follow this and additional works at: https://pdxscholar.library.pdx.edu/open_access_etds

Part of the Chemistry Commons, and the Nanoscience and Nanotechnology Commons Let us know how access to this document benefits you.

\section{Recommended Citation}

Dereviankin, Vitalii Alekseevich, "Development of a Liquid Contacting Method for Investigating Photovoltaic Properties of PbS Quantum Dot Solids" (2018). Dissertations and Theses. Paper 4240. https://doi.org/10.15760/etd.6124

This Dissertation is brought to you for free and open access. It has been accepted for inclusion in Dissertations and Theses by an authorized administrator of PDXScholar. Please contact us if we can make this document more accessible: pdxscholar@pdx.edu. 
Development of a Liquid Contacting Method for

Investigating Photovoltaic Properties of PbS Quantum Dot Solids

by

Vitalii Alekseevich Dereviankin

A dissertation submitted in partial fulfillment of the requirements for the degree of

Doctor of Philosophy

in

Chemistry

Dissertation Committee:

Erik Johansson, Chair

Andrea Goforth

Theresa McCormick

Shankar Rananavare

Rajendra Solanki

Portland State University

2018 
(C) 2017 Vitalii Alekseevich Dereviankin 


\begin{abstract}
Photovoltaic (PV) devices based on $\mathrm{PbS}$ quantum dot (QD) solids demonstrate high photon-to-electron conversion yields. However, record power conversion efficiencies remain limited mainly due to bulk and interfacial defects in the light absorbing material (QD solids). Interfacial defects can be formed when a semiconductor, such as QD solid, is contacted by another material and may predetermine the semiconductor/metal or semiconductor/metal-oxide junction properties. The objective of the work described in this dissertation was set to explore whether electrochemical contacting using liquid electrolytes can provide sufficient means of contacting the QD solids to investigate their PV performance without introducing the unwanted interfacial defects. I have initially focused on optimizing processing conditions for efficient QD solids deposition and studied their photovoltaic properties in a standardized solid-state, depleted heterojunction solar cell configuration. Further, a liquid contacting method was developed to study the relationship between photovoltages of QD solids and the energetics (e.g. reduction potentials) of the liquid contacting media. This electrochemical contacting of PbS QD solids was achieved by using anhydrous liquid electrolytes containing fast, non-coordinating, outer-sphere redox couples. Depending on the energetics of a redox couple, both rectifying and nonrectifying (Ohmic) PbS QD solid/electrolyte junctions were successfully formed with both p- and n-type QD solids. Furthermore, application of the liquid solution contacting method in studies of the PbS QD solids has unprecedentedly demonstrated that an ideal behavior of the photovoltage changes with respect to the changes in the energetics of the contacting media can be achieved. This fact supports the initially proposed hypothesis that such liquid
\end{abstract}


contacting method will not introduce surface defects to the studied QD materials, allowing for their intrinsic properties to be better understood. The applicability of this method to both p- and n- type QD solids was demonstrated. Finally, a better understanding of the relationships between the surface and ligand chemistries of both p- and n-type QD solids and their photovoltaic properties was possible via applications of such method in conjunction with XPS and UPS studies. 


\section{Dedication}

This work is dedicated to my wife, Marina, my parents and my best friends, whose support brings immeasurable values to my life, passions, and education.

"To raise new questions, new possibilities, to regard

old problems from a new angle, requires creative imagination and marks real advance in science."

Albert Einstein 


\section{Acknowledgments}

I am thoroughly thankful to my research adviser, Dr. Erik Johansson, for guiding and assisting me in my research adventures. His exceptional electrochemistry knowledge, and the accessible way of teaching it, has significantly inspired me to always strive to understand more about the theories and areas of study I was going through.

I also want to thank all professors, I had fruitful times working with, at both Portland State and Kyiv State Universities, and in both laboratory and class environments. Their shared experiences do bring unpriced values to my academic and professional growth and teach me how to ask new questions, open new possibilities, solve problems, and how to turn interesting ideas into realizable projects. Rest assured, according to the quote above.

I specifically want to thank rest of my graduate committee members, Andrea Goforth, Theresa McCormick, Shankar Rananavare, and Rajendra Solanki for their support in my doctoral studies, and, of course, for the great classes that they taught to me! 


\section{Table of Contents}

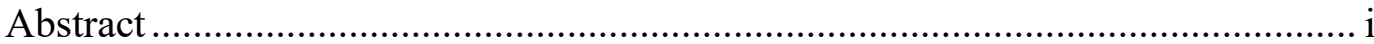

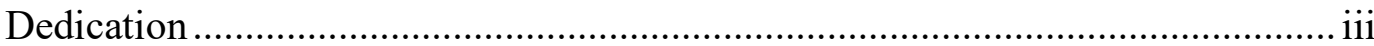

Acknowledgments.................................................................................. iv

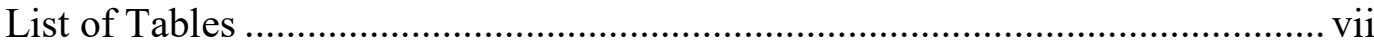

List of Figures ..................................................................................... viii

List of Abbreviations and Symbols......................................................... xii

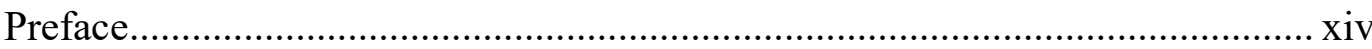

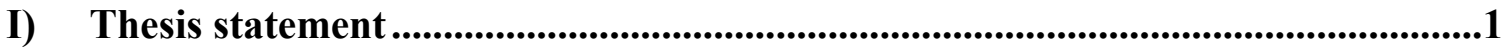

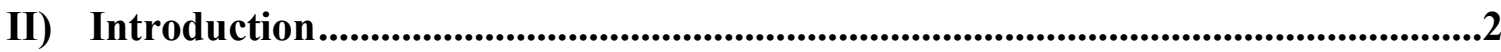

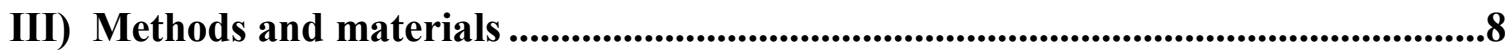

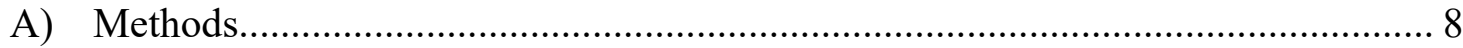

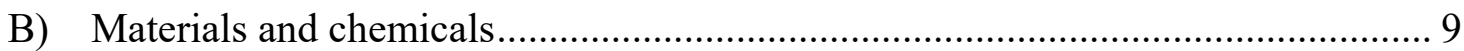

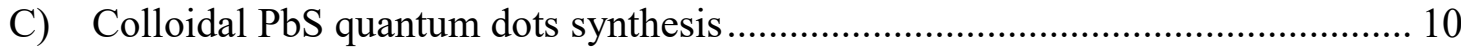

D) Preparation of p-type and n-type PbS QD solids ............................................ 11

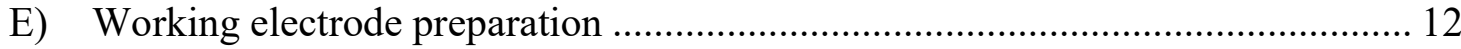

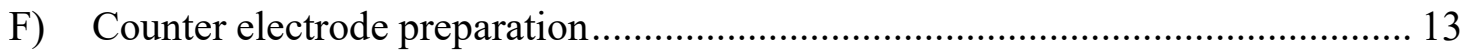

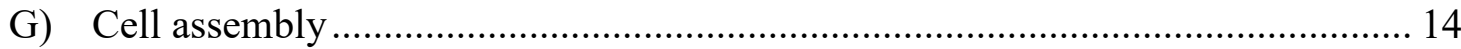

H) Redox electrolytes for contacting the QD solids ...................................... 15

I) Reduction potentials of contacting solutions ................................................ 16

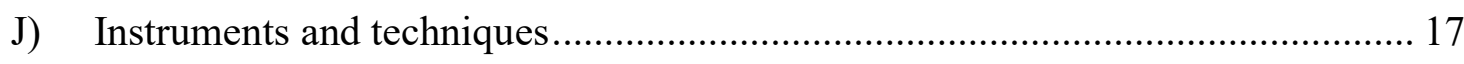

IV) Proof of concept: liquid contacting as a method to study PbS QD solids...........18

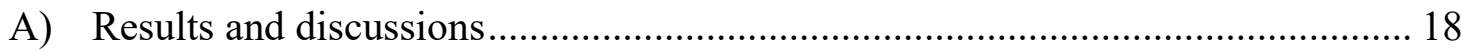

1) Electrochemical studies of p-type QD solids .............................................. 18

2) Understanding of Schottky junction interface formation............................... 26

3) Air exposure effect on the 3-MPA:PbS QD solids .......................................29

Effect of air exposure on inertly-deposited QD solids....................................... 34

Inhibition of the air effect .......................................................................... 35

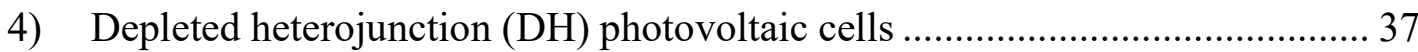

Photovoltaic performance of p-type QD solids in DH configuration .................. 39

Optical properties of the DH substrates - $\mathrm{TiO}_{2} / \mathrm{PbS}$ QDs .................................. 40

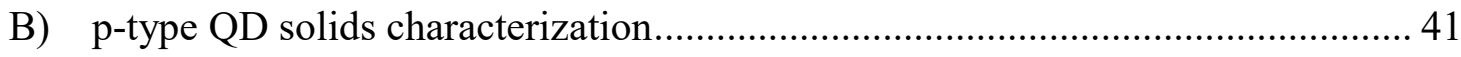

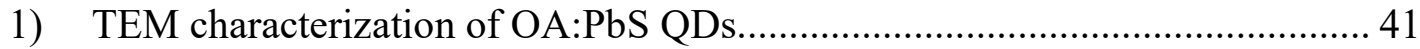

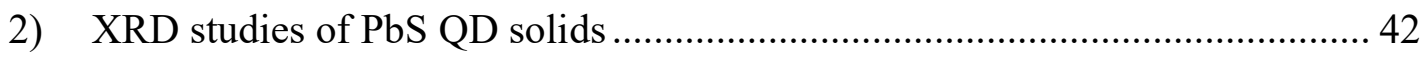

3) Photoluminescence studies of $\mathrm{PbS}$ QDs ...................................................... 43

4) UV-Vis-NIR spectroscopy of PbS QD solutions and films........................... 44

5) XPS characterization of MPA:PbS solids................................................. 49

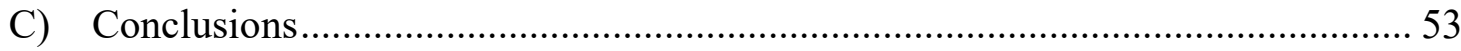


V) Understanding the relationship of QD ligands chemistry and QD solids PV

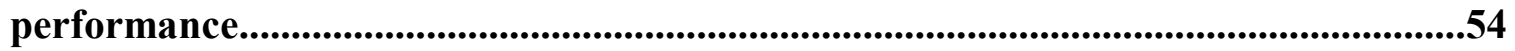

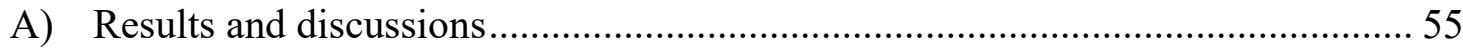

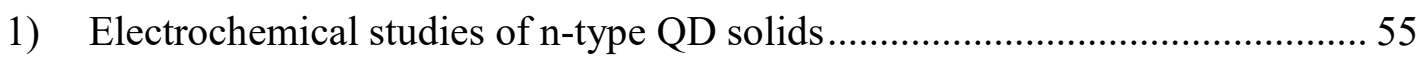

EDT:PbS QD solid/liquid junctions with $\mathrm{Cp}_{2} \mathrm{Fe}^{+/ 0}$ and $\mathrm{Cp}_{2} \mathrm{Co}^{+/ 0}$ redox couples . 56

$\mathrm{BT}$ :PbS QD solid/liquid junctions with $\mathrm{Cp}_{2} \mathrm{Fe}^{+/ 0}$ and $\mathrm{Cp}_{2} \mathrm{Co}^{+/ 0}$ redox couples .... 58

TBAI:PbS QD solid/liquid junctions with $\mathrm{Cp}_{2} \mathrm{Fe}^{+/ 0}$ and $\mathrm{Cp}_{2} \mathrm{Co}^{+/ 0}$ redox couples 60 n-type MPA:PbS QD solid/liquid junctions with $\mathrm{Cp}_{2} \mathrm{Fe}^{+/ 0}$ and $\mathrm{Cp}_{2} \mathrm{Co}^{+/ 0}$ redox

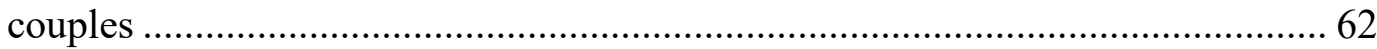

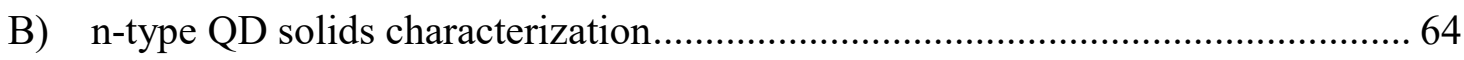

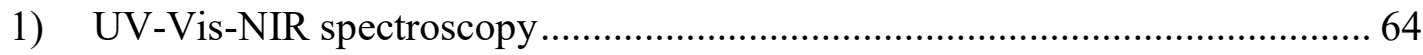

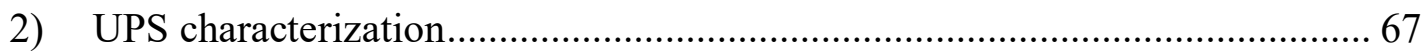

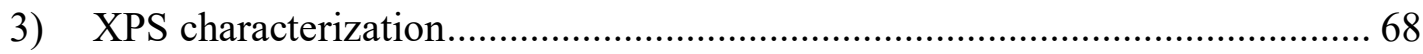

Air exposure: surface chemistry of PbS QD solids ......................................... 76

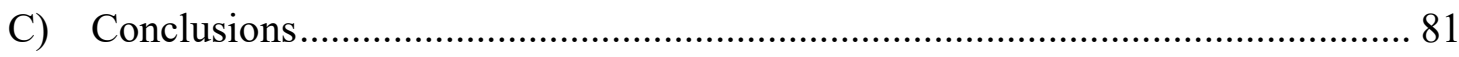

References ..............................................................................................................................82

Appendix A) "Sandwich" cell optimizations for QD solids studies..............................89

Appendix B) Automated programmable spin coater ...............................................93 


\section{List of Tables}

Table 1. Summary of experimentally measured solution potentials, open-circuit voltages, and short-circuit current densities for the MPA:PbS QD solids contacted by electrolytes.

Table 2. Energy band gap of OA:PbS QDs in solution, and $V_{\text {oc }}$ values of their MPA:PbS

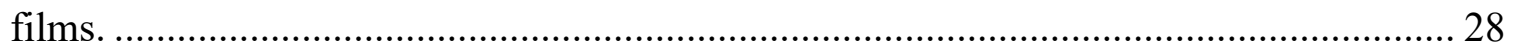

Table 3. The redshift of excitonic absorption peak for PbS QD solids as a result of ligand

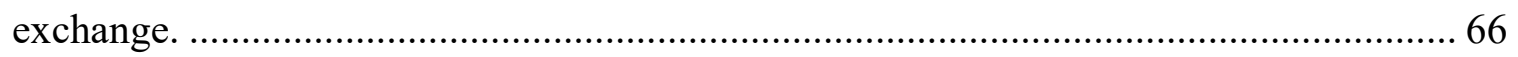

Table 4. The experimental S2p peak position and sulfur identity in PbS QD solids....... 73

Table 5. Experimental C1s peak position and carbon identity in PbS QD solids............ 74

Table 6. Pb:S ratio and sulfur species content analysis on the surface of EDT:PbS QD solid

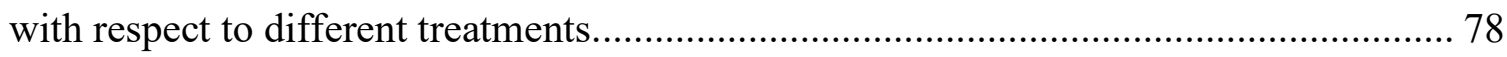




\section{List of Figures}

Figure 1. Illustration of size-dependent band-gap of quantum dots. ................................ 2

Figure 2. Illustration of electrical characteristics of a solar cell and dependence of power conversion efficiency on values of $V_{o c}, I_{s c}$, and $F F$.

Figure 3. Illustration of $V_{\mathrm{ph}}$. of a QD/metal junction as a function of metal's work function.

Figure 4. Schematic illustration of the liquid contacting method's principles. ................. 8

Figure 5. Typical MPA:PbS QD film, deposited on FTO substrate. ............................. 11

Figure 6. Schematic drawing of the test cell used in this work. ................................... 14

Figure 7. A simple model of energetic alignment between the p-type PbS QD solid and liquid electrolytes with various redox couples........................................................ 19

Figure 8. J-V curves for illuminated p-type MPA:PbS QD solids / liquid devices (a), and

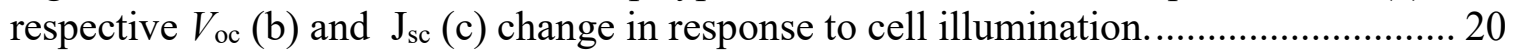

Figure 9. Photovoltages as a function of the solution potential for 3-MPA PbS QD solid contacted with different redox electrolytes.............................................................. 22

Figure 10. Electrochemical data (a-c) for air exposed p-type MPA:PbS QD solid contacted

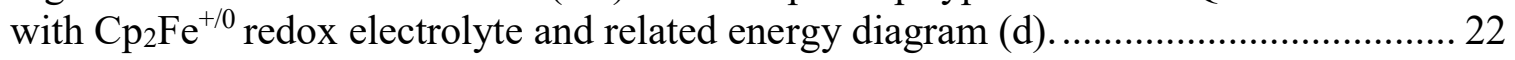

Figure 11. Electrochemical data (a-c) for MPA:PbS QD solid contacted with $\mathrm{Me}_{10} \mathrm{Cp}_{2} \mathrm{Fe}^{+/ 0}$

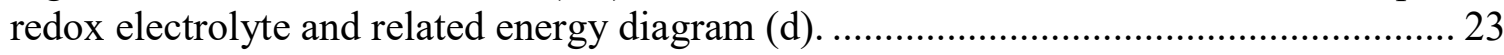

Figure 12. Electrochemical data (a-c) for MPA:PbS QD solid contacted with $\mathrm{MV}^{2+/+} \cdot$ redox

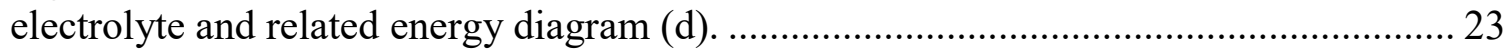

Figure 13. Electrochemical data (a-c) for MPA:PbS QD solid contacted with $\mathrm{Cp}_{2} \mathrm{Co}^{+/ 0}$ redox electrolyte and related energy diagram $(\mathrm{d})$.................................................. 24

Figure 14. Photovoltage response as a function of illuminating a sandwich cell through the working electrode versus through the counter electrode. Thicker (50 cycles) PbS QD films were used for this study. 26

Figure 15. Change in photovoltage $\left(V_{\mathrm{oc}}\right)$ and photocurrent $\left(\mathrm{J}_{\mathrm{sc}}\right)$ as a function of air-exposure time of the p-type $\mathrm{PbS}$ solids that were contacted with $\mathrm{Cp}_{2} \mathrm{Co}^{+/ 0}$ following the air-exposure. 29

Figure 16. Power conversion efficiency as a function of air-exposure time of the p-type $\mathrm{PbS}$ solids contacted with $\mathrm{Cp}_{2} \mathrm{Co}^{+/ 0}$ after the exposure. 30

$$
\text { viii }
$$


Figure 17. Change in photocurrent $\left(\mathrm{J}_{\mathrm{sc}}\right)$ as a function of air-exposure time of the p-type $\mathrm{PbS}$ solids contacted with $\mathrm{Cp}_{2} \mathrm{Co}^{+/ 0}$ after the exposure........................................................ 31

Figure 18. Resistance of the low-dark-current window of the non-illuminated I- $V$ curve as a function of air-exposure time of MPA:PbS QD solids.

Figure 19. Schottky barrier height $\left(\varphi_{\mathrm{B}}\right)$ and low-dark-current window $\left(V_{\text {flat }}\right)$ as a function of air exposure of the MPA-QD solids (a), and graphical illustration of methods for determining these parameters $(b, c)$. 33

Figure 20. J-V curves obtained in dark and light for inertly deposited but air exposed

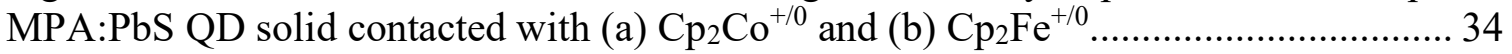

Figure 21. Current-voltage curves (a) and $V_{\text {oc }}$ response (b) produced by a 22 -hour airexposed MPA-LiI:PbS solid contacted with $\mathrm{Cp}_{2} \mathrm{Co}^{+/ 0}$ 36

Figure 22. Current-voltage curves (a) and $V_{\mathrm{oc}}$ response (b) produced by a 22-hour airexposed MPA-LiI:PbS solid contacted with $\mathrm{Cp}_{2} \mathrm{Fe}^{+/ 0}$ 36

Figure 23. Digital photographs of a DH solar cell with 9 devices on one substrate (left), and a schematic cross-sectional illustration of the DH cell components (right)................ 38

Figure 24. A digital photograph of DH cell testing setup................................................ 38

Figure 25. J- $V$ curves (in dark and under 1Sun illumination) for a DH device. The dashed line represents a power curve. 39

Figure 26. Optical properties of MPA:PbS QD solid deposited on $\mathrm{TiO}_{2} / \mathrm{FTO}$ substrate (solid line) and of original OA:PbS QDs suspended in n-hexane. 41

Figure 27. Transmission electron micrograph of $\mathrm{OA}$ capped $\mathrm{PbS}$ quantum dots and the size distribution histogram for QD particles. 42

Figure 28. (a) X-ray diffraction patterns of 3-MPA exchanged PbS QD solid deposited on FTO (green line) and (b) OA:PbS QDs (blue line) along with PbS galena reference (red, vertical lines). 42

Figure 29. OA:PbS QDs in solution; absorption (solid) and photoluminescence (dashed) spectra. 44

Figure 30. Absorbance spectra for MPA:PbS QD solids on FTO and OA:PbS QDs in solution (top) and reflectance spectra of 4 layers MPA:PbS QD solid (bottom). 45

Figure 31. UV-Vis-NIR spectra of OA:PbS QDs in solution (dashed) and OA:PbS QDs deposited on FTO substrate. 46 
Figure 32. Absorption spectra of MPA:PbS QD solids of varying thickness deposited on glass. 47

Figure 33. Absorption spectra of the 3-MPA exchanged $\mathrm{PbS}$ solid films deposited on FTO and soaked in (a) $\mathrm{Cp}_{2} \mathrm{Co}^{+/ 0}$, (b) $\mathrm{MV}^{2+/+}$, (c) $\mathrm{Me}_{10} \mathrm{Cp}_{2} \mathrm{Fe}^{+/ 0}$ and (d) $\mathrm{Cp}_{2} \mathrm{Fe}^{+/ 0}$ redox electrolytes. 48

Figure 34. XPS spectra of MPA:PbS QD solid after 20 hours of air exposure. 49

Figure 35. Elemental (Pb, S, C, and O) XPS spectra of MPA:QD solids at $0.3($ left $)$ and 20 (right) hours of air exposure. 50

Figure 36. C1s XPS spectra of MPA:PbS QD solids deposited in the air, and air exposed for 0.1 and 19 hours respectively. Effect of $\mathrm{Ar}^{+}$etch. 51

Figure 37. Elemental XPS spectra of MPA:PbS QD solid deposited in air, analyzed after 19 hours of air exposure. 52

Figure 38. J-V characteristics of inertly deposited EDT:PbS QD solids contacted with $\mathrm{Cp}_{2} \mathrm{Fe}^{+/ 0}$ (a) and $\mathrm{Cp}_{2} \mathrm{Co}^{+/ 0}$ (c) along with corresponding energy diagrams (b, d)............ 56

Figure 39. J-V characteristics of inertly deposited BT:PbS QD solids contacted with $\mathrm{Cp}_{2} \mathrm{Fe}^{+/ 0}$ (a) and $\mathrm{Cp}_{2} \mathrm{Co}^{+/ 0}$ (c) along with corresponding energy diagrams (b, d)............ 58

Figure 40. J-V characteristics of TBAI:PbS QD solids contacted with $\mathrm{Cp}_{2} \mathrm{Fe}^{+/ 0}$ (a) and $\mathrm{Cp}_{2} \mathrm{Co}^{+/ 0}$ (c) along with corresponding energy diagrams (b, d). 60

Figure 41. $V_{\text {oc }}$ change upon illumination for in-air deposited TBAI:PbS QD solid contacted with $\mathrm{Cp}_{2} \mathrm{Fe}^{+/ 0}$ 61

Figure 42. J-V curves for inertly and in-air deposited MPA:PbS solids contacted with $\mathrm{Cp}_{2} \mathrm{Co}^{+/ 0}$ and $\mathrm{Cp}_{2} \mathrm{Fe}^{+/ 0}$ electrolytes. 62

Figure 43. Absorbance spectra for EDT:PbS QD solids and of a source OA:PbS QDs in nhexane. 64

Figure 44. Absorbance spectra for BT:PbS QD solids and of source OA:PbS QDs in $\mathrm{n}$ hexane. 65

Figure 45. Absorbance spectra for TBAI:PbS QD solids and of a source OA:PbS QDs in n-hexane. 66

Figure 46. UPS spectra of three n-type QD solids deposited with EDT, BT, and TBAI ligands. 
Figure 47. Energy band diagrams for the n-type QD solids (UPS), and energetics (qE) of

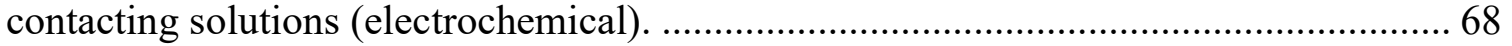

Figure 48. XPS spectra of EDT:PbS QD solid deposited in $\mathrm{N}_{2}$ atmosphere ..................... 69

Figure 49. XPS spectra of BT:PbS QD solid deposited in $\mathrm{N}_{2}$ atmosphere....................... 69

Figure 50. XPS spectra of TBAI:PbS QD solid deposited in $\mathrm{N}_{2}$ atmosphere.................... 70

Figure 51. Lead (Pb4f) XPS spectra of QD solids deposited with different ligands ........ 71

Figure 52. Sulfur (S2p) XPS spectra of QD solids deposited with varying ligands......... 72

Figure 53. Carbon (C1s) XPS spectra of QD solids deposited with different ligands...... 73

Figure 54. Oxygen (O1s) XPS spectra of QD solids deposited with different ligands .... 74

Figure 55. S2p XPS spectra of EDT:PbS QD solids (air exposure and $\mathrm{Ar}^{+}$etch effect).. 77

Figure 56. Test cell used for the cell optimizations studies............................................. 89

Figure 57. Effect of spacer's thickness on series resistance of the test cell filled with

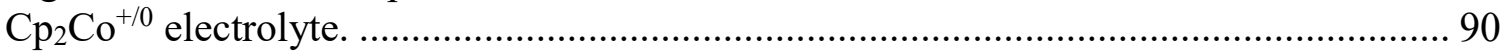

Figure 58. Effect of spacer's thickness on limiting current of the test cell filled with

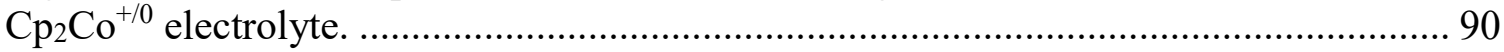

Figure 59. The I- $V$ curve obtained with Sandwich cell $\left(\mathrm{FTO} / \mathrm{Cp}_{2} \mathrm{Co}^{+/ 0} / \mathrm{FTO}\right)$ that used a

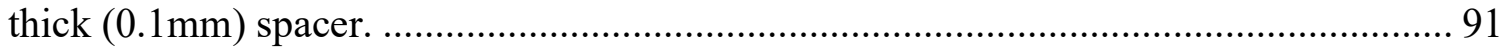

Figure 60. Mechanically clamped test cell with a soft spacer (Elastosil) ......................... 91

Figure 61. A photograph of the automated injection system and the spin coater chamber. 93

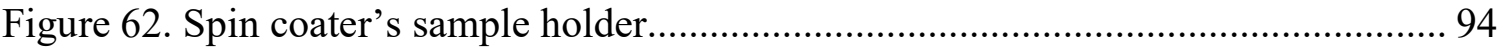

Figure 63. Remote controller and parameters display of the spin coater......................... 94

Figure 64. Differences in quality of PbS QD solid films deposited on FTO manually (left), and with use of automated spin coater (right). 95 


\section{List of Abbreviations and Symbols}

BT - Benzenethiol

$\mathrm{Cp}_{2} \mathrm{Co}^{+/ 0}-$ Cobaltocenium hexafluorophosphate/cobaltocene

$\mathrm{Cp}_{2} \mathrm{Fe}^{+/ 0}, \mathrm{Fc}-$ Ferrocenium tetrafluoroborate/ferrocene

CQD - Colloidal quantum dot

DH - Depleted hetero-junction

E - Electrochemical reduction potential

E - Energy

$E^{0 \prime}-$ Formal reduction potential

Ecb - Energy of conduction band minima

EDT - Ethanedithiol

$\mathbf{E}_{\mathbf{f}}-$ Fermi energy

Eg - Band gap energy

$\mathbf{E}_{\mathbf{v b}}$ - Energy of valence band maxima

FF - Fill factor

FTO - Fluorine doped tin dioxide

$\varphi_{\mathrm{B}} \quad-$ Schottky barrier height

$I_{\mathrm{sc}} \quad-$ Short-circuit current

$J_{\mathrm{sc}} \quad-$ Short-circuit current density

$\mathrm{Me}_{10} \mathrm{Cp}_{2} \mathrm{Fe}^{+/ 0}, \mathrm{dmFc}$ - deca-methylferrocenium tetrafluoroborate/deca-methylferrocene,

MPA -3-mercaptopropionic acid

$\mathrm{MV}^{2+++} \cdot$ - Methyl viologen / methyl viologen radical hexafluorophosphate

PCE - Power conversion efficiency 


$$
\begin{aligned}
& \mathrm{PV} \quad \text { - Photovoltaic } \\
& \mathrm{q} \quad \text { - Fundamental charge of an electron } \\
& \mathrm{R}_{\mathrm{ser}}-\text { Series resistance } \\
& \mathrm{R}_{\mathrm{sh}} \quad-\text { Shunt resistance and } \\
& \mathrm{R}_{\mathrm{ct}} \quad-\text { Charge transfer resistance } \\
& \text { TBAI }- \text { Tetrabutylammonium iodide } \\
& \text { TCO - Transparent conductive oxide } \\
& \text { UPS - Ultraviolet photoelectron spectroscopy } \\
& V_{\mathrm{oc}} \quad-\text { Open-circuit voltage } \\
& \boldsymbol{W}_{\mathrm{f}} \quad-\text { Work function } \\
& \text { XPS }- \text { X-ray photoelectron spectroscopy }
\end{aligned}
$$




\section{Preface}

This dissertation is based on the work conducted by me under Dr. Johansson's supervision during my graduate studies at Portland State University. Results reported in this dissertation are partially contained in the following papers:

I) Dereviankin, V.A.; Young, E.; Johansson, E., Understanding of p- and n-type thin film solids of $\mathrm{PbS}$ nanocrystals with application of electrochemical liquid contacting. Manuscript in preparation.

II) Dereviankin, V.A.; Young, E.; Johansson, E., Development of a compact, automatic spin coater for the air-free thin film deposition of QD solids. Manuscript in preparation.

III) Dereviankin, V.A., Johansson, E. Liquid contacting as a method to study photovoltaic properties of PbS quantum dot solids. J. Mater. Chem. A, 2016, 4(23), 9009-9013. ${ }^{1}$

The contribution of Vitalii Dereviankin to the above papers is as follows:

I Performed research and optimized the air-free processes for both $\mathrm{p}$ - and n-type thin film deposition QD solids deposition, assembled and electrochemically tested photovoltaic devices. Significantly contributed to data processing and manuscript writing.

II Engineered and developed an automated spin-coating process, applied DOE methodology enabling waste minimal, air-free preparation of photovoltaic devices. Wrote majority of the manuscript.

III Performed majority of research, performed materials synthesis, contributed to the design of the cell, assembled and performed electrochemical testing of the photovoltaic devices. Performed data analysis. Contributed about 50\% of the manuscript writing. 


\section{I) THESIS STATEMENT}

Liquid contacting of QD based semiconducting solids, as a method optimized within the scope of this work, can be used to study the optoelectronic and intrinsic photovoltaic properties of such solids without introducing unwanted surface defects, which take place during traditional deposition of metal/metal-oxide contacting materials. Specifically:

1. Electrochemical liquid contacting method, when applied to QD solids characterization showed an ideal behavior of photovoltage response with respect to changes in contacting electrolyte's energetics, which was not achieved in the case with metal-QD solid junctions. This suggests that in order to understand genuine photovoltaic properties of QD solids, such "soft" electrochemical contacting method is a better approach.

2. The versatility of the liquid contacting method was extended with a successful demonstration of its applicability to study electrochemical properties of both $\mathrm{p}$ - and n-type QD solids. Furthermore, advancements in the understanding of the relationship between the QD ligands chemistry and the photovoltaic performance of QD solids were possible by application of this method. 


\section{II) INTRODUCTION}

Quantum dots (QDs) are semiconductor nanocrystals with optoelectronic properties that are easily tunable due to size-dependent quantum confinement of electrons and holes. ${ }^{2-4}$ Thus, for example, the energy gap $\left(\mathbf{E}_{\mathrm{g}}\right)$ of a QD is inversely proportional to its physical size because electrons and holes are spatially confined by the size of the QD (Figure 1). This enables size-dependent control of energetics and optoelectronic properties of quantum

dot materials. Applications of QDs include but are not limited to QDs-based bio-labeling ${ }^{5,6}$, LEDs $^{7}$, lasers $^{8-10}$ and solar cells. ${ }^{11-13}$

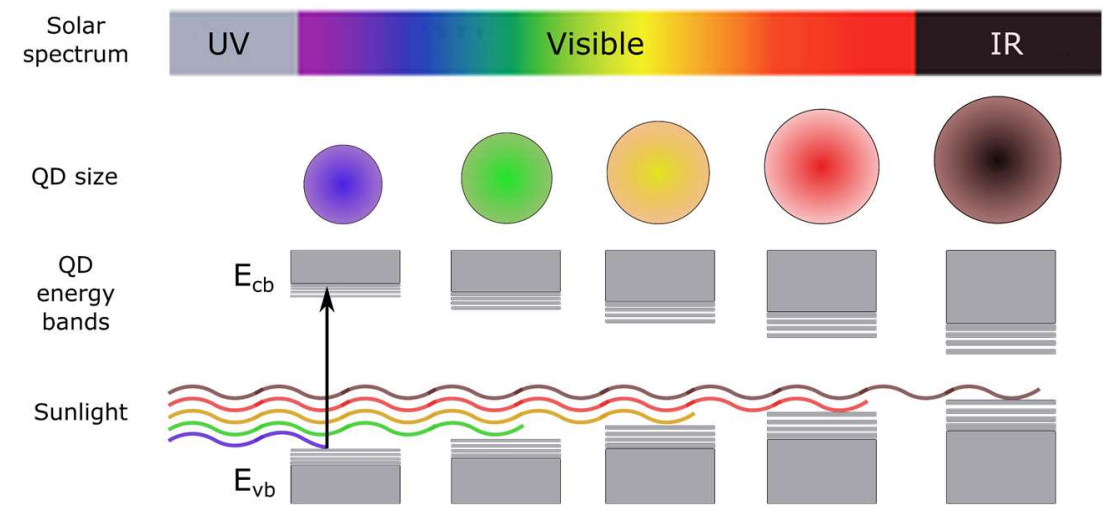

Figure 1. Illustration of size-dependent band-gap of quantum dots.

Quantum dots have been used as light absorbers in photovoltaics for over 17 years and have shown promises for this application. Most of the original work in this area was directed toward the use of QDs in place of dyes in quantum dot sensitized solar cells. ${ }^{14-17}$ Quantum dots have more recently been used to make solids either with their native solution-stabilizing ligands or with new, replaced ligands, thus effectively creating a crystal of crystals. These solids usually preserve the essential optoelectronic properties of QDs, which makes them ideal materials for solid-state devices. In order for the QDs solids to be 
used for solar cells, a replacement of insulating, long-chain coordinating ligands for shorter conductive molecules (organic or inorganic) must be done in order to improve the charge transport properties of such solids. Proper ligands selection for the QDs is important, as it seems to remain the major parameter determining both chemical and optoelectronic properties of the resulting QDs solids. Majority of studies of the optoelectronic properties of the QD solids rely on metal contacts placed on the thin-films of QDs. However, it was shown that metallic contacting to metal-chalcogenides can affect their measured electronic properties, ${ }^{18}$ which can likely take place in case of metal chalcogenide QDs as well. Another downside of using metal-semiconductor junctions, to study QD solids properties, is that this approach is sensitive to the pre-deposition surface preparation and postdeposition heat treatments. ${ }^{19}$

Figure 2 illustrates typical electronic characteristics of a solar cell. Three parameters that determine overall solar-to-electricity conversion efficiency are: open-circuit voltage $\left(V_{o c}\right)$, short-circuit current $\left(I_{s c}\right)$ and fill-factor $(F F)$, which is a ratio between areas of rectangles A and $\mathrm{B}$, whose magnitudes are determined by the characteristic shape of the $I-V$ curve (red, solid line in Figure 2). The I- $V$ curve is typically obtained by connecting a cell to potentiostat or source-meter while illuminating the former. The blue line in Figure 2 represents a power curve which is a product of voltage (bias) and current at each point of the I- $V$ curve. An electrical circuit schematic of a solar cell is also shown as an inset in Figure 2. 


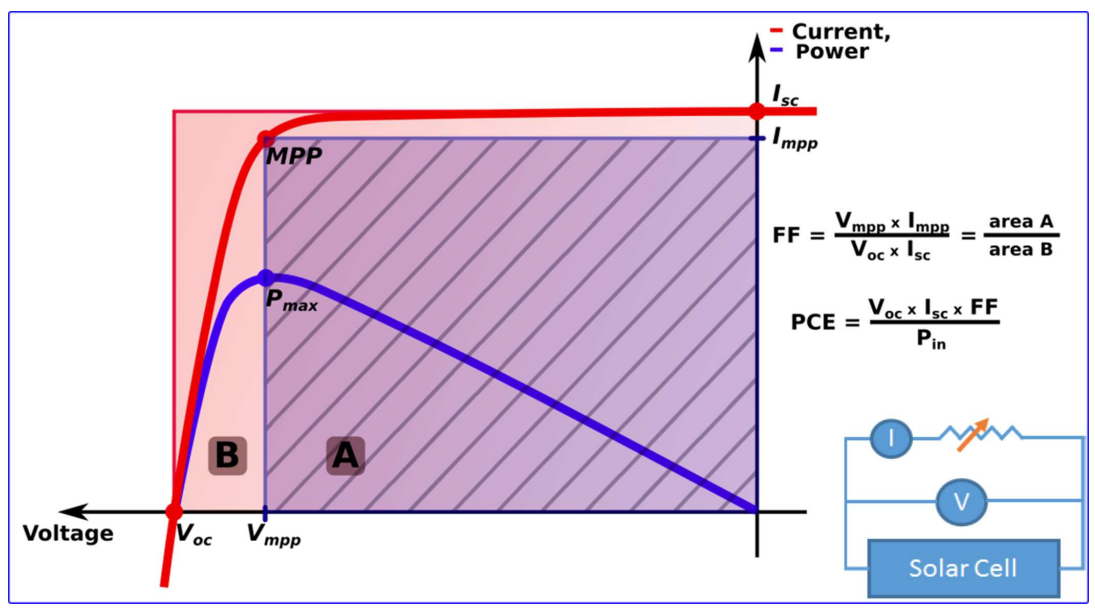

Figure 2. Illustration of electrical characteristics of a solar cell and dependence of power conversion efficiency on values of $V_{o c}, I_{s c}$, and $F F$.

Since the first attempts to utilize QDs for solar cells, a vast amount of research, aimed on improving the PV performance of such devices, was performed, mainly covering the use of different ligand chemistries ${ }^{20-22}$, device design optimizations ${ }^{11,23-25}$ and energy bands alignment engineering. ${ }^{26}$ These milestones allowed to increase the PCE values of QD solar cells to as high as $13.4 \%{ }^{27}$

However, as a literature overview shows, there is a continued existence of the lack of knowledge and efficient experimental methods to directly study the QD solids' energetics near its contacting interface, as it is, in the working device. This prevents full understanding of challenges like low $V_{o c}$ and short minority carrier diffusion lengths in the QD solids. Experimental values of $V_{\mathrm{oc}}$ and FF obtained in current QD based solar cells are far below those thermodynamically possible, thus ultimate efficiencies are not yet achievable. For reference, the Shockley-Queisser (S-Q) limit for a single bandgap solar cell is $31 \%$ for $\mathbf{E}_{\mathbf{g}}$ $=1.1 \mathrm{eV} \cdot{ }^{28}$ The current record efficiency of PbS QD based solar cells is $13.4 \% .{ }^{27}$ If the $V_{\text {oc }}$ were to be increased to $0.9 \mathrm{~V}$, and the $\mathrm{FF}$ to 0.8 , energy-conversion efficiency would 
increase to $18 \%$. This comparison clearly illustrates the importance of addressing the aforementioned issues. $V_{\text {oc }}$ is described to be limited by factors like Fermi-level pinning ${ }^{29-}$ ${ }^{30}$ and bulk or surface defects, ${ }^{31}$ which are related to QD surface chemistry, e.g. type of ligands and their binding properties. Minority carrier diffusion length places limits on photo-generated charge extraction efficiency in QD solids. ${ }^{11}$ This parameter is responsible for the low fill-factors ( 0.6) of QDs based photovoltaics because of the losses for charge transport from beyond the depletion region of QD solids. Additionally, bulk defects were shown to affect open-circuit voltages by allowing for unwanted charge-carrier recombination within light absorbing material. ${ }^{32-35}$ For PbS QD solids, specifically, it has been shown that non-optimal QD surface chemistry leads to, among other things, greater densities of sub-bandgap states. ${ }^{36}$ Surface defects affect the performance of photovoltaic devices through charge-carrier recombination, but also through Fermi-level pinning. ${ }^{18}$ For PbS QD solid devices, specifically, defects at the interface between the QD solid and contacts are known to affect photovoltaic properties. ${ }^{31,37}$ Trap states chemically associated with $\mathrm{TiO}_{2}$ have been shown to limit the performance of $\mathrm{PbS} \mathrm{QD}$ solid/ $/ \mathrm{TiO}_{2}$ heterojunction devices. ${ }^{37}$ Here, trap-states were seen to promote charge-carrier recombination at the $\mathrm{QD} / \mathrm{TiO}_{2}$ interface.

Investigations on the dependence of $V_{o c}$ on band-gap energy $\left(\mathbf{E}_{\mathbf{g}}\right)$ for both p-n junction ${ }^{38}$ and Schottky type ${ }^{39} \mathrm{PbS}$ QD based solar cells, showed the $\Delta V_{o c} / \Delta \mathbf{E}_{\mathbf{g}}$ ratio being 0.36 and 0.55 respectively. This retracement is significantly lower than 1 and hence, similarly suggests towards presence of earlier discussed unwanted effects that pre-determine and limit the full photovoltaic potential of QD solids. 
Current most commonly used solid-state contacts (e.g. metals) evaporated or sputtered onto QDs solids offer a limited choice of energetics and have destructive effects. Additionally, QD-solid / metal junctions provide only a limited ability to tune open-circuit voltage as a function of metal work function $\left(\boldsymbol{W}_{\mathrm{f}}\right)$, as shown for $\mathrm{PbSe} \mathrm{QD} /$ metal Schottky junction devices. ${ }^{20,29,40,41}$ To better illustrate this, Figure 3 shows the theoretical alignment of energy levels of a QD solid and different contacting metals. Red arrow illustrates that with farther separation of metals work function ( $\left.\boldsymbol{W}_{\mathbf{f}}\right)$ from the $\mathbf{E}_{\mathbf{F}}$ level of QD semiconducting solid, we expect higher photovoltage values for that $\mathrm{QD} /$ metal pair. In theory, change in $V_{\text {ph }}$ values as a result of changes in contacting metal's $\boldsymbol{W}_{\mathrm{f}}$ is expected to be ideally proportional $\Delta V_{p h} / \Delta \mathbf{W}_{\mathbf{f}}=1$, however much smaller proportionality factors were reported ( 0.16) for PbSe QD/metal junctions. ${ }^{29}$
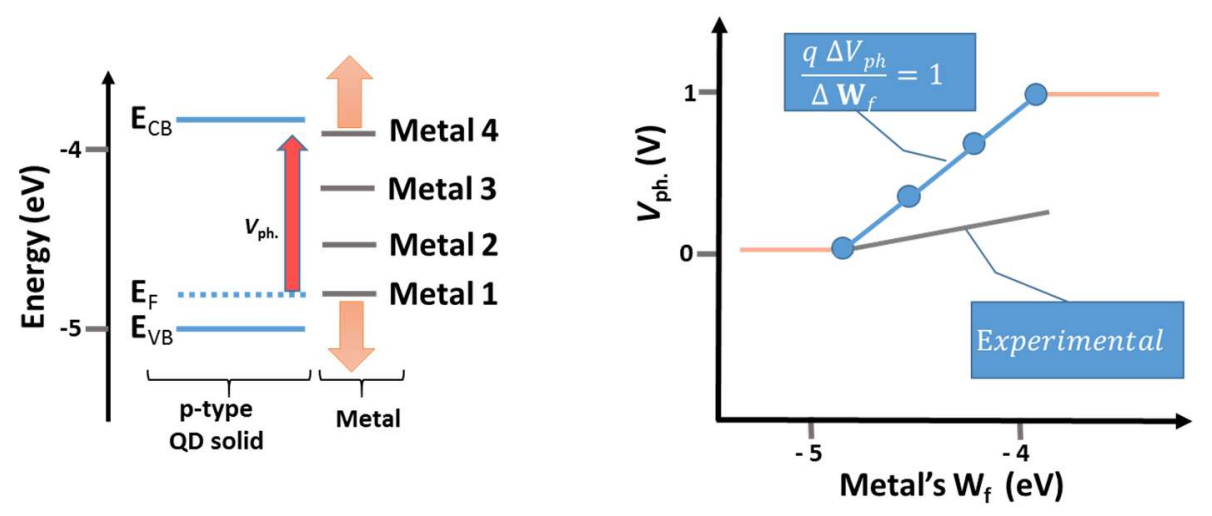

Figure 3. Illustration of $V_{\text {ph. }}$ of a QD/metal junction as a function of metal's work function.

Another demonstration of the fact that metals evaporation on QD solids introduces unwanted surface states was shown by utilizing an organic PCBM layer (placed between QD and metal layers), which nearly doubled the $V_{\text {oc }}$ and $\mathrm{FF}^{42}$ Additionally, semiconductor/metal Schottky junction formation was shown to introduce surface defects, leading to Fermi-level pinning in other bulk semiconductors. ${ }^{18}$ 
On the other hand, electrochemical contacting by liquid electrolytes was shown to eliminate such problems. Such "soft" contacting method also offers a possibility of feasible tuning of solutions' reduction potential providing a versatile control over energetics of studied junctions. Electrochemical contacting has previously been used to study Si and GaAs crystalline semiconductors properties. Semiconductor/liquid junctions have been shown to display photovoltages close to maximum possible values, ${ }^{43-45}$ substantially exceeding those reported for the analogous semiconductor/noble metal Schottky junctions. ${ }^{43}$ Additionally, using this approach, it was possible to relate changes of $V_{o c}$ of $\mathrm{Si}$ semiconductor/liquid junctions to the changes in corresponding energetics (e.g. reduction potential $\left.E\left(A / A^{-}\right)\right)$of the contacting liquid electrolyte. These results were consistent with no Fermi-level pinning present on semiconductor surface. ${ }^{43}$ Further benefits of solution contacting lie in the possibilities to study the interfacial kinetic processes of the solid/liquid interface, ${ }^{43,45,46}$ and to determine minority carrier diffusion length of studied semiconductors. ${ }^{47}$

As it was discussed above, since surface states (defects) play an important role in limiting the PV performance of $\mathrm{PbS}$ QD solids, I sought to investigate experimentally whether electrochemical solution contacting can help us better understand maximum attainable $V_{\text {oc }}$ values for $\mathrm{PbS} \mathrm{QD}$ solids. Knowing maximum attainable open-circuit voltages and understanding how they correlate with respect to QDs ligand chemistry will cover the knowledge gap and identify what materials or their preparation approaches should receive field's further attention, bringing the future of QDs usage as PV materials one step closer. 


\section{III) METHODS AND MATERIALS}

\section{A) Methods}

Electrochemical characterization of QD solids contacted by liquid redox electrolytes was performed using so-called "sandwich" type cell, engineered and optimized during this work, as it will be described later on pages 14 and 89 . Figure 4 shows a cross-sectional schematic of the test cell (a), and a proposed band-edge energy diagrams for a QD solid contacted with a redox couple $\left(\mathrm{A} / \mathrm{A}^{-}\right)$- under thermodynamic equilibrium (b) and under light illumination (c), illustrating the flow of charge carriers through the device.
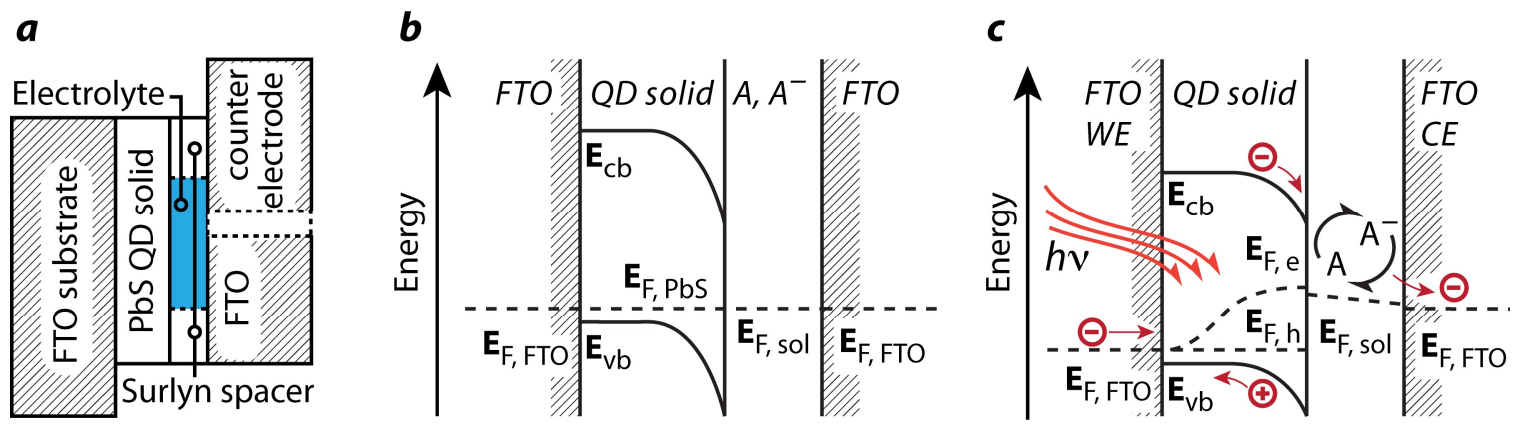

Figure 4. Schematic illustration of the liquid contacting method's principles.

Instruments and other techniques (including sample preparation and characterizations) are described below. 


\section{B) Materials and chemicals}

All chemicals were used as received unless specified otherwise. Lead oxide ( $\mathrm{PbO}$, 99.999+ \%, Strem Chemicals), oleic acid (OA, $90 \%$, Sigma-Aldrich), 1-octadecene (ODE) (90\%, Sigma-Aldrich), bis(trimethylsilyl) sulfide (TMS, $\left.\left(\mathrm{CH}_{3}\right)_{3} \mathrm{Si}\right)_{2} \mathrm{~S}, 96 \%, \mathrm{ACROS}$

Organics), 3-mercaptopropionic acid (3-MPA, $\mathrm{HSC}_{2} \mathrm{H}_{4} \mathrm{COOH}, \geq 99 \%$, Sigma-Aldrich), ferrocene $\left(\mathrm{Cp}_{2} \mathrm{Fe}, 98 \%\right.$, Sigma-Aldrich), ferrocenium tetrafluoroborate $\left(\mathrm{Cp}_{2} \mathrm{FeBF}\right.$, tech. grade, Sigma-Aldrich), decamethylferrocene ( $\mathrm{Me}_{10} \mathrm{Cp}_{2} \mathrm{Fe}, 99 \%$, Alfa Aesar), methyl viologen (1,1'-dimethyl-4,4'-bipyridinium bis(hexafluorophosphate) - $\mathrm{MVPF}_{6} \quad 98 \%$, Sigma-Aldrich), ammonium hexafluorophosphate $\left(\mathrm{NH}_{4} \mathrm{PF}_{6}, 99 \%\right.$, ACROS Organics), bis(cyclopentadienyl)cobalt(II) ( $\mathrm{Cp}_{2} \mathrm{Co}$, Sigma-Aldrich), bis(cyclopentadienyl)cobalt(III) hexafluorophosphate $\left(\mathrm{Cp}_{2} \mathrm{CoPF}_{6}, \quad>95.0 \%(\mathrm{~T}), \quad \mathrm{TCI}\right.$ America $)$, nitrosonium tetrafluoroborate $\left(\mathrm{NOBF}_{4}, 98 \%\right.$, Alfa Aesar). Acetone (>99.5\%, BAKER ANALYZED® A.C.S. Reagent), n-hexane (anhydrous, 99.99\%, Alfa Aesar), acetonitrile (anhydrous, 99.8\%, DriSOLV, EMD), methanol (anhydrous, 99.8\%, DriSOLV, EMD Millipore), ethanol (absolute, $\geq 99.5 \%$, Sigma-Aldrich) and Sparkleen laboratory detergent (Fisher Scientific) were used as received. Ferrocenium tetrafluoroborate $\left(\mathrm{Cp}_{2} \mathrm{FeBF}_{4}\right.$, tech. grade $)$ was purchased from Sigma-Aldrich, and purified by sublimation. Methyl viologen dichloride hydrate (98\%, Sigma-Aldrich) was purified by recrystallization from ethanol. Fluorine-doped tin oxide (FTO) (TEC 15, $13 \Omega /$ sq., $2.3 \mathrm{~mm}$, Sigma-Aldrich), aluminum foil tape (0.3 mil, All-Spec), thermoplastic sealant (Surlyn) (TPS 065096-30, Dyesol) and Vycor ${ }^{\circledR}$ Porous Glass Frits (Gamry instruments) were used as received unless additional cleaning steps and treatments are specified. 


\section{C) Colloidal PbS quantum dots synthesis}

Oleate $\left(\mathrm{Oa}^{-}\right)$capped $\mathrm{PbS}$ quantum dots were synthesized using literature method, ${ }^{48}$ with small modifications. Briefly, $10 \mathrm{ml}$ of octadecene (ODE) in a 3-neck round-bottom flask was degassed for 16 hours by heating to $80{ }^{\circ} \mathrm{C}$ under active vacuum ( 200 millitorrs). After that, the flask was refilled with $\mathrm{N}_{2}$ and maintained under its positive pressure. Using a syringe, $0.213 \mathrm{ml}$ of bis(trimethylsilyl) sulfide (TMS) was added. The mixture's temperature was then increased to $100{ }^{\circ} \mathrm{C}$. In a separate 3-neck round bottom flask $0.45 \mathrm{~g}$ $\mathrm{PbO}, 18 \mathrm{ml}$ of the $\mathrm{ODE}$, and $1.51 \mathrm{ml}$ oleic acid (OA) were mixed and similarly degassed under vacuum at $95{ }^{\circ} \mathrm{C}$ for 16 hours after which temperature was increased to $125{ }^{\circ} \mathrm{C}$ to achieve a clear solution. After this, the TMS/ODE mixture was injected into the Pboleate/ODE solution using a syringe. The solution immediately turned black and was kept at $125{ }^{\circ} \mathrm{C}$ for 1 minute, after which it was gradually cooled to $50{ }^{\circ} \mathrm{C}$ with tap water and iced water to $15^{\circ} \mathrm{C}$. The content was divided into two $50 \mathrm{ml}$ centrifuge tubes, which were then filled with acetone, mixed, centrifuged, and decanted. Precipitated QDs in both centrifuge tubes were re-dispersed into $20 \mathrm{ml}$ of toluene each, mixed, and $30 \mathrm{ml}$ of acetone was again added to each tube to cause flocculation after which solutions were centrifuged and decanted again. The last step was repeated two more times. Finally, the solid QDs were dried under vacuum and stored in the $\mathrm{N}_{2}$ filled glovebox. 


\section{D) Preparation of p-type and n-type PbS QD solids}

All QD solids studied in this work were produced by a spin coating method, also called a solid-state or in-situ ligand exchange technique. In order to achieve a reproducible deposition of quality films and to be able to deposit these in an $\mathrm{N}_{2}$ filled glovebox, I made and used a compact and automated spin coater (described in Appendix 0.

The QD solid deposition involves initial deposition of original OA:PbS QDs suspended in a nonpolar solvent, followed by deposition of a solution containing new ligand. These new ligands supposedly replace the original, long-chain oleic acid ligands, thus reducing interQD distances and allowing for better electronic communication between individual quantum dots. A sample solid QD film with a thickness of $300 \pm 25 \mathrm{~nm}$ is shown in Figure 5 and possesses transparent and mirror-like reflective properties.

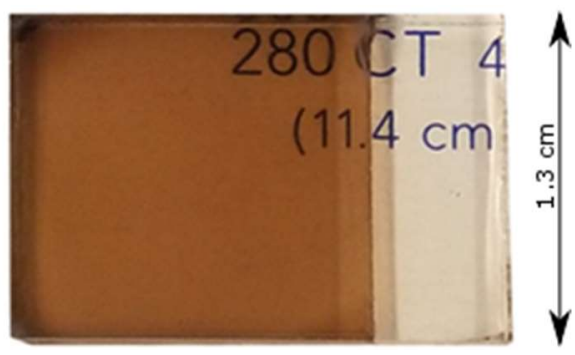

Figure 5. Typical MPA:PbS QD film, deposited on FTO substrate.

$\mathrm{PbS}$ QD semiconducting solids of p-type character were deposited on desired substrates $\left(\mathrm{FTO}\right.$ or $\left.\mathrm{FTO} / \mathrm{TiO}_{2}\right)$ in ambient atmosphere, in accordance with established in-situ ligand exchange procedure. ${ }^{49}$ 3-mercaptopropionic acid (MPA) was used as a new ligand for $\mathrm{p}$ type QD solids.

Preparation of n-type $\mathrm{PbS} \mathrm{QD}$ solids was carried out according to other published procedures. $^{22,50}$ For n-type solids (EDT:PbS and $\mathrm{BT}: \mathrm{PbS}$ ) I used ethanedithiol and 
benzenethiol ligands solutions and QD solid deposition was performed in the $\mathrm{N}_{2}$ filled glovebox, as it was necessary to preserve the n-type character of these solids. Tetrabutylammonium iodide ligand solution was used for the preparation of TBAI:PbS solids in the air as this ligands were shown to produce n-type solids of QDs even when deposited in ambient atmosphere. QD solids were typically dried with vacuum and exposed to air prior to electrochemical testing.

\section{E) Working electrode preparation}

Working electrodes were prepared similarly to literature procedures for depositing QDs on transparent conductive oxide substrates or FTO.$^{51}$ As an example, MPA:PbS solids were prepared as follows. A $1.3 \times 1.8 \mathrm{~cm}^{2}$ FTO substrate was cleaned by sonicating in $20 \%$ by mass Sparkleen solution in DI water followed by copious DI water rinse and dried in an oven at $100{ }^{\circ} \mathrm{C}$. The substrate was then partially masked using low adhesion paint tape to prevent QD deposition onto the contacting area. The masked FTO substrate was placed on a spin coater. The spin coater speed was set to $2500 \mathrm{rpm}$ and the substrate was spinning continuously during the QD film deposition. A cycle of QD deposition consisted of depositing $50 \mu \mathrm{L}$ of OA-capped PbS QDs in n-hexane $(10 \mathrm{mg} / \mathrm{ml})$ onto the spinning FTO substrate followed by $150 \mathrm{uL}$ of $10 \% \mathrm{v} / \mathrm{v}$ mercaptopropionic acid (3-MPA) in methanol and finished by $300 \mathrm{uL}$ of methanol deposition. Typically, QD solids were made using 15 consecutive deposition cycles, while on last two cycles, a ligand containing and washing solutions injection was repeated twice. For the preparation of optically thick FTO/QD solid electrodes, used for studying effects of directional solar cell illumination (working vs. 
counter electrode), 50 deposition cycles were used instead. PbS QD solids that required an air-free deposition were also prepared by spin coating but in nitrogen filled glovebox $\left(\mathrm{O}_{2}\right.$ $\left.<2 \mathrm{ppm}, \mathrm{H}_{2} \mathrm{O}<0.5 \mathrm{ppm}\right)$.

Solutions that were used for n-type QD solids preparation are $4 \mathrm{mM}$ benzenethiol in acetonitrile, $10 \mathrm{mM}$ ethanedithiol in acetonitrile, and $30 \mathrm{mM}$ tetrabutylammonium iodide in methanol. Additionally, for n-type QD solids preparation, a longer reaction time was used to allow for the new ligand-containing solution to react with previously deposited QD layer. For BT:PbS and EDT:PbS this time was 5 seconds, while for TBAI - it was necessary to extend this to up to 2 minutes.

\section{F) Counter electrode preparation}

The counter electrode (CE) was prepared by drilling a $1.2 \mathrm{~mm}$ diameter hole in a $1.3 \mathrm{~cm} \mathrm{x}$ $1.8 \mathrm{~cm}$ FTO substrate. The substrate was then cleaned similarly to WE (Appendix AD). Aluminum pad served to aid the alligator-clip ended potentiostat cables connections to the tested cell. Gold plasma sputter deposition on the CE and aluminum pads were shown to only minimally affect the device's performance, hence both are considered as optional. 


\section{G) Cell assembly}

A $1.4 \mathrm{~cm}$ x $1.4 \mathrm{~cm}$ Surlyn spacer with a $0.45 \mathrm{~cm}^{2}$ circular hole was cut and used to provide an electrolyte chamber. The working electrode, Surlyn spacer, and the counter electrode were assembled at ambient conditions according to Figure 6. The cell was placed on a hotplate $\left(105^{\circ} \mathrm{C}\right)$, a counter electrode facing down, and a moderate pressure was applied to ensure good adhesion of softened surlyn spacer to both electrodes. The cell was immediately taken into an $\mathrm{N}_{2}$ filled glovebox, where it was filled with electrolyte using a syringe with a soft tip. A slight vacuum was created inside the cell by retracting the syringe plunger, which, when released, injected the electrolyte into the cell. Finally, the predrilled hole was sealed using adhesive tape and the cell could be taken out from the glovebox to the test station.

General schematics and the "Sandwich" type cell geometry of a Schottky device based on PbS QD solids and liquid contacting redox couples are shown in Figure 6. The cell geometry was designed within the dissertation work and is optimized to utilize benefits of close positioning of the two electrochemical electrodes, working (WE), and counter (CE) electrodes.

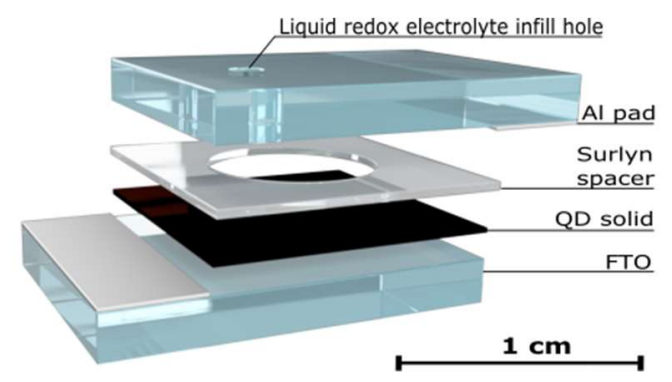

Figure 6. Schematic drawing of the test cell used in this work. 
Proximity is beneficial in such application, as it allows for elimination of diffusion limitations for low concentrations electrolytes, in the case when redox species have limited solubility in desired contacting solvent and use of supporting salts in the contacting electrolyte is undesirable. Supporting salts could potentially affect the electronic or chemical properties of the studied QD solids.

\section{H) Redox electrolytes for contacting the QD solids}

All electrolytes were prepared to contain the same ratio (1:1) and equal concentrations $(1 \mathrm{mM})$ of reduced and oxidized species. This was done in an $\mathrm{N}_{2}(\mathrm{~g})$ filled glovebox containing less than $0.5 \mathrm{ppm} \mathrm{H}_{2} \mathrm{O}(\mathrm{g})$ and $<2 \mathrm{ppm}_{2}$. Maintaining equal concentrations and ratio of reduced and oxidized species across all redox couples is important. Varying the concentrations of reduced and oxidized species can change both solution potential and minority and majority charge-transfer rates, which can affect the open-circuit voltage under illumination of semiconductor/liquid junctions. ${ }^{45}$ Thus, to allow results to be compared more easily across a series of redox couples the concentrations of reduced and oxidized species were prepared to nominally $1 \mathrm{mM}$. $1 \mathrm{mM}$ is a low concentration compared to what is commonly used for photoelectrochemical experiments. The concentration was chosen due to solubility limitations of some of the redox species in acetonitrile. Ferrocenium tetrafluoroborate /ferrocene $\left(\mathrm{Cp}_{2} \mathrm{Fe}^{+/ 0}\right)$ electrolyte was prepared by dissolving ferrocene and ferrocenium tetrafluoroborate in acetonitrile to $1 \mathrm{mM}$ of each. Decamethylferrocenium tetrafluoroborate / decamethylferrocene $\left(\mathrm{Me}_{10} \mathrm{Cp}_{2} \mathrm{Fe}^{+/ 0}\right)$ was prepared by dissolving decamethylferrocene in acetonitrile to $2 \mathrm{mM}$ followed by addition of $1 \mathrm{mM}$ equivalent nitrosonium tetrafluoroborate to oxidize half of the decamethylferrocene to 
$\begin{array}{llll}\text { decamethylferrocenium } & \text { tetrafluoroborate. } & \text { Methyl viologen }\end{array}$ bis(hexafluorophosphate)/methyl viologen radical hexafluorophosphate $\left(\mathrm{MV}^{2+/+} \bullet\right)$ electrolyte was prepared as follows. Methyl viologen bis(hexafluorophosphate) $\left(\mathrm{MV}\left(\mathrm{PF}_{6}\right)_{2}\right)$ was synthesized according to a previously published method. ${ }^{52}$ Briefly, $55 \mathrm{mg}$ ( $0.2 \mathrm{mmol})$ of methyl viologen dichloride hydrate and $65 \mathrm{mg}(0.4 \mathrm{mmol})$ of ammonium hexafluorophosphate was dissolved in $9 \mathrm{ml}$ of DI water by gentle heating to $\sim 50{ }^{\circ} \mathrm{C}$. When the solution was clear it was placed in an ice bath for 2 hours. Clear-white needle-like crystals of $\mathrm{MV}\left(\mathrm{PF}_{6}\right)_{2}$ were recovered by centrifugation and filtration. The crystals were dried under vacuum and kept in the $\mathrm{N}_{2}$ filled glovebox. A solution of $6.8 \mathrm{mM}$ solution of $\mathrm{MV}\left(\mathrm{PF}_{6}\right)_{2}$ in dry acetonitrile was prepared in the glovebox and in-situ reduced via controlled potential electrolysis in order to form 1:1 ratio of oxidized $\left(\mathrm{MV}^{2+}\right)$ and reduced $\left(\mathrm{MV}^{+}\right)$species, which yielded an intense blue coloration of the solution. Prior to use, this solution was diluted with the acetonitrile to $1 \mathrm{mM} \mathrm{MV}^{2+/+}$ electrolyte. Cobaltocenium hexafluorophosphate/cobaltocene $\left(\mathrm{Cp}_{2} \mathrm{Co}^{+/ 0}\right)$ electrolyte was prepared by dissolving bis(cyclopentadienyl)cobalt(II) and bis(cyclopentadienyl)cobalt(III) hexafluorophosphate in acetonitrile to $2 \mathrm{mM}$ each. Prior to use, equal amounts of both cobaltocene/cobaltocenium solutions were mixed together to yield $1 \mathrm{mM}$ redox solution.

\section{I) Reduction potentials of contacting solutions}

Solution potentials $\left(E_{\text {soln. }}\right)$ were measured versus the reduction potential of ferrocene/ferrocenium tetrafluoroborate $\left(\mathrm{Cp}_{2} \mathrm{Fe}^{+/ 0}\right)(1 / 1 \mathrm{mM}$ in acetonitrile) using a twoelectrode setup. A Pt button working-electrode was submerged in the measured electrolyte along with the $\mathrm{Cp}_{2} \mathrm{Fe}^{+/ 0}$ reference electrode. The solution was stirred and the open circuit 
potential between the two electrodes was recorded using Gamry Reference 600 potentiostat (note: average bench multi-meter is not suitable for this application). The $\mathrm{Cp}_{2} \mathrm{Fe}^{+/ 0}$ reference electrode consisted of a Pt wire inserted into a $3 \mathrm{~mm}$ OD glass tube, with heatshrink attached Vycor ${ }^{\circledR}$ porous frit tip, which was also filled with the $\mathrm{Cp}_{2} \mathrm{Fe}^{+/ 0}$ containing the electrolyte. Solution potentials were, in all cases, close to the calculated formal potentials, based on measured solution potentials and relative concentrations of redox species, estimated using experimentally observed limiting currents measured during separate three-electrode experiments.

\section{J) Instruments and techniques}

Mbraun Labstar 1200 Glovebox (Mbraun) was used to perform most of the air-free experiments. Gamry Reference 600 potentiostat/galvanostat/ZRA instrument (Gamry) was used for the electrochemical characterization of the QD based devices. FEI Tecnai F-20 TEM/STEM microscope was used for TEM characterization of PbS QDs. XRD diffraction characterization of PbS QD solids was done on Rigaku Ultima IV X-Ray diffractometer. UV-3600 Shimadzu UV-VIS-NIR spectrophotometer was used for light absorbance characterization of QD solutions and solids. Reflectance spectra were collected on FILMetrics F20 instrument. Infrared spectra were collected using Nicolet 6700 FTIR instrument and Nicolet iS10 with "smart iTR" attachment. ABET solar simulator Model 10500 was used to illuminate the photovoltaic cells and was calibrated for illumination intensities by use of standard UV005 photodiode (OSI Optoelectronics). XPS and UPS spectra were collected on PHI versaprobe II photoelectron spectroscopy instrument equipment with Al ka X-ray source of $1486.6 \mathrm{eV}$ and He-I UV light source (21.22 eV). 


\section{IV) PROOF OF CONCEPT: LIQUID CONTACTING AS A METHOD TO STUDY PBS QD SOLIDS}

In this chapter, photovoltaic results of p-type PbS QD solids contacted by liquid solutions of fast, outer-sphere redox couples will be discussed. We will attempt to understand the Schottky junction formation mechanism as well as discuss effects of air on establishing a stronger p-type character of said solids. The discussion will be supported by results of the characterization of both colloidal QDs suspended in solutions and solids formed by ligand exchange involved deposition.

\section{A) Results and discussions}

All photoelectrochemical experiments were performed using two-electrode sandwich cells (Figure 6). The construction, assembly, and structure of the test cell are described in section III)G) on page 14. Sample band and Fermi-level alignment of a p-type QD solid contacted with an electrolyte having a reduction potential higher than $\mathbf{E F}_{\mathbf{F}}$ of QD solid, is shown in Methods section on page 8 .

\section{1) Electrochemical studies of p-type $Q D$ solids}

A series of non-rectifying and rectifying MPA:PbS QD solid/electrolyte junctions were established using solutions of four outer-sphere, fast redox couples dissolved in anhydrous acetonitrile. Specifically, ferrocenium tetrafluoroborate/ferrocene $\left(\mathrm{Cp}_{2} \mathrm{Fe}^{+/ 0}\right)$, decamethylferrocenium tetrafluoroborate/deca-methylferrocene $\left(\mathrm{Me}_{10} \mathrm{Cp}_{2} \mathrm{Fe}^{+/ 0}\right)$, methyl viologen (1,1'-dimethyl-4,4'-bipyridinium bis(hexafluorophosphate))/methyl viologen

radical hexafluorophosphate $\quad\left(\mathrm{MV}^{2+++} \cdot\right), \quad$ and $\quad$ cobaltocenium 
hexafluorophosphate/cobaltocene $\left(\mathrm{Cp}_{2} \mathrm{Co}^{+/ 0}\right)$ were used. These four redox couples were chosen for their formal reduction potentials. The formal potential $\left(E^{0}\right)$ of $\mathrm{Cp}_{2} \mathrm{Fe}^{+/ 0}$ and the Fermi level $\left(\mathbf{E}_{\mathrm{F}}\right)$ of 3-mercaptopropionic acid (3-MPA) linked PbS QD films fabricated under ambient conditions have similar energy values. The formal potential of $\mathrm{Cp}_{2} \mathrm{Fe}^{+/ 0}$ has been reported as $+0.311 \mathrm{~V}$ vs. SCE (corresponding to $-4.982 \mathrm{eV}$ vs. vacuum). ${ }^{46}$ The Fermi level of 3-MPA linked PbS QD solids is known to be approximately $-4.9 \mathrm{eV} v s$. vacuum. ${ }^{22,53}$ Literature values ${ }^{46}$ place $E^{0 \prime}$ for $\mathrm{Me}_{10} \mathrm{Cp}_{2} \mathrm{Fe}^{+/ 0}, \mathrm{MV}^{2+/+} \cdot$ and $\mathrm{Cp}_{2} \mathrm{Co}^{+/ 0}$ roughly evenly spaced at increasingly more negative values (Figure 7). This was consistent with measured solution potentials $(E)$ of each electrolyte vs. the $\mathrm{Cp}_{2} \mathrm{Fe}^{+/ 0}$ electrolyte (Table 1, on page 20).

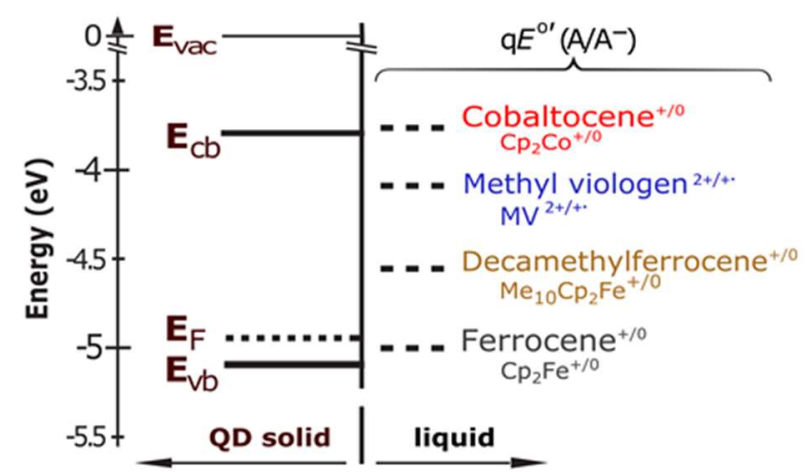

Figure 7. A simple model of energetic alignment between the p-type PbS QD solid and liquid electrolytes with various redox couples.

Representative $J-V$ data for corresponding QD solid/liquid cells measured under 1-sun illumination $\left(100 \mathrm{~mW} / \mathrm{cm}^{2}\right)$ is shown in Figure 8 . These results clearly illustrate an increase in both open-circuit voltages and short-circuit current densities with increasing negative solution potentials of the contacting electrolytes. 

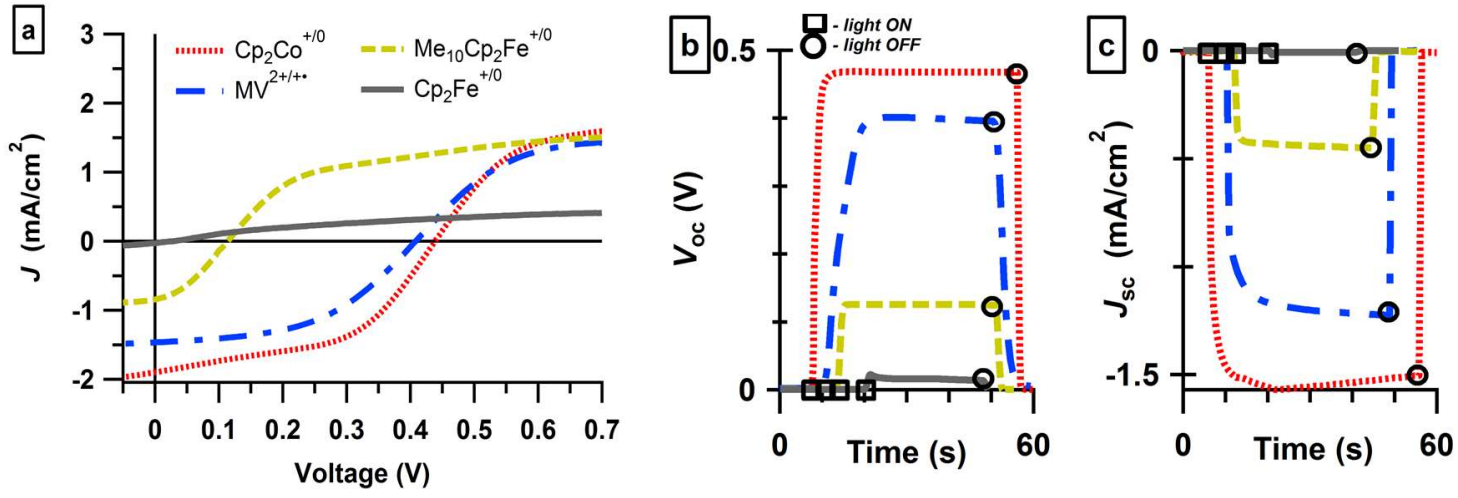

Figure 8. J-V curves for illuminated p-type MPA:PbS QD solids / liquid devices (a), and respective $V_{\text {oc }}(\mathrm{b})$ and $\mathrm{J}_{\mathrm{sc}}(\mathrm{c})$ change in response to cell illumination.

This trend was also observed in the chronopotentiometry data (Figure 8b, and Table 1). Short-circuit current density was negligible in the absence of a significant photovoltage (the case with $\mathrm{Cp}_{2} \mathrm{Fe}^{+/ 0}$ ), and within a factor of 3 when significant photovoltages were measured. This is in qualitative agreement with the $J-E$ behavior of $\mathrm{Si}$ /electrolyte junctions as a function of $E^{0,46}$

Table 1. Summary of experimentally measured solution potentials, open-circuit voltages, and short-circuit current densities for the MPA:PbS QD solids contacted by electrolytes. Values are reported as mean \pm 1 standard deviation and derived from a minimum of three independent measurements.

\begin{tabular}{cccc} 
Redox couple & $\begin{array}{c}E\left(\mathrm{~A} / \mathrm{A}^{-}\right) \\
\left(\mathrm{mV} \text { vs. } \mathrm{Cp}_{2} \mathrm{Fe}^{+/ 0}\right)\end{array}$ & $\begin{array}{c}V_{\mathrm{oc}} \\
(\mathrm{mV})\end{array}$ & $J_{\mathrm{sc}}\left(\mathrm{mA} / \mathrm{cm}^{2}\right)$ \\
\hline $\begin{array}{c}\text { Ferrocene } \\
\left(\mathrm{Cp}_{2} \mathrm{Fe}^{+/ 0}\right)\end{array}$ & $0(\mathrm{ref})$ & $14 \pm 7$ & $-0.01 \pm 0.00$ \\
$\begin{array}{c}\text { Decamethylferrocene } \\
\left(\mathrm{Me}_{10} \mathrm{Cp}_{2} \mathrm{Fe}^{+/ 0}\right)\end{array}$ & $-536 \pm 5$ & $119 \pm 13$ & $-0.43 \pm 0.06$ \\
$\begin{array}{c}\text { Methylviologen } \\
\left(\mathrm{MV}^{2+/++}\right)\end{array}$ & $-786 \pm 5$ & $389 \pm 15$ & $-1.04 \pm 0.26$ \\
$\begin{array}{c}\text { Cobaltocene } \\
\left(\mathrm{Cp}_{2} \mathrm{Co}^{+/ 0}\right)\end{array}$ & $-1334 \pm 5$ & $475 \pm 21$ & $-1.30 \pm 0.61$ \\
\hline
\end{tabular}

$J-V$ and chronopotentiometric data are consistent with the hypothesized model presented in Figure 4, on page 8. Broadly, the dependence of $J-V$ and chronopotentiometric data on 
formal potential should exhibit three distinct regions. The model predicts non-rectifying $J-V$ behavior when contacting the p-type QD solid with redox couples with a sufficiently positive formal potential. In line with this prediction, a weakly rectifying junction was observed with $\mathrm{Cp}_{2} \mathrm{Fe}^{+/ 0}$. Redox couples with sufficiently negative formal potentials were expected to form rectifying junctions, with unvarying photovoltages, to the p-type semiconductor. At very negative $E^{0 \prime}$ the near-surface layer of the QD solid would become heavily n-type doped creating, in essence, a buried junction within the QD solid. As expected, strongly rectifying behavior was observed with both $\mathrm{MV}^{2+/+} \cdot$ and $\mathrm{Cp}_{2} \mathrm{Co}^{+/ 0}$ electrolytes with the open-circuit voltage nearly independent $\left(\Delta V_{\mathrm{oc}} / \Delta E \sim 0.08\right)$ of the solution and formal potentials of the redox couples. Open-circuit voltages as high as 475 $\mathrm{mV}$ were observed, which compares well to many reported FTO/PbS/Al Schottky type devices. ${ }^{39,54-56}$ In between these two extremes, $V_{\text {oc }}$ was expected to depend on the formal solution potential; changing the formal solution potential $\left(\Delta E^{0}\right)$ should cause a concurrent change in open-circuit voltage $\left(\Delta V_{\text {oc }}\right)$. Ideally, $\Delta V_{\text {oc }} / \Delta E^{0 \prime}=1$ when redox couple concentrations are constant and interfacial charge transfer rate constants are identical. ${ }^{43,45}$ $\Delta V_{\mathrm{oc}} / \Delta E^{0 \prime}<1$ can be ascribed to defects present at the semiconductor/liquid interface. ${ }^{32,43}$ Given that all redox couples' concentrations were approximately equal for reduced and oxidized species and across the electrolytes, $\Delta V_{\mathrm{oc}} / \Delta E \approx \Delta V_{\mathrm{oc}} / \Delta E^{0,45}$. Thus, the change in $V_{\mathrm{oc}}$ as a function of solution potential, $\Delta V_{\mathrm{oc}} / \Delta E$, is diagnostic of the method's ability to probe ultimate open-circuit potentials. Our initial studies gave a maximum $\Delta V_{\mathrm{oc}} / \Delta E$ of $1.08 \pm 0.04$ based on the open-circuit voltages and solution potentials of methyl viologen $^{2+/+} \cdot$ and decamethylferrocene ${ }^{+/ 0}$, respectively, as shown in Figure 9. 


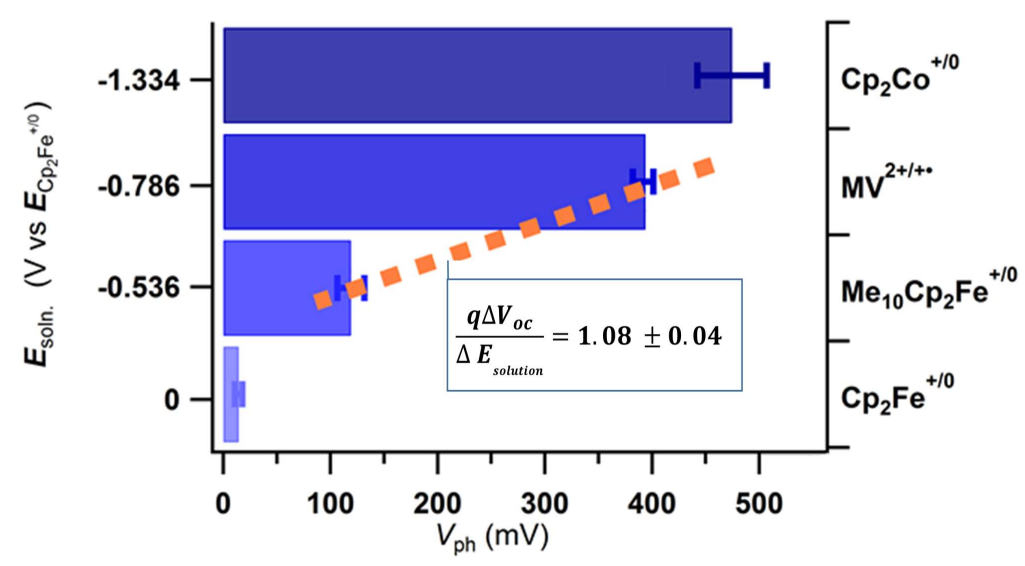

Figure 9. Photovoltages as a function of the solution potential for 3-MPA PbS QD solid contacted with different redox electrolytes.

Separate graphs displaying $J-V$ data collected in the dark and under illumination for each electrolyte / MPA:PbS QD solid pair, as well as corresponding energy levels for both solid and liquid, are provided next in order of increasing of solution's reduction potential.

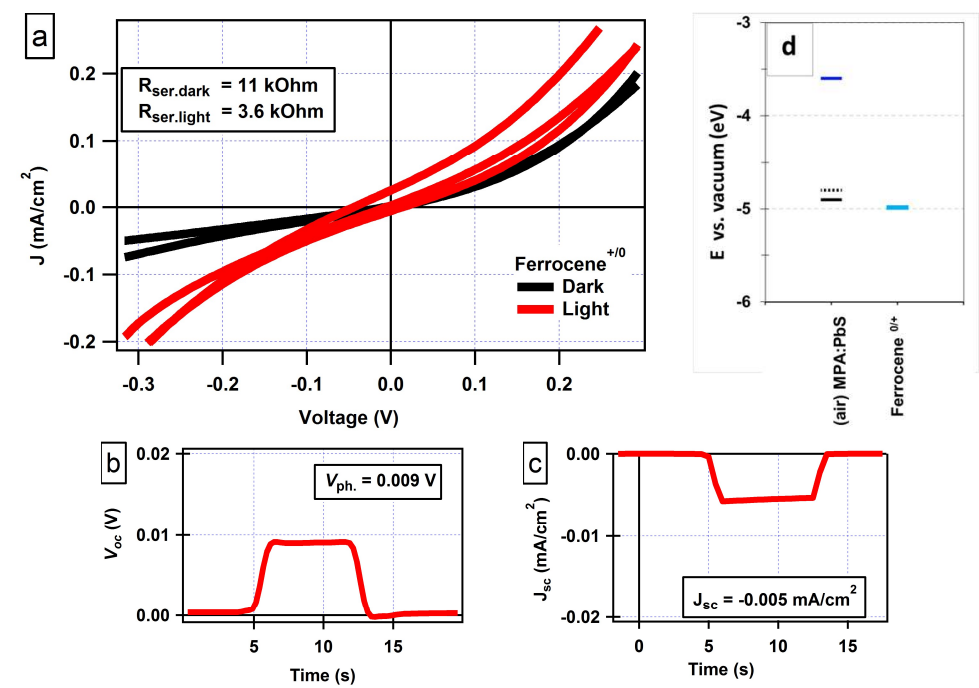

Figure 10. Electrochemical data (a-c) for air exposed p-type MPA:PbS QD solid contacted with $\mathrm{Cp}_{2} \mathrm{Fe}^{+/ 0}$ redox electrolyte and related energy diagram (d). 

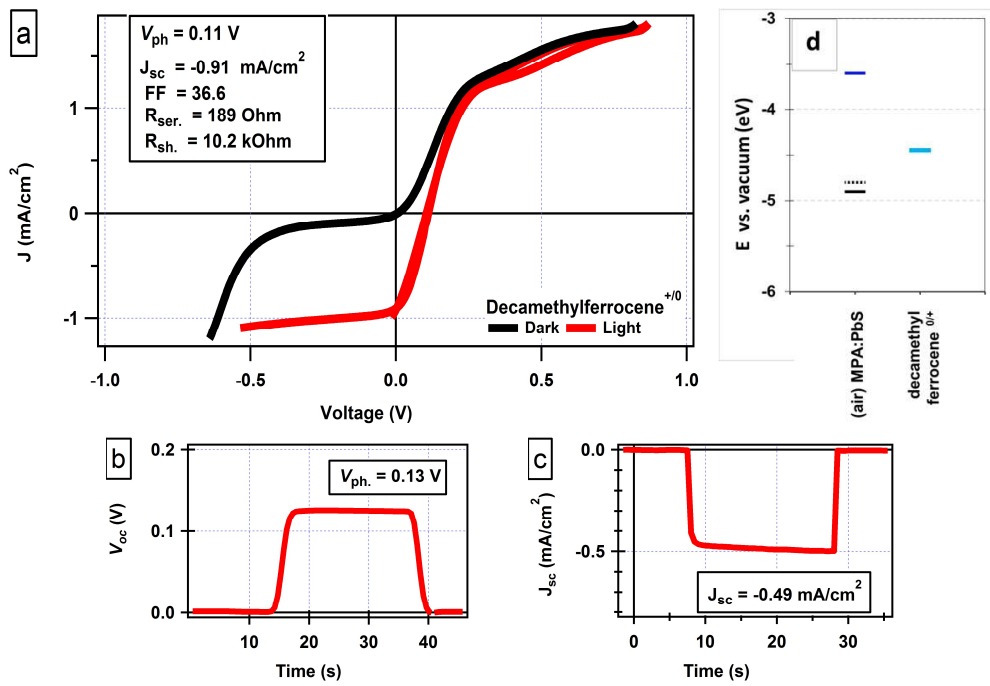

Figure 11. Electrochemical data (a-c) for MPA:PbS QD solid contacted with $\mathrm{Me}_{10} \mathrm{Cp}_{2} \mathrm{Fe}^{+/ 0}$ redox electrolyte and related energy diagram (d).
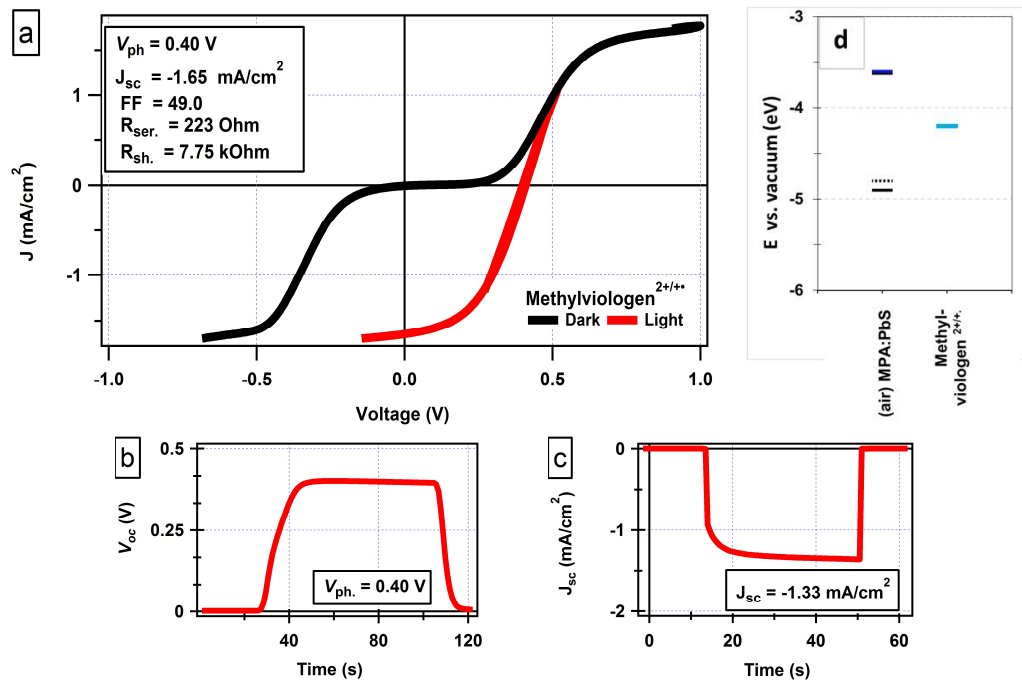

Figure 12. Electrochemical data (a-c) for MPA:PbS QD solid contacted with $\mathrm{MV}^{2+/+} \cdot$ redox electrolyte and related energy diagram (d). 

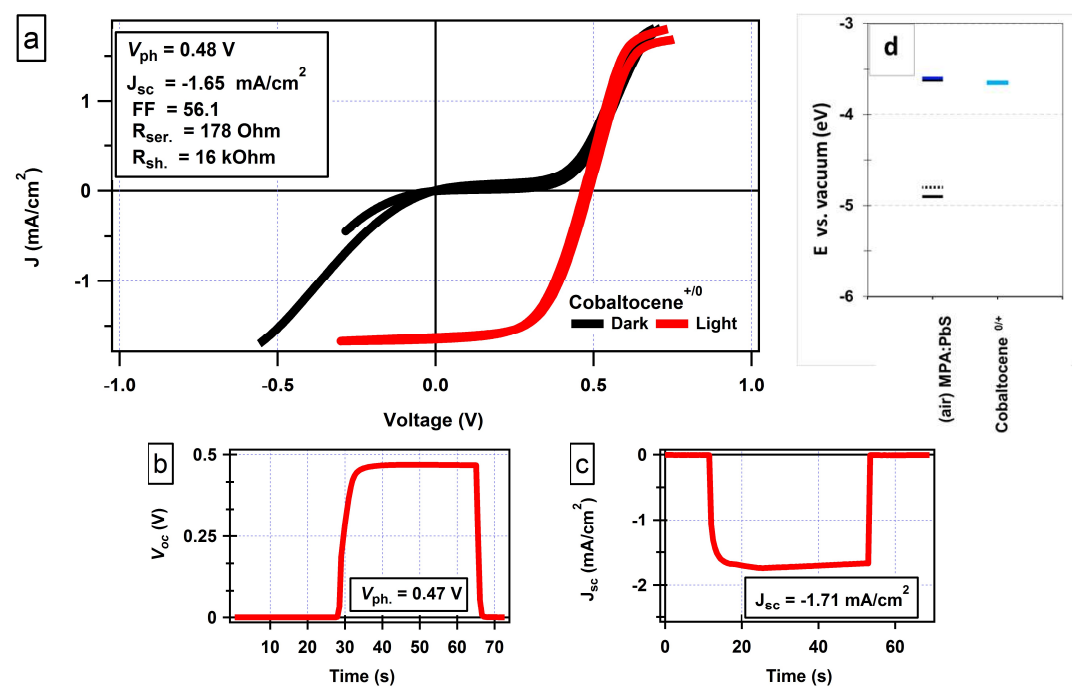

Figure 13. Electrochemical data (a-c) for MPA:PbS QD solid contacted with $\mathrm{Cp}_{2} \mathrm{Co}^{+/ 0}$ redox electrolyte and related energy diagram (d).

Energy band diagrams present in four figures above are based on electrochemical measurements of electrolytes reduction potentials (page 16) and literature values of $\mathbf{E}_{\mathrm{vb}}$ and $\mathbf{E}_{\mathrm{F}}$ energy levels for a p-type QD solid. ${ }^{22,53}$ The position of $\mathbf{E}_{\mathrm{cb}}$ was established according to films' absorbance data for the studied QD solid (Figure 30, page 45). This data illustrates a good agreement of the energetics and related electrochemical data for each QD/electrolyte pair.

These results suggest that photoelectrochemical investigation of quantum dot solids is a promising approach. Furthermore, these initial results show promise in the context of previously reported $\Delta V_{\mathrm{oc}}$ as a function of the optical band gap $\left(\Delta V_{\mathrm{oc}} / \Delta \mathbf{E}_{\mathrm{g}}\right)$. Such investigations utilized metallic or metal oxide contacting methods and yielded $\Delta V_{\mathrm{oc}} / \Delta \mathbf{E}_{\mathrm{g}} \approx$ 0.4. ${ }^{38,39,57} \Delta V_{\mathrm{oc}} / \Delta \mathbf{E}_{\mathrm{g}}$ measurements are difficult to accurately interpret, as they require an intimate knowledge of how the Fermi level changes with bandgap. In this respect, $\Delta V_{\mathrm{oc}} / \Delta E$ measurements are more easily interpreted as only contacting energetics are modulated, not 
the optoelectronic properties of the absorber itself. The results presented herein are also promising in the context of previous studies that investigated the photovoltage of PbSe QD solids/metal devices as a function of contacting metal work function. ${ }^{29} V_{\mathrm{oc}}$ were in these instances only weakly dependent on metal's work function.

The $J-V$ data in Figure 8 and on pages 22-24 are consistent with the following explanations: 1) a Schottky-junction at the p-type QD solid/electrolyte interface (see Figure 4), 2) a rectifying junction at an FTO/n-type QD solid interface, and 3) partial n-type doping of the QD solid to yield a buried p-n junction. All three predict a positive photovoltage, which was observed. Furthermore, all three predict negative photocurrents (electrons moving from the external circuit into the working electrode), which was also observed.

Electrochemical doping of QDs and QD solids is a known phenomenon. Electrochemical means have previously been applied to study and affect specific properties of quantum dots and quantum dot films. The n-type colloidal nanocrystals have been produced using redox chemistry ${ }^{58,59}$ showing that the electrical properties of individual QDs can be tuned using redox chemistry. Expanding this to QD films, the carrier concentration in $\mathrm{PbS}$ and $\mathrm{PbSe}$ films with ethanedithiol (EDT) and native oleate (OA) ligands has been reversibly and incrementally adjusted by exposing said films to solutions of metallocenes. ${ }^{60,61}$ In both cases, doping of the QD films was proposed to explain the observed results. The electrochemical results presented above can also be considered consistent with electrochemical doping of the QD solid followed by junction formation at the FTO/QD solid interface. 


\section{2) Understanding of Schottky junction interface formation}

To determine whether the rectifying junction was near the QD solid/electrolyte interface (cases 1 or 3, above), or near the FTO/QD solid interface (case 2, above) optically thick devices were constructed and tested.

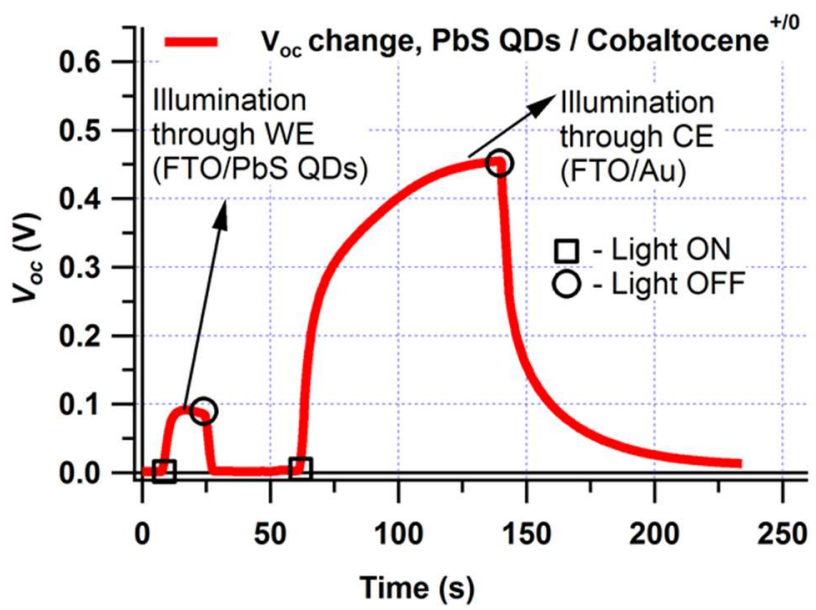

Figure 14. Photovoltage response as a function of illuminating a sandwich cell through the working electrode versus through the counter electrode. Thicker (50 cycles) PbS QD films were used for this study.

With optically thick devices, illumination through the FTO working electrode will illuminate a junction at the FTO/QD solid interface, but not a junction at the QD solid/electrolyte interface; illumination through the FTO counter electrode will illuminate a junction at the QD solid/electrolyte interface but not a junction at the FTO/QD solid interface. Consequently, the presence of a significant photovoltage will be diagnostic of the location of the rectifying junction. Chronopotentiometric data for illuminated, optically thick FTO/QD solid $/ \mathrm{Cp}_{2} \mathrm{Co}^{+/ /} / \mathrm{FTO}$ devices were consistent with the junction being near the QD solid/electrolyte interface (Figure 14). High photovoltages were observed when 
illuminating through the FTO counter electrode and electrolyte, with light illuminating the QD solid near the solid/electrolyte interface (junction). Much smaller photovoltages were observed when illuminating the QD solid near FTO/QD solid interface. Thus, the data is consistent with explanations 1 and 3; Schottky-junction at the QD solid/electrolyte interface, and with partial doping of the QD solid.

The first case, Schottky-junction formation, is a simpler process than partial doping of the quantum dot solid. Doping of quantum dot solids requires migration of charged species through the QD solid in concert with redox chemistry involving dopant sites in the QD film and redox active species in the solution. Without migration of charged species, a spacecharge region will be established which is better described by Schottky-junction formation. Previous literature has shown that the chosen electrolytes should not interact strongly with the QD solid. The solvent, acetonitrile, has been shown to interact only minimally with similar PbS QD solids. ${ }^{62}$ Furthermore, while incorporation of counterions into nanoparticle films has been shown to be important for some nanoparticle films, ${ }^{63}$ previous investigations of a similar system did not show counter-ion penetration into the film. ${ }^{60}$ Finally, the effect of prolonged exposure to all 4 electrolytes on the optical absorption spectra of the QD films yielded no significant changes to QD film absorption spectra (Figure 33, page 48).

However regardless of the formation of a Schottky junction or partial doping of the nearsurface layer the observed $\Delta V_{\text {oc }} / \Delta E$ of $1.08 \pm 0.04$ show the importance of the results in that electrochemical contacting shows no evidence of inducing interfacial defects, and absence of Fermi level pinning. Thus, this method can be applied to investigate 
photovoltaic properties (including $V_{\text {oc }}$ and carrier diffusion lengths ${ }^{43,47,64}$ ) of PbS QD solids while reducing the impact of electrical defects at the QD solid interfaces.

As we discussed above, maximum $V_{\text {oc }}$ measured for the p-type MPA:QD solids was 0.475 $\pm 0.021 \mathrm{~V}$, in the case with $\mathrm{Cp}_{2} \mathrm{Co}^{+/ 0}$. This was obtained for PbS QDs with their first excitonic peak (OA:PbS in n-hexane) located at $925 \mathrm{~nm}$ suggesting for $\mathbf{E}_{\mathbf{g}}=1.34 \mathrm{eV}$. When synthesis of OA:PbS QDs was performed with shorter reaction times, QDs with $\mathbf{E}_{\mathbf{g}}=1.44$ $\mathrm{eV}$ were produced. Both of these QD samples were used to make p-type MPA:PbS QD solids that were contacted by $\mathrm{Cp}_{2} \mathrm{Co}^{+/ 0}$ in order to understand the effects of QD's band gap on the photovoltage values. Results are summarized in the following table.

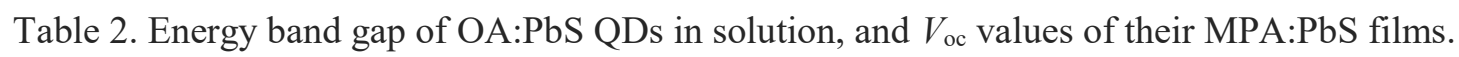

\begin{tabular}{|c|c|c|}
\hline Cell structure & E $_{\mathbf{g}}$ OA:PbS QDs $(\mathrm{eV})$ & $V_{\mathrm{oc}}(\mathrm{V})$ \\
\hline FTO / MPA:PbS / $\mathrm{Cp}_{2} \mathrm{Co}^{+/ 0}$ & 1.34 & $0.475 \pm 0.021$ \\
\hline FTO / MPA:PbS / $\mathrm{Cp}_{2} \mathrm{Co}^{+/ 0}$ & 1.44 & $0.575 \pm 0.033$ \\
\hline
\end{tabular}

This data is a promising point towards the possibility of more closely studying and better understanding the relationship of $\mathbf{E}_{\mathbf{g}}$ values of QDs solids and obtainable photovoltages. Data in Table 2, suggests that with solution contacting this can be done nondestructively as $\Delta V_{o c} / \Delta \mathbf{E}_{\mathbf{g}}=1.0 \pm 0.1$ was observed. However, a more detailed study needs to be performed that would cover a wider range of $\mathbf{E}_{\mathbf{g}}$ values as well as careful UPS characterization of studied solids to understand the changes in $\mathbf{E}_{\mathbf{F}}$ position with changing the band gap. 


\section{3) Air exposure effect on the 3-MPA:PbS QD solids}

During the studies of the p-type 3-MPA linked QD solids in the configuration of liquid contacted photovoltaic devices, I discovered that prolonged air exposure of as-deposited 3MPA:PbS QD solids plays a critical role in consolidating their p-type character. This effect is most prominently seen in the dependencies of the device photovoltaics performance in strongly rectifying configuration (3-MPA:PbS QDs with $\mathrm{Cp}_{2} \mathrm{Co}^{+/ 0}$ electrolyte). This study was performed using QDs with $\mathbf{E}_{\mathbf{g}}$ of $1.44 \mathrm{eV}$, hence higher $V_{\mathrm{oc}}$ values were achieved (up to $620 \mathrm{mV}$ ) than those discussed before $(475 \mathrm{mV})$, where $1.34 \mathrm{eV}$ QDs were used (page 28$)$.
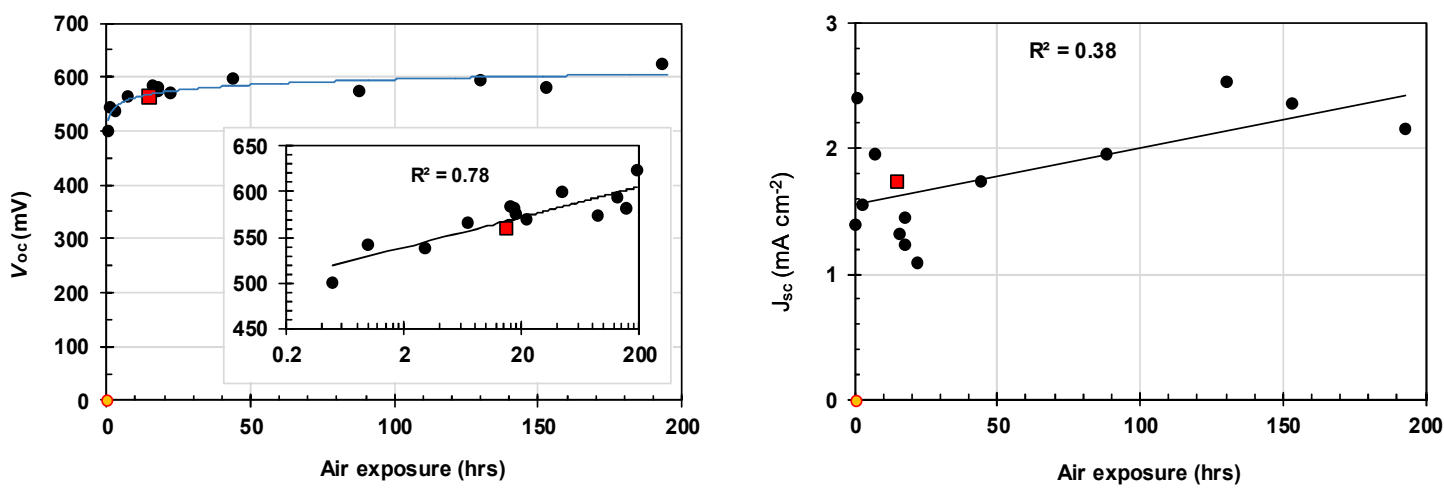

Figure 15. Change in photovoltage $\left(V_{\mathrm{oc}}\right)$ and photocurrent $\left(\mathrm{J}_{\mathrm{sc}}\right)$ as a function of air-exposure time of the p-type $\mathrm{PbS}$ solids that were contacted with $\mathrm{Cp}_{2} \mathrm{Co}^{+/ 0}$ following the air-exposure.

As data shows in Figure 15, $V_{\text {oc }}$ value increased significantly with an exponential character between 0.3 and 20 hours of films air exposure. Note that yellow point in this figure represents an actual photovoltage and current values measured for the same cell configuration, but the in-air deposited QD solid was immediately taken into $\mathrm{N}_{2}$ filled glovebox where it was tested. $\mathrm{J}-V$ characterization of this cell showed an Ohmic type behavior, similar to that shown in Figure 38(c), for n-type QD solids. Similar results were obtained for MPA:QD solids but both deposited and tested in an inert atmosphere. Red, 
square-shaped point on the two graphs above represents a device made with QD solid that was treated with air differently. Instead of depositing 15 layers of QDs at once, followed by air exposure, the film was fabricated in such a way that it was air exposed for $\sim 17$ hours after deposition of every $5^{\text {th }} \mathrm{QD}$ layer until all 15 layers were deposited. The fact that this point does not differ significantly from rest of the devices (in both $V_{\mathrm{oc}}$ and $\mathrm{J}_{\mathrm{sc}}$ values) suggests that chemistry that takes place on the surface of the whole QD solid plays a more important role in establishing the p-type character of such films. We will further discuss this in the chapter $(\mathrm{V}) \mathrm{B}) 3)$. Figure 16 plots power conversion efficiency versus air exposure time of MPA:PbS QD solids, which has also demonstrated an up-trend.

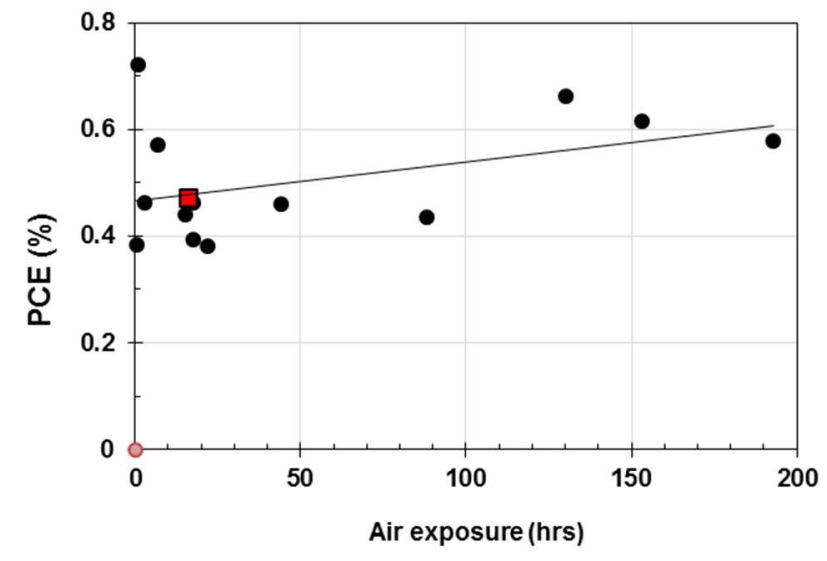

Figure 16. Power conversion efficiency as a function of air-exposure time of the p-type $\mathrm{PbS}$ solids contacted with $\mathrm{Cp}_{2} \mathrm{Co}^{+/ 0}$ after the exposure.

Overall, we conclude the positive effect of air exposing MPA:PbS QD solids. Both $V_{\mathrm{oc}}$ and $\mathrm{I}_{\mathrm{sc}}$ values were improved. However, with increasing the air exposure time we observe a decrease in $\mathrm{FF}$ values for said $\mathrm{QD} / \mathrm{Cp}_{2} \mathrm{Co}^{+/ 0}$ junctions as shown in the following figure. 


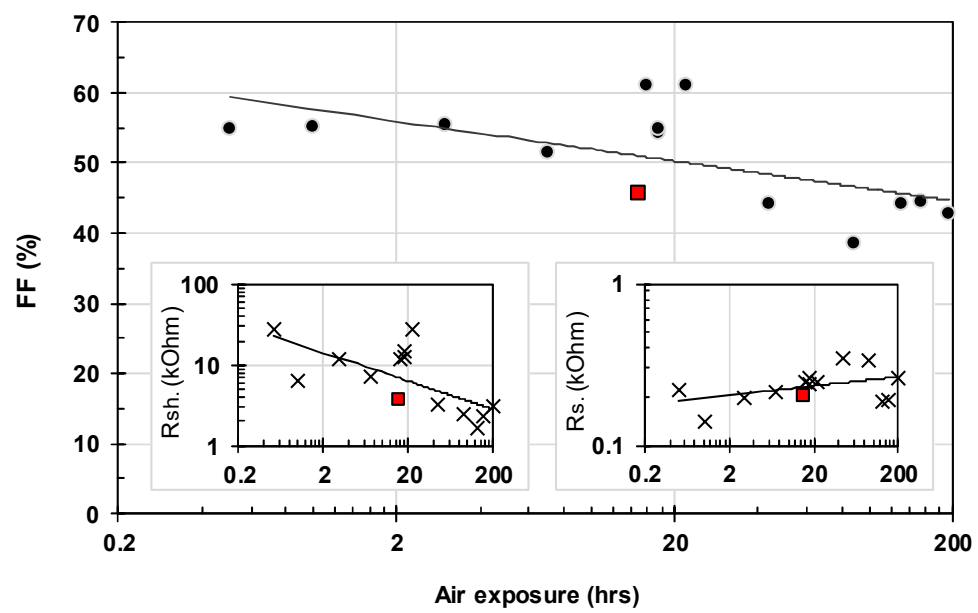

Figure 17. Change in photocurrent $\left(\mathrm{J}_{\mathrm{sc}}\right)$ as a function of air-exposure time of the p-type $\mathrm{PbS}$ solids contacted with $\mathrm{Cp}_{2} \mathrm{Co}^{+/ 0}$ after the exposure.

As data suggests, FF values were negatively affected, especially somewhat more significantly after 20 hours of air exposure of MPA:PbS QD solids. FF parameter is directly related to shunt $\left(\mathrm{R}_{\text {sh. }}\right)$ and series $\left(\mathrm{R}_{\text {ser. }}\right)$ resistance values measured on I- $V$ curve of illuminated cells, the slope of I- $V$ curve near $\mathrm{I}_{\mathrm{sc}}$ and $V_{\mathrm{oc}}$ points (see Figure 2). In order to better understand this, we need to consider the charge carriers transport mechanisms in QD solids. It was shown that electron-hole pair (exciton) separation and diffusivity across the QD solid needs to be considered differently than that for single crystalline semiconductors. ${ }^{65}$ In this work, exciton diffusion and dissociation phenomena were modeled and described, suggesting that proper chemical engineering needs to be done in order to establish good inter-QD charge communication (exciton hopping) properties. Furthermore, it was proposed that hole mobility $\left(\mu_{\mathrm{s}}\right)$ through the QD solid plays a key role in determining the FF of QD solar cells. This suggests that surface chemistry taking place during the QD solids air exposure (section IV)B)5), page 49) could affect the hole mobility properties of such solids resulting in observed FF changes as described above. 
Additional Schottky junction parameter that was observed to depend on the air exposure of MPA:PbS solids to air was resistance in the low-forward-bias region of I- $V$ curve measured in the dark. We will call it $\mathrm{R}_{\text {flat }}$ as it refers to the low-dark-current window on the I- $V$ curve (Figure $18 \mathrm{~b})$.

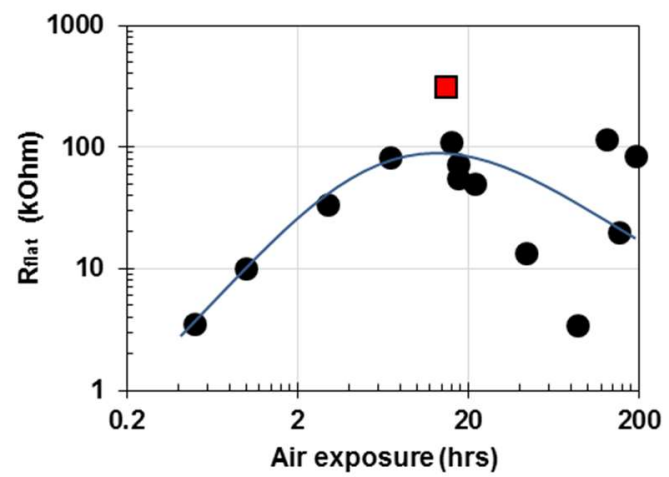

(a)

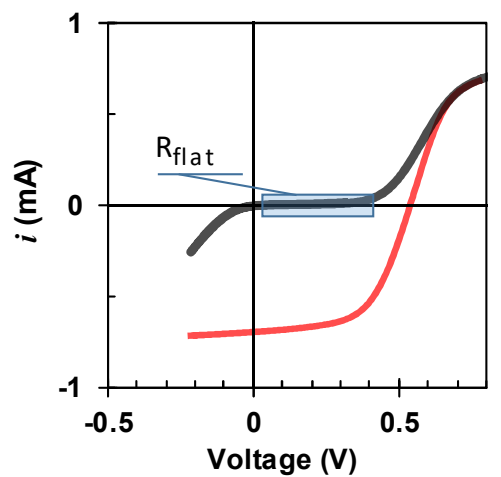

(b)

Figure 18. Resistance of the low-dark-current window of the non-illuminated I- $V$ curve as a function of air-exposure time of MPA:PbS QD solids.

This portion of I- $V$ curve is known to characterize the Schottky barrier height in a device, and hence carries a significance to understanding the relationship of QD solids chemistry and maximum obtainable photovoltage values for their junctions with an electrolyte. Figure 18 shows that $\mathrm{R}_{\text {flat }}$ value increases initially but has a downtrend after for QD films with over 20 hours of air exposure. Interestingly, the highest value is observed for the described earlier intercalated, air exposed QD solid, which suggests that surface chemistry of the QDair interaction, once understood, may need to be utilized throughout the QD film deposition, during ligand exchange process, in order to achieve higher $V_{\mathrm{oc}}$ values per given value of $\mathbf{E}_{\mathrm{g}}$ of said QD solid. The reason for this is that $V_{\mathrm{oc}}$ is directly proportional to the barrier height. 
To extrapolate the barrier height values for QD solid $/ \mathrm{Cp}_{2} \mathrm{Co}^{+/ 0}$ junctions we take a closer look at the low-dark-current window on I- $V$ curve measured in the dark. By extrapolating the dark I-V curve plotted as $\log \mathrm{J}$ vs. $V$ (see Figure $19(\mathrm{~b})$ ), and using equation 1 , we can measure the Schottky barrier height $(\varphi в)$.

$$
\boldsymbol{\varphi}_{B}=\frac{k T}{q} \ln \left[\frac{A * * T^{2}}{J_{0}}\right]
$$

where, $\mathrm{k}$ is the Boltzmann's constant, $\mathrm{T}$ - absolute temperature, $\mathrm{q}$ is a unit electronic charge, $\mathrm{A}^{* *}$ is effective Richardson constant and $J_{0}$ is a saturation current density.
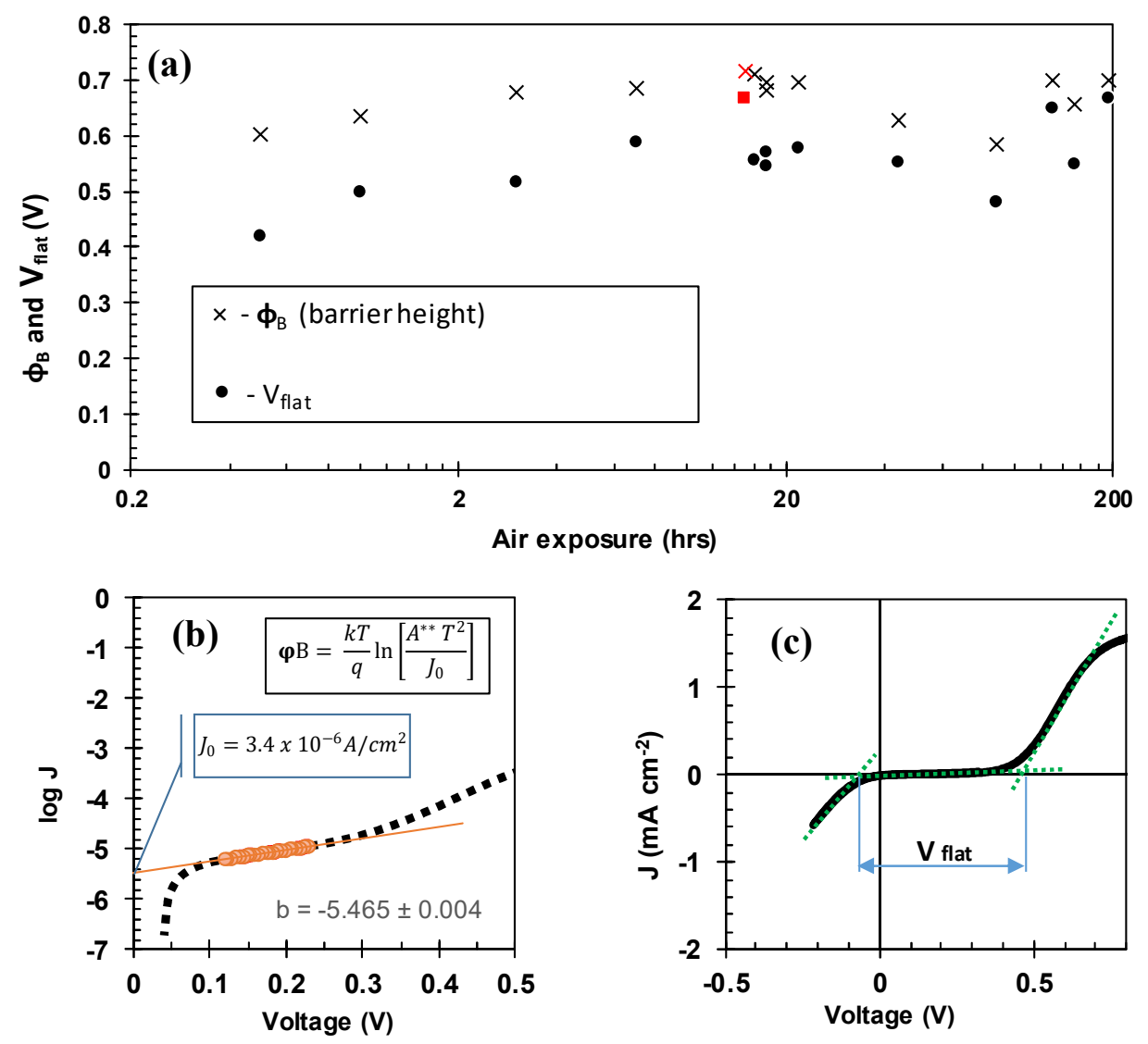

Figure 19. Schottky barrier height $\left(\varphi_{\mathrm{B}}\right)$ and low-dark-current window $\left(V_{\text {flat }}\right)$ as a function of air exposure of the MPA-QD solids (a), and graphical illustration of methods for determining these parameters $(b, c)$. 
As Figure 19 shows, Schottky barrier height $\left(\varphi_{\mathrm{B}}\right)$ and low-dark-current window $\left(\mathrm{V}_{\text {flat }}\right)$ values are in good retracement with each other. This is also somewhat consistent with corresponding $V_{\mathrm{oc}}$ values shown as a function of air exposure time in Figure 15. Theoretically, the difference between $\varphi_{\mathrm{B}}$ and electrochemically measured $\mathrm{V}_{\text {flat }}$ values could indicate the offset of $\mathbf{E}_{\mathrm{F}}$ values from those of $\mathbf{E}_{\mathrm{vb}}$ in the QD solids. This brings a value, as the fact that $\left|\varphi_{\mathrm{B}}-\mathrm{V}_{\text {flat }}\right|$ becomes smaller with longer QD solid air exposure times is consistent with the hypothesis that air exposure consolidates the p-type character of said solids.

\section{Effect of air exposure on inertly-deposited QD solids}

In order to better understand the nature of this air exposure effect on the MPA:PbS QD solids, an experiment was performed where the QD solid was deposited in an inert atmosphere ( $\mathrm{N}_{2}$ filled glovebox). The deposited film was then exposed to air for 15 hours in analogy as it was described above. The question was whether the supposed film oxidation is required to be done throughout the entire film (i.e. taking place during the deposition of QD solids) or a partial oxidation of just the surface layer of inertly deposited QD solid will yield a similar desired photovoltaic performance.
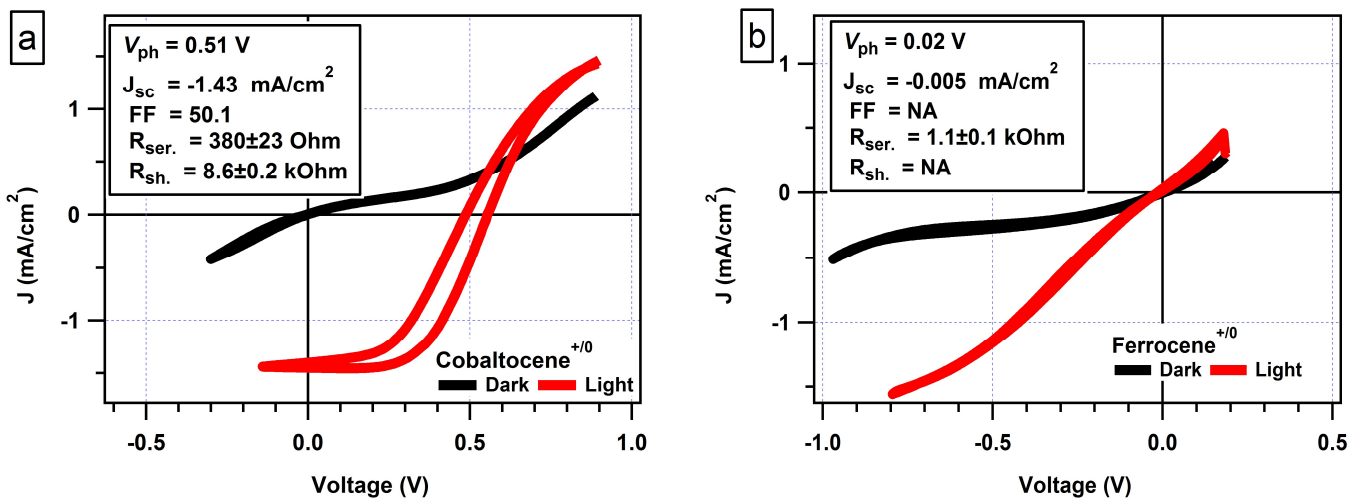

Figure 20. J-V curves obtained in dark and light for inertly deposited but air exposed MPA:PbS QD solid contacted with (a) $\mathrm{Cp}_{2} \mathrm{Co}^{+/ 0}$ and (b) $\mathrm{Cp}_{2} \mathrm{Fe}^{+/ 0}$ 
The current-voltage curve obtained in dark for the aforementioned cell was analyzed further to extract the Schottky barrier height information according to (Equation 1 above). The barrier height value was determined to be $0.603 \pm 0.016 \mathrm{~V}$ which is $\sim \mathbf{0 . 1 0 4} \mathrm{V}$ lower than that of MPA:PbS QD solids, both deposited in- and exposed to air for the same amount of time (see Figure 19a). This supports the earlier stated hypothesis that the surface chemistry of the QD-air interaction may need to be utilized on a per-QD basis rather than to a QD solid as a whole in order to achieve higher photovoltage values. Comparison of Figure 20(a) and Figure 13(a) suggests for the presence of hysteresis in I- $V$ curves associated with not fully air exposed films. This also supports that air exposing QD films improves the inter-QD charge transfer properties of such solids.

\section{Inhibition of the air effect}

As discussed above, surface chemistry of QD-air interactions was shown to play an important role in determining the electronic properties of QD solids, i.e. p-type character of said QD solids was shown to be more defined in case of air exposing of these films. The literature contains cases in which iodide $\left(\mathrm{I}^{-}\right)$as the ionic ligand was shown to protect QDs from reacting with ambient oxygen ${ }^{66}$. In the scope of this study, we attempted to inhibit the effects of air on the deposited PbS QD solids in order to better understand this process. For this, we sought to incorporate LiI as a source of $\mathrm{I}^{-}$ionic ligands to complete the coverage of unbound sites of a QD. According to published results, this could result in inhibition of oxygen influence on the QD solids. Namely, we used 1:1 molar ratio MPA:LiI as a new ligand-containing solution for depositing QD solids via spin coating (see page 12). 
This new QD solid was exposed to air for 22 hours and studied in solid/liquid junction configuration using $\mathrm{Cp}_{2} \mathrm{Fe}^{+/ 0}$ and $\mathrm{Cp}_{2} \mathrm{Co}^{+/ 0}$ electrolytes.
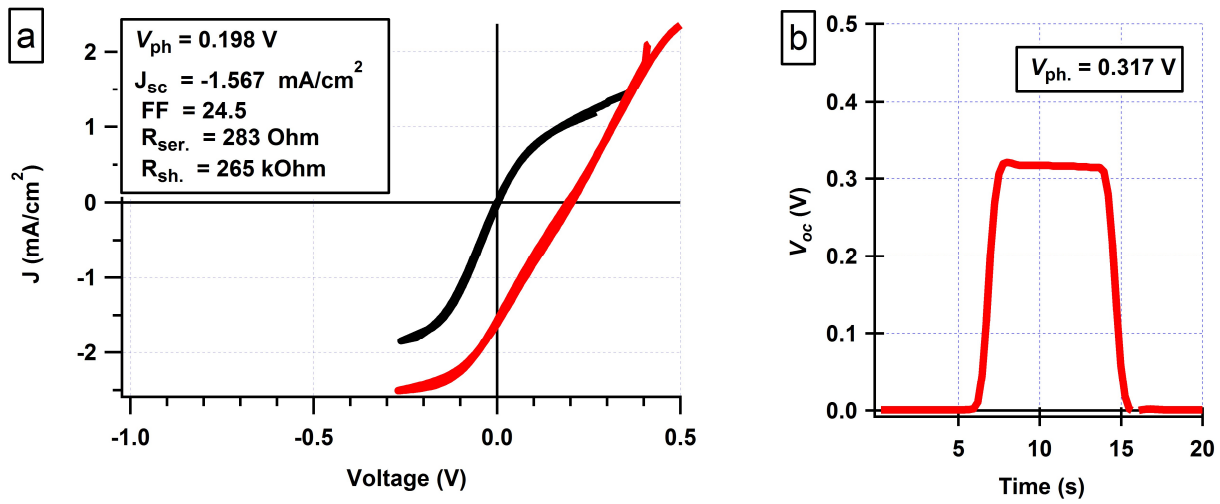

Figure 21. Current-voltage curves (a) and $V_{\text {oc }}$ response (b) produced by a 22-hour air-exposed MPA-LiI:PbS solid contacted with $\mathrm{Cp}_{2} \mathrm{Co}^{+/ 0}$
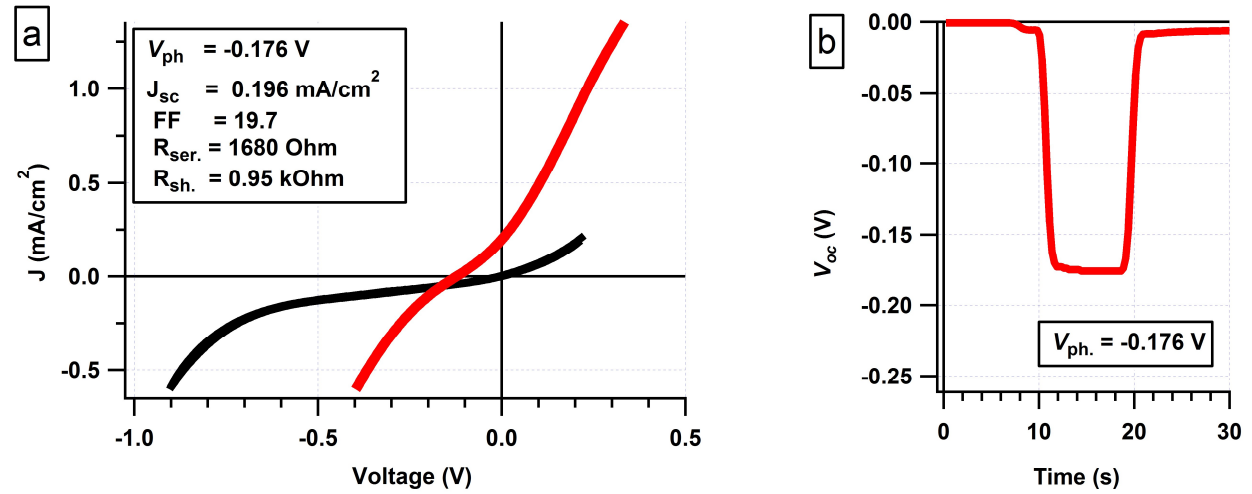

Figure 22. Current-voltage curves (a) and $V_{\text {oc }}$ response (b) produced by a 22-hour air-exposed MPA-LiI:PbS solid contacted with $\mathrm{Cp}_{2} \mathrm{Fe}^{+/ 0}$

Electrochemical data shown above suggests rectifying junction formation with both electrolytes, however, an important observation is that photovoltage values obtained for each of these electrolytes have opposite sign. This suggests that $\mathbf{E}_{\mathbf{F}}$ level of such QD solids is being located in between those of $\mathbf{E}_{\text {soln }}^{\prime}$ of $\mathrm{Cp}_{2} \mathrm{Co}^{+/ 0}$ and $\mathrm{Cp}_{2} \mathrm{Fe}^{+/ 0}$. Data shown in Figure 21 suggests that these new $\mathrm{PbS}$ solids have very poor shunt resistance, resulting in absence 
of low-current voltage window ( $\left.V_{\text {flat }}\right)$ in I- $V$ curve measured in dark. A similar situation was demonstrated by Zhao et.al., ${ }^{42}$ in case of annealing QD solids in the $\mathrm{N}_{2}$ atmosphere instead of oxygen environment. In this case formation of wider band gap oxide layers on QD surface was thought to be responsible for preventing electron-hole pair recombination, thus improving shunt resistance values that led to better PV performance.

Data shown in Figure 22 suggests negative photovoltage values, and similar low values of $\mathrm{R}_{\text {sh }}$ that most likely limit the maximum $V_{\text {oc }}$ value to $-0.176 \mathrm{mV}$ (see red curve in Figure 22). These results suggest a hypothesis that air-involving chemistry taking place on the surface of QD solids involves access of air species to the QD core sites, as I- ionic ligands covering those sites inhibited the process of QD film's p-type stabilization in the air.

\section{4) Depleted heterojunction (DH) photovoltaic cells}

After the successful outcomes of liquid contacting method developments and optimizations discussed above, I sought to benchmark the QD solids in a standardized, all-solid-state device configuration. Commonly used photovoltaic device architecture for the p-type PbS QD solids is a depleted heterojunction (DH) type devices. Here, QD solid serves as light absorbing material and is deposited on a wide band-gap semiconducting film. Typically, this is $\mathrm{TiO}_{2}$ or $\mathrm{ZnO}$ in form of a transparent, dense films that are deposited on FTO or ITO substrates. QDs are deposited over this layer and are back contacted by low work-function metals, like $\mathrm{Au}$. DH devices were fabricated in according to published literature

procedures. ${ }^{48}$ Figure 23 shows a digital photograph of such device with dimensions of $23 \times 19 \mathrm{~cm}$ and a schematic (not to scale) diagram showing its components. As it is shown below, there were 9 individual sub-devices on one substrate. This allows for statistically 
meaningful PV performance measurements, as $\mathrm{QD}$ and $\mathrm{TiO}_{2}$ films' non-uniformity across the substrate needs to be considered.
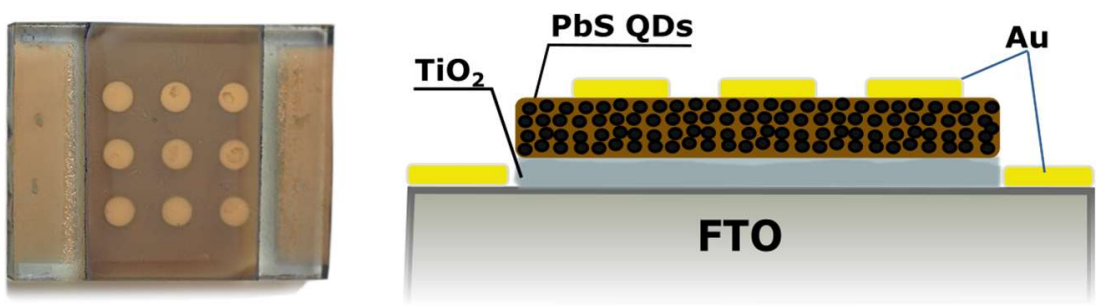

Figure 23. Digital photographs of a DH solar cell with 9 devices on one substrate (left), and a schematic cross-sectional illustration of the DH cell components (right).

These PV devices were tested in a testing setup (Figure 24) equipped with spring-assisted contact probes that I designed, machined and put together with help and guidance from PSU's science support machine shop. (Thanks, Alex Chally and Dr. Sanchez!)

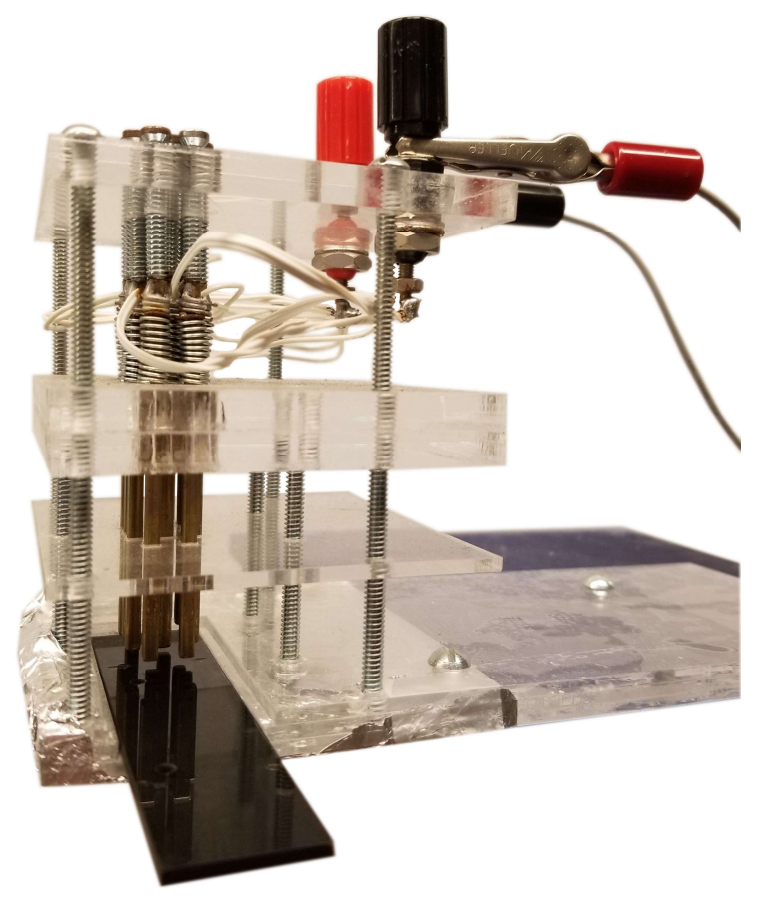

Figure 24. A digital photograph of DH cell testing setup. 
Light illumination is done from the bottom, while the cell is placed right under the contacting probes and is rested on the black sliding mask. The mask allows illumination of only one out of nine devices at a time, which also is electrically contacted.

\section{Photovoltaic performance of p-type QD solids in DH configuration}

Typical current-voltage characteristics for a DH solar cell described above is shown in Figure 25. This data is in strong correlation with that published for similar DH devices based on MPA:PbS QDs solids. ${ }^{48}$

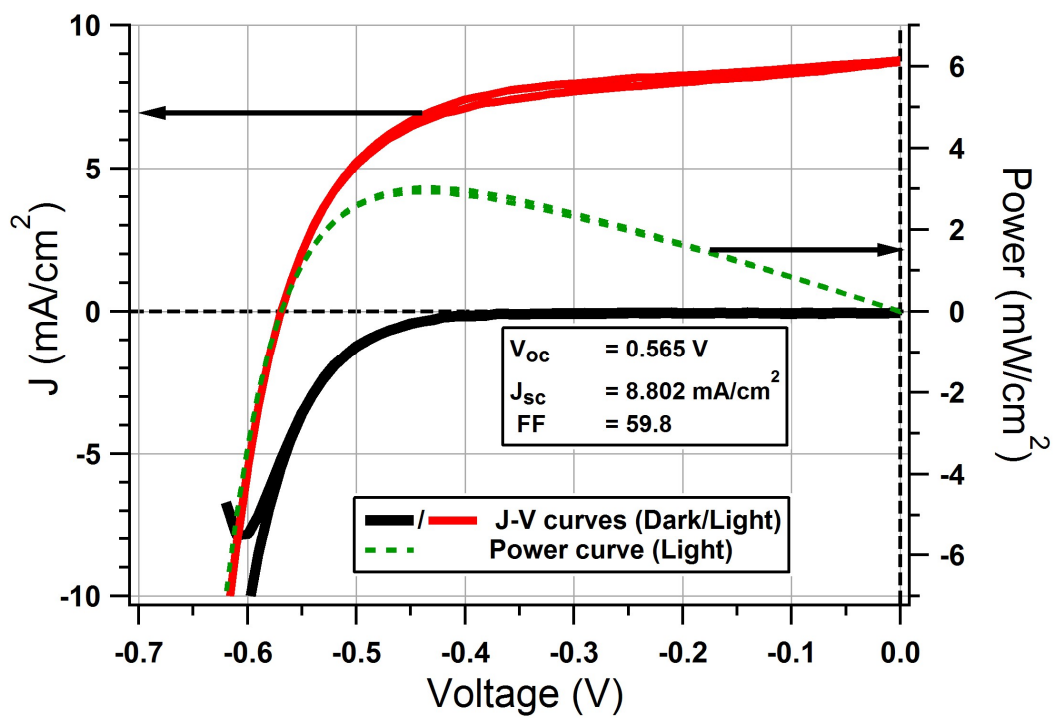

Figure 25. J- $V$ curves (in dark and under 1Sun illumination) for a DH device. The dashed line represents a power curve.

Photovoltage values were measured to be $560 \pm 19 \mathrm{mV}$ for QD solids with $1.31 \mathrm{eV}$ band gap (Figure 26), which is about $95 \mathrm{mV}$ higher than those measured for similar $\mathbf{E}_{\mathbf{g}}$ QD solids but contacted by $\mathrm{Cp}_{2} \mathrm{Co}^{+/ 0}$. Power conversion efficiency and $\mathrm{J}_{\mathrm{sc}}$ values were measured at $3 \pm 0.4 \%$ and up to $10.0 \pm 2.5 \mathrm{~mA} / \mathrm{cm}^{2}$ respectively. These $\mathrm{J}_{\mathrm{sc}}$ values are higher within a factor of 3 than those measured with QD solid/liquid junction cells, which can be explained 
by differences in active device's area $\left(0.036 \mathrm{~cm}^{2}\right.$ for $\mathrm{DH}$, and $0.5 \mathrm{~cm}^{2}$ for $\left.\mathrm{QD} / \mathrm{Cp}_{2} \mathrm{Co}^{+/ 0}\right)$. Bigger device's area can limit the PV measured performance, including Voc, as there are more chances of defects inclusions across the QD film, which leads to higher unwanted carrier recombination rates. In summary, electrochemical data obtained for DH solar cells was consistent with that obtained for $\mathrm{PbS} / \mathrm{Cp}_{2} \mathrm{Co}^{+/ 0}$ junctions, however further device engineering advances could potentially improve the PV performance of solid/liquid junctions.

\section{Optical properties of the $\mathrm{DH}$ substrates - $\mathrm{TiO}_{2} / \mathrm{PbS} \mathrm{QDs}$}

Light absorbing properties of working electrode used in $\mathrm{DH}$ cells studies were characterized by UV-Vis-NIR spectroscopy (Figure 26). Black dashed line represents absorbance of source OA:QD colloidal suspended in n-hexane solution and suggests that optical band-gap of QDs used to make DH cells is $1.34 \mathrm{eV}$ (excitonic peak at $927 \mathrm{~nm}$ ). After deposition of QDs in form of MPA:PbS (with exchanged ligands), the excitonic peak of resulting QD solid red-shifts to $1.31 \mathrm{eV}$ (945 nm wavelength), which is in agreement with previous reports for both solution and solid-state ligand exchange. ${ }^{67-70}$ The peak observed at approximately $1310 \mathrm{~nm}$ is expected to originate due to $\mathrm{FTO} / \mathrm{TiO}_{2} / \mathrm{QD}$ films light interactions (reflectance peak). This will be further discussed along with absorbance data for FTO/QD films (Figure 30, on page 45). 


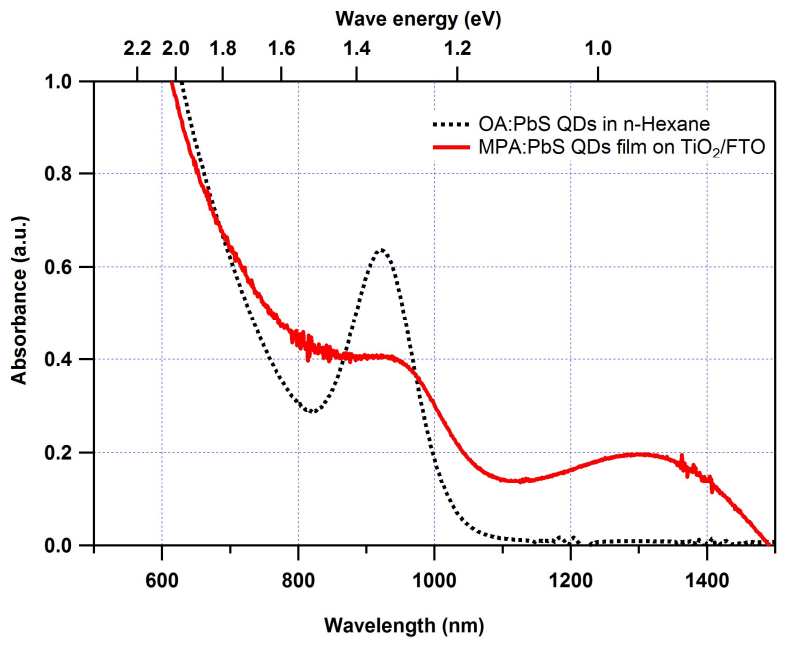

Figure 26. Optical properties of MPA:PbS QD solid deposited on $\mathrm{TiO}_{2} / \mathrm{FTO}$ substrate (solid line) and of original $\mathrm{OA}: \mathrm{PbS}$ QDs suspended in n-hexane.

\section{B) p-type QD solids characterization}

Once these promising electrochemical results were obtained for both Schottky type QD solid/liquid junctions and DH cells, I looked to further characterize both colloidal QDs and the QD solids, in order to better understand the processes that enable observed PV properties.

\section{1) TEM characterization of $O A: P b S Q D s$}

To assess QDs size information, multiple TEM images of the same batch of QDs were manually analyzed using ImageJ software. Results of this analysis are shown in Figure 27. This data suggests the average QD size is $3.18 \mathrm{~nm}$, while size ranged from $2.5-4 \mathrm{~nm}$. The excitonic peak for this QD sample was located at a wavelength of $925 \mathrm{~nm}$ which corresponds to photon energy being $1.34 \mathrm{eV}$, which also suggests for $\mathbf{E}_{\mathbf{g}}$ value. 

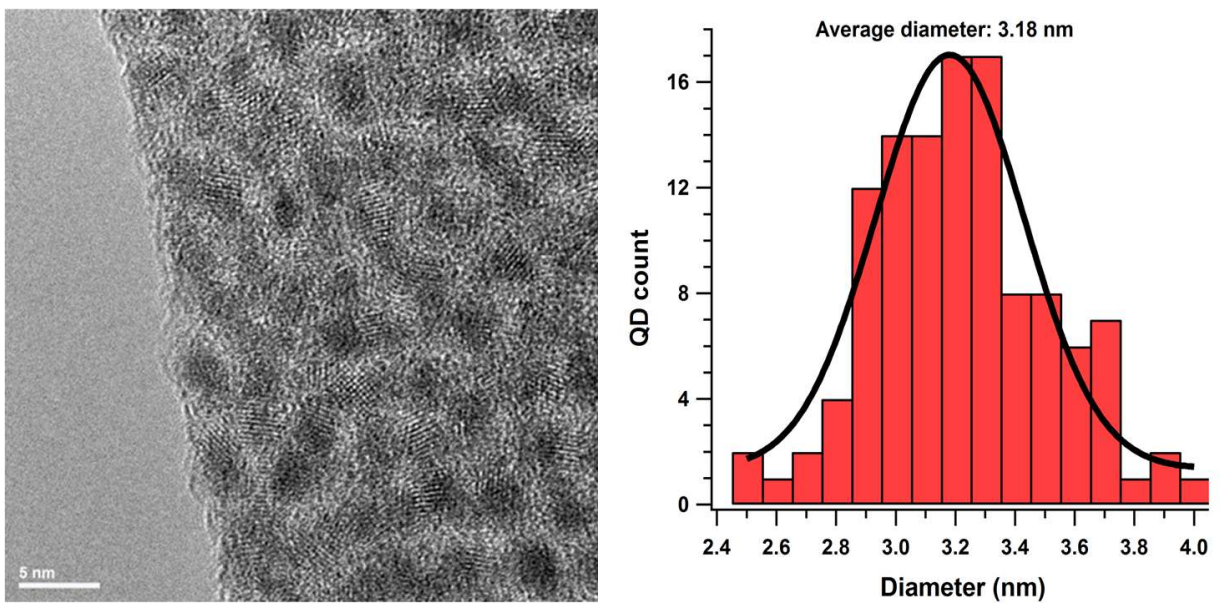

Figure 27. Transmission electron micrograph of OA capped $\mathrm{PbS}$ quantum dots and the size distribution histogram for QD particles.

According to study that reveals the relationship between PbS QD size and excitonic peak position, ${ }^{71} 1.34 \mathrm{eV}$ corresponds to QD size of $3.0 \mathrm{~nm}$, which is in good agreement with TEM data.

2) XRD studies of PbS QD solids

XRD patterns for both MPA and OA capped QD solids are shown in the following figure.

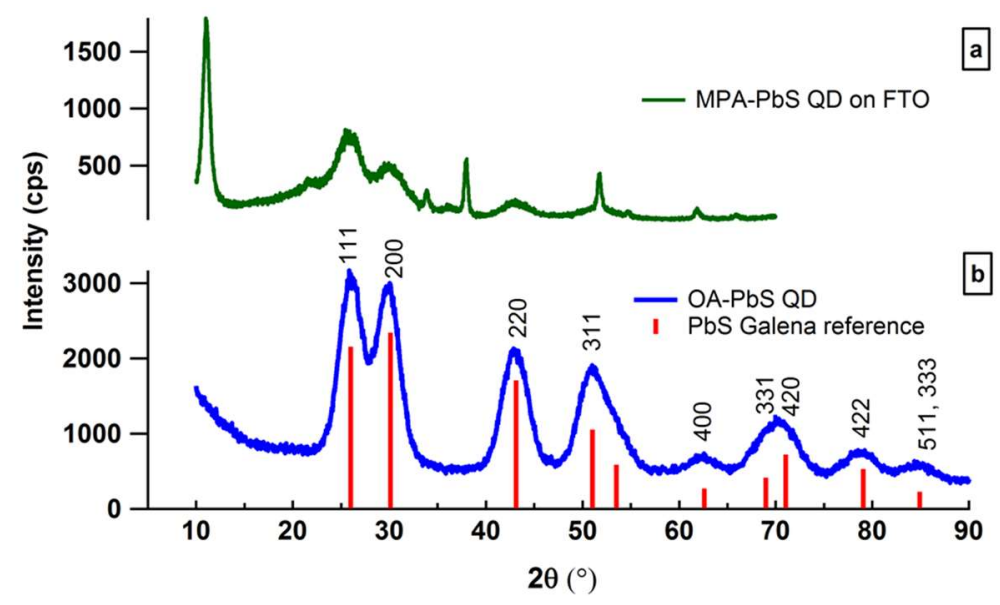

Figure 28. (a) X-ray diffraction patterns of 3-MPA exchanged PbS QD solid deposited on FTO (green line) and (b) OA:PbS QDs (blue line) along with PbS galena reference (red, vertical lines). 
Analysis of peak broadening using Scherrer equation yielded particle diameter of $3.04 \pm$ $0.06 \mathrm{~nm}$ for OA capped QDs, which also agrees well with TEM and Uv-Vis results as discussed above. Scherrer equation can be written as:

$$
d=\frac{K \lambda_{\operatorname{CuK} \alpha}}{w \cos \theta_{220}}
$$

Where $\mathrm{d}$ is the mean size of the QDs, $\mathrm{K}$ is a shape factor, with a value close to unity (0.9), $\lambda$ is the X-ray wavelength of $\mathrm{CuK} \alpha(8047.8 \mathrm{eV}), w$ - is the line broadening at half the maximum intensity (FWHM) measured in radians, and $\theta$ is the Bragg's angle (in degrees). XRD spectra for MPA:PbS QD solids showed crystalline PbS peaks less explicitly which could be explained by the fact that much thinner films are obtained with in-situ ligand exchange deposition of MPA:PbS QDs, comparing to direct deposition of oily solids of OA:PbS QDs. Sharp peaks in the XRD spectrum (Figure 28a) result from the FTO substrate.

\section{3) Photoluminescence studies of PbS QDs}

Photoluminescence is an important feature of quantum dots as it provides information about their optoelectronic-electronic properties. Multiphoton assisted carrier trapping to states outside a PbS QD, and lowest exciton splitting energy and lifetimes of exciton states of PbS QDs were studied by photoluminescence measurements. ${ }^{72}$ 


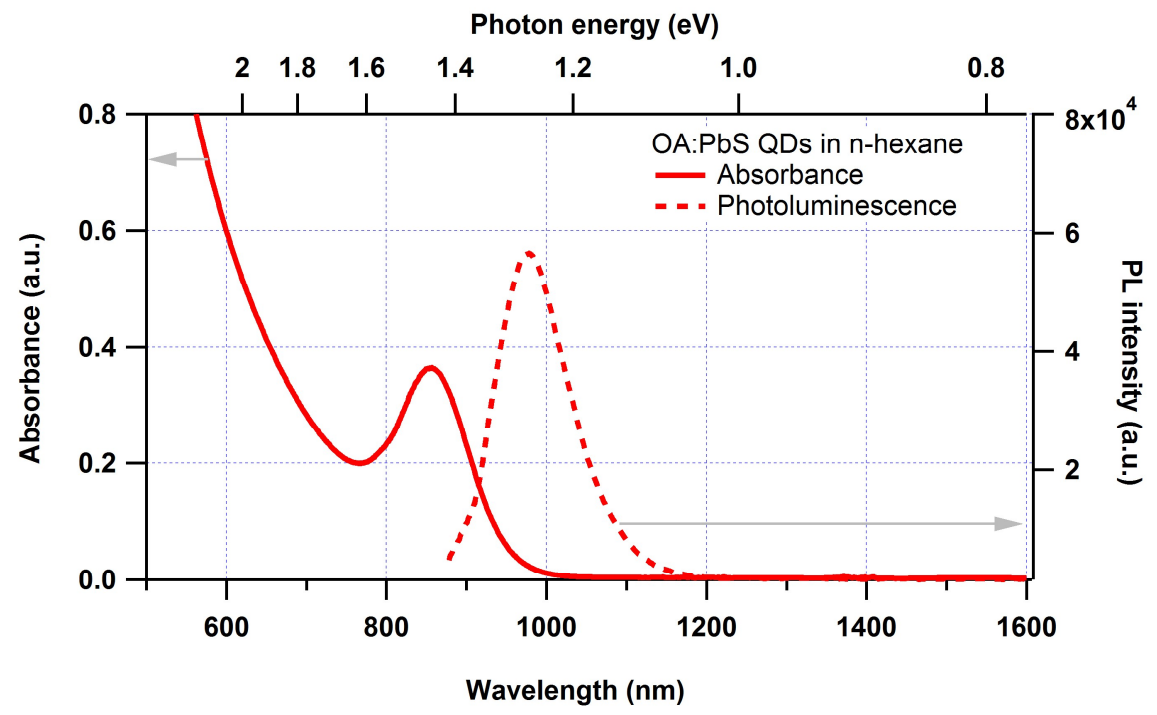

Figure 29. OA:PbS QDs in solution; absorption (solid) and photoluminescence (dashed) spectra.

The PL results suggest for successful preparation of quality QDs with strong photoluminescence properties. Presence of Stokes shift, a red shift of the emitted wavelength of QDs which is consistent with that reported in literature. ${ }^{73}$ Changing excitation wavelength for PL measurements did not affect PL peak position significantly.

\section{4) UV-Vis-NIR spectroscopy of PbS QD solutions and films}

Light absorption properties of as-synthesized, oleate capped PbS QDs in n-hexane and their corresponding QD solids, deposited with in-situ ligand exchange were also studied in this work in order to understand the specifics of thin films depositions. Figure 30 shows absorbance spectra for OA:PbS QD solids and change in such spectra measured during QD solids deposition, i.e. after 1,2,4,8,15,24 and 35 MPA:PbS layer deposited on FTO. 


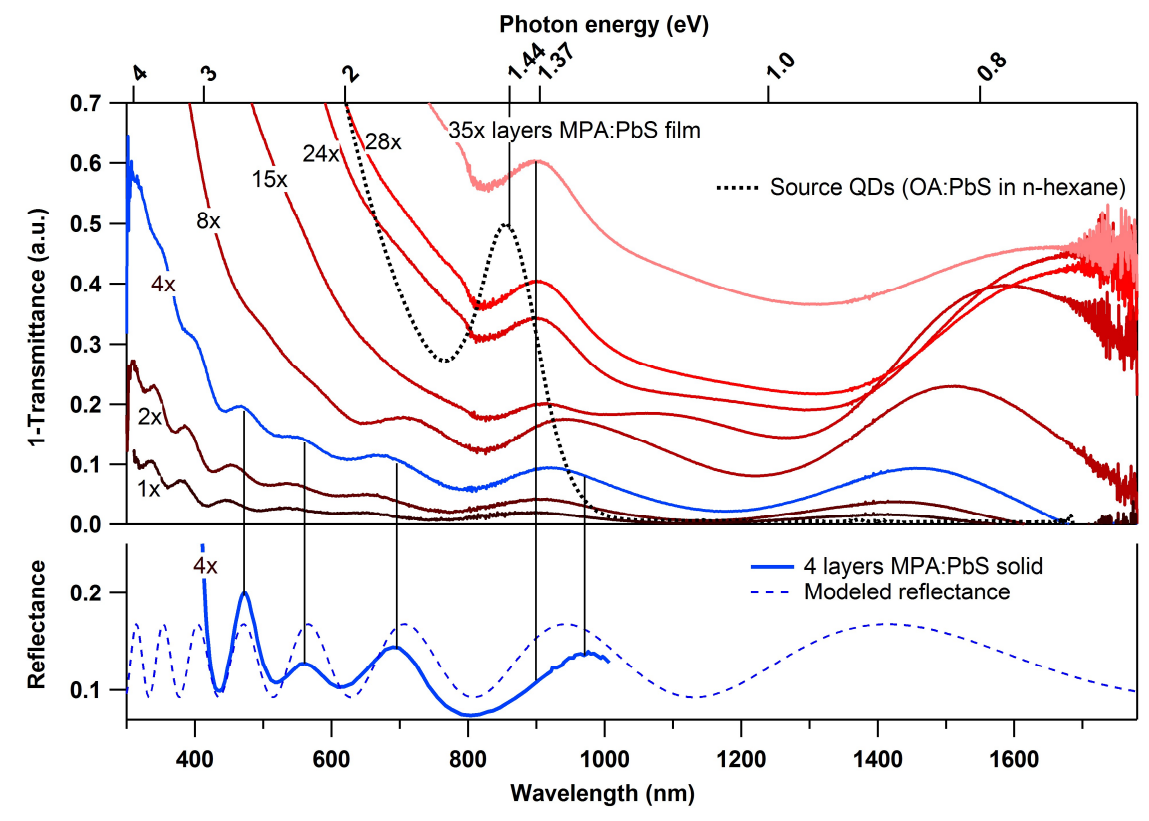

Figure 30. Absorbance spectra for MPA:PbS QD solids on FTO and OA:PbS QDs in solution (top) and reflectance spectra of 4 layers MPA:PbS QD solid (bottom).

Reflectance spectra (both modeled and measured) is also shown in the figure above. Blue lines in both abs. and reflectance spectra represent a sample of 4 layers MPA:PbS QD solids deposited on FTO, and clearly illustrate origins of multiple periodic peaks observed in Uv-Vis spectra (measuring light intensity attenuation of beam passed through the FTO/QD sample). These data suggest that the peaks are not necessarily of an absorption nature but might be resulted from the light reflectance on the interface between two solid films with different refractive indexes (n). However, as films thickness increases, these reflectance peaks are diminished, with exception of one located at $1.37 \mathrm{eV}$, which is believed to be the true first excitonic peak of MPA:PbS QDs solids.

Evolution of peak starting at $\sim 1400 \mathrm{~nm}$, and going towards $1650 \mathrm{~nm}$, caught my attention as it is not clearly obvious whether it is purely originated from reflectance. This peak's respective photons energies could potentially indicate that the $\mathbf{E} \mathbf{g}$ values of deposited QD 
solids after ligand exchange are much smaller $(\sim 0.8 \mathrm{eV})$ than those measured of QDs in solution (1.44eV, Figure 30 - black dashed line). This would be consistent with highest $\mathbf{V}_{\mathbf{o c}}$ values for such films being $0.6 \mathrm{~V}$ and barrier height values of $0.7 \mathrm{~V}$ (see pages 29 and 33). To further investigate this, oleic acid capped PbS QDs were deposited on FTO substrate (without ligand exchange) and characterized with Uv-Vis.

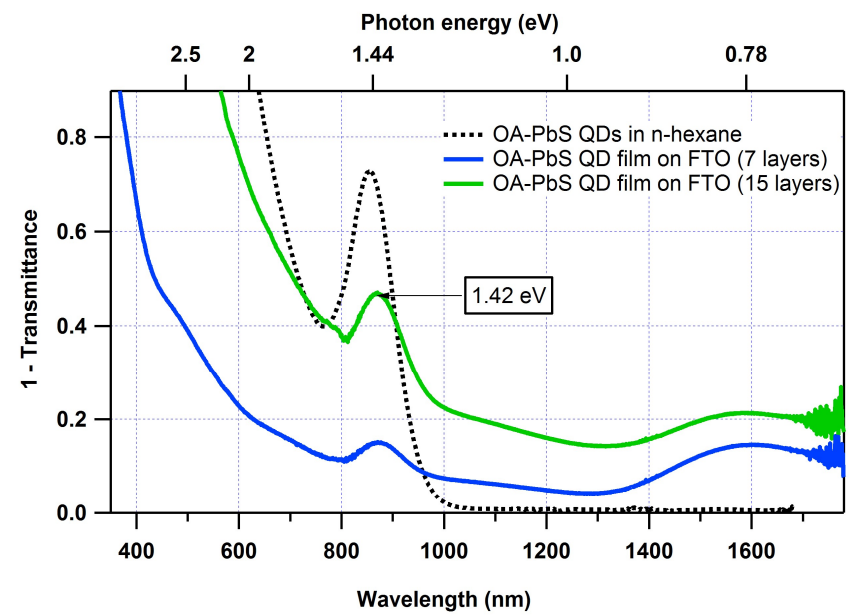

Figure 31. UV-Vis-NIR spectra of OA:PbS QDs in solution (dashed) and OA:PbS QDs deposited on FTO substrate.

Surprisingly, this sample also resulted in the appearance of this new peak located around $1600 \mathrm{~nm}(0.8 \mathrm{eV})$. This does not support the hypothesis that this peak, when observed for MPA:PbS QD solids, could be resulting from procedures of ligand exchange during film's deposition. $1600 \mathrm{~nm}$ peak is consistent with reflectance data as modeled in Figure 30 for refractive indexes of FTO and PbS being approximately 4.1 in range of 500-1500 nm wavelength of light. ${ }^{74} \mathrm{Uv}$-Vis data for OA:PbS sample (Figure 31) showed much smaller red-shift $(0.02 \mathrm{eV})$ of the excitonic peak than that observed for MPA:PbS solids $(0.07 \mathrm{eV})$, which is consistent with previous reports for effects of ligand exchange on optoelectronic properties of QDs. ${ }^{67-70}$ 
To further confirm the nature of the $0.8 \mathrm{eV}$ peak MPA:PbS QDs were deposited on cleaned glass (microscope slide). This was done in order eliminate possible hypothesized reflectance nature of this peak resulting in light reflectance at $\mathrm{FTO} / \mathrm{PbS}$ interface. More detailed structure of this interface would look like Glass/F: $\mathrm{SnO}_{2} / \mathrm{QD}$ solid. This time, same deposition technique was used as above for depositing solids on FTO.

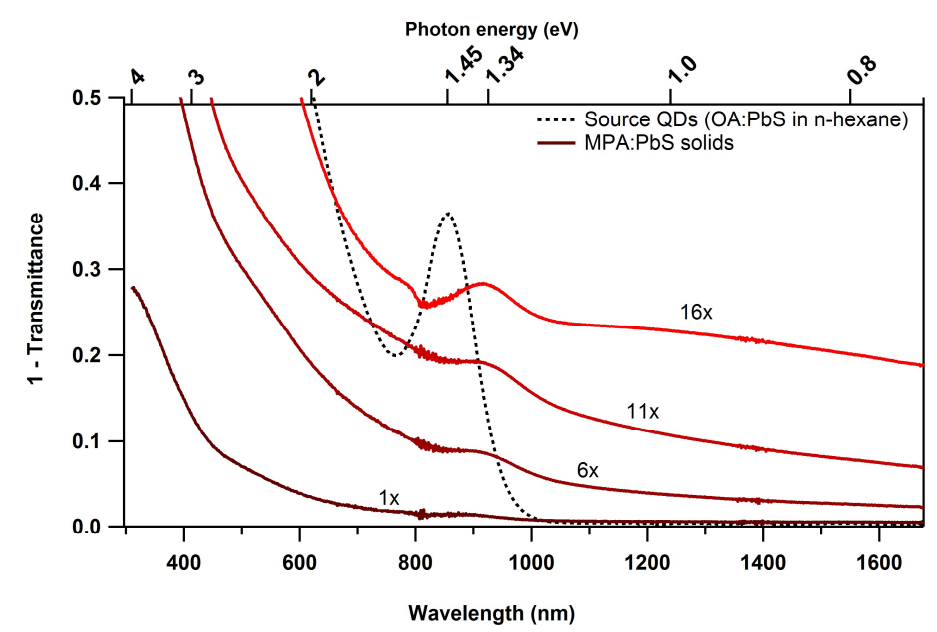

Figure 32. Absorption spectra of MPA:PbS QD solids of varying thickness deposited on glass.

Results are shown in Figure 32 suggested absence of the "mysterious" $0.8 \mathrm{eV}$ peak which supports the earlier mentioned hypothesis. Hence, we conclude that the first true absorbance excitonic peak is in a range of $1.34-1.37 \mathrm{eV}$ for MPA:PbS solids deposited on FTO substrate. 
Further Uv-Vis spectroscopy characterization of MPA:PbS QD solids was carried out in order to understand whether these solids undergo any change in their optoelectronic properties as a result of their contact with the redox solutions (in acetonitrile). Four samples of MPA:PbS solid were soaked in their respective electrolyte for 45 hours. Absorption spectra of the solids were acquired prior to (solid lines) and after the soaking (dashed lines). Results shown in Figure 33 suggest only minimal changes observed for these solids after they were in contact with their corresponding electrolytes.

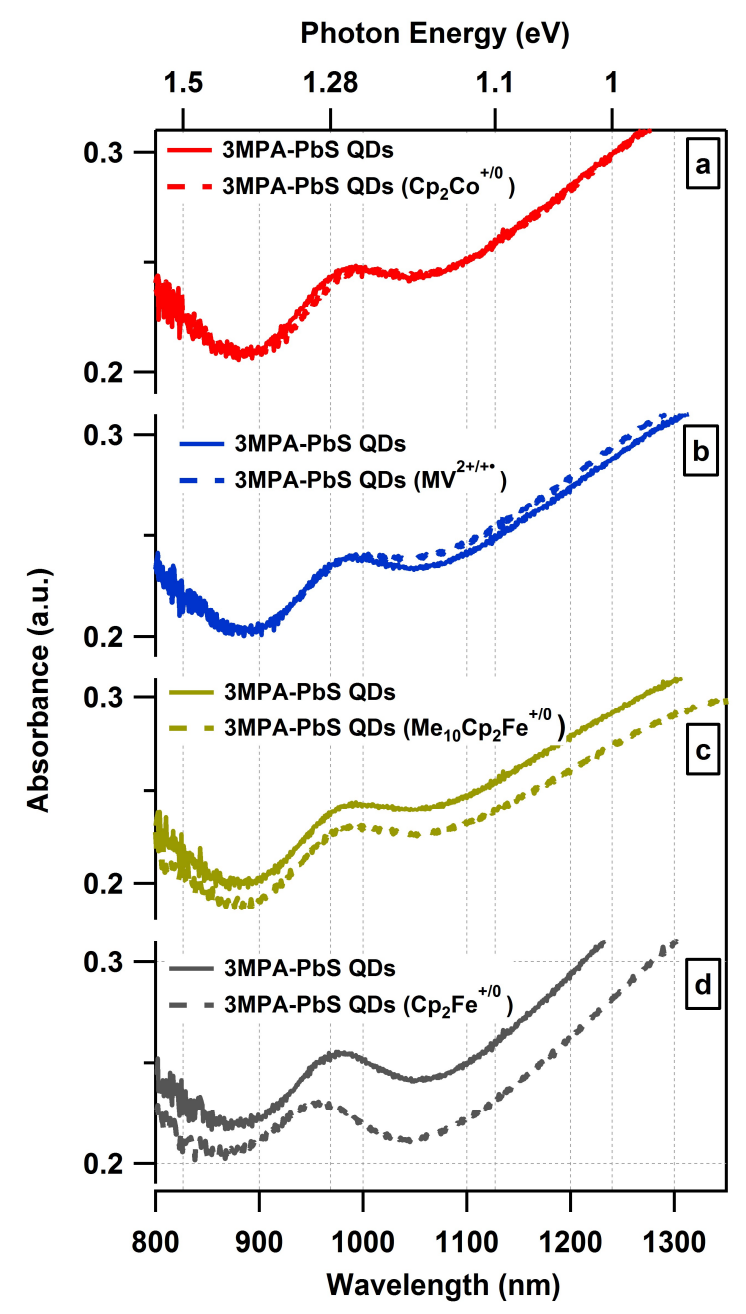

Figure 33. Absorption spectra of the 3-MPA exchanged $\mathrm{PbS}$ solid films deposited on FTO and soaked in (a) $\mathrm{Cp}_{2} \mathrm{Co}^{+/ 0}$, (b) $\mathrm{MV}^{2+/+}$, (c) $\mathrm{Me}_{10} \mathrm{Cp}_{2} \mathrm{Fe}^{+/ 0}$ and (d) $\mathrm{Cp}_{2} \mathrm{Fe}^{+/ 0}$ redox electrolytes. 


\section{5) XPS characterization of MPA:PbS solids}

X-ray photoelectron spectroscopy was also implemented in MPA:PbS QD solids characterization. XPS is a surface sensitive technique, which provides a chemical elemental composition of the sample, and typically has a penetration range of approximately $10 \mathrm{~nm}$ into the material. However, this value depends on sample and X-ray energy. As shown in Figure 34, MPA:PbS solids surface contains $\mathrm{Pb}, \mathrm{S}, \mathrm{C}$, and $\mathrm{O}$ elements. Carbon is expected to be present on most XPS spectra which can be explained by the presence of so-called adventitious carbon (air born carbon species adsorbed on the sample). However, MPA ligands attached to QD surface are also expected to contribute to the presence of carbon. Oxygen species could also come from carboxylic groups of MPA, however, it is not excluded that these could be resulted in the air exposure of this QD sample for 20 hours prior to XPS study.

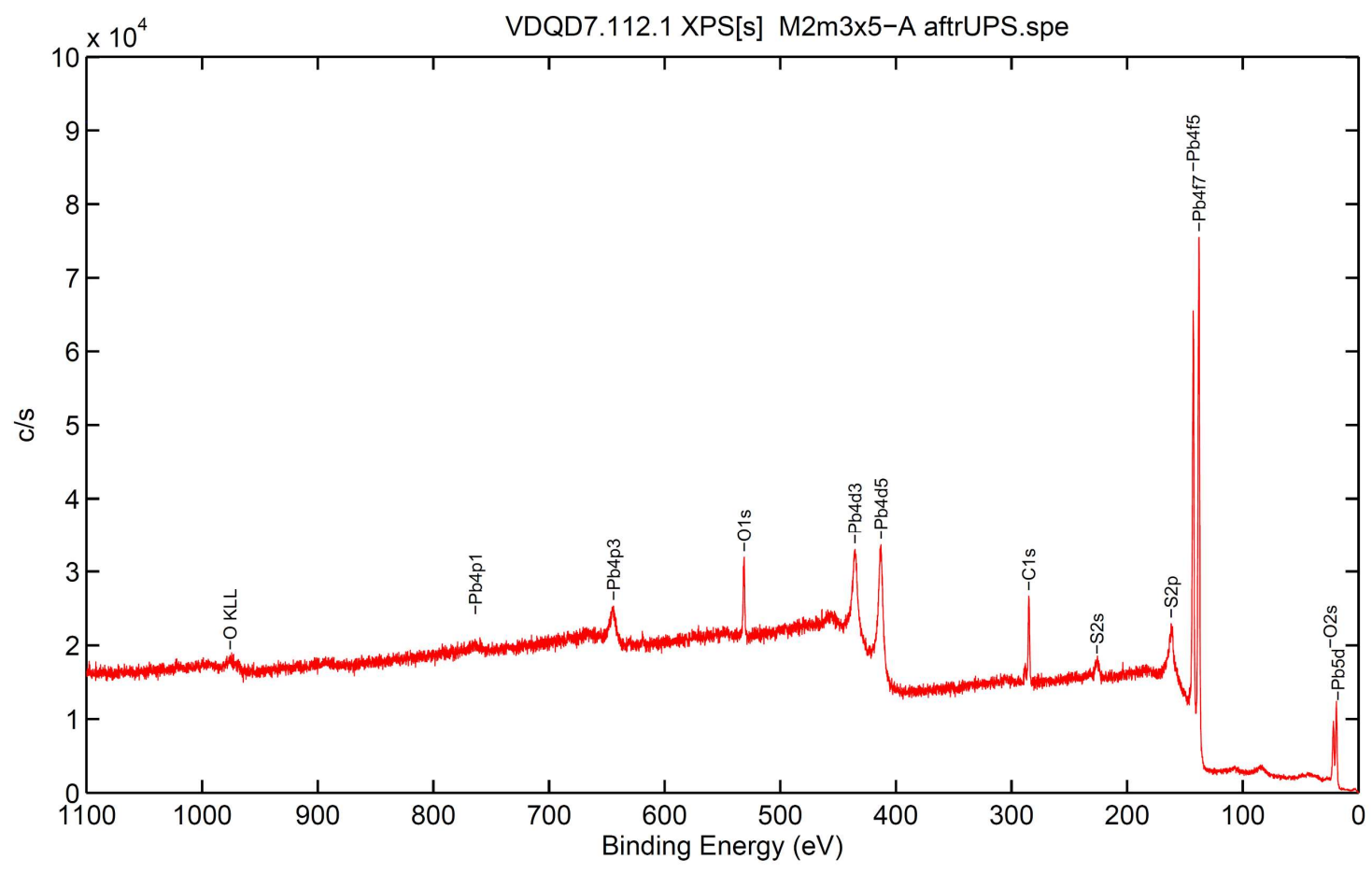

Figure 34. XPS spectra of MPA:PbS QD solid after 20 hours of air exposure. 
Detailed elemental XPS spectra for MPA:PbS QD solids exposed to air for 0.3 and 20 hours is shown in Figure 35. This data clearly illustrates growth in $\mathbf{P b}-\mathrm{OH}$ peak upon air exposing the QD solid. Sulfur also has undergone oxidative changes as suggested by the growth of $\mathrm{S}^{0}$ and appearance of sulfate peaks. Changes in carbon chemical
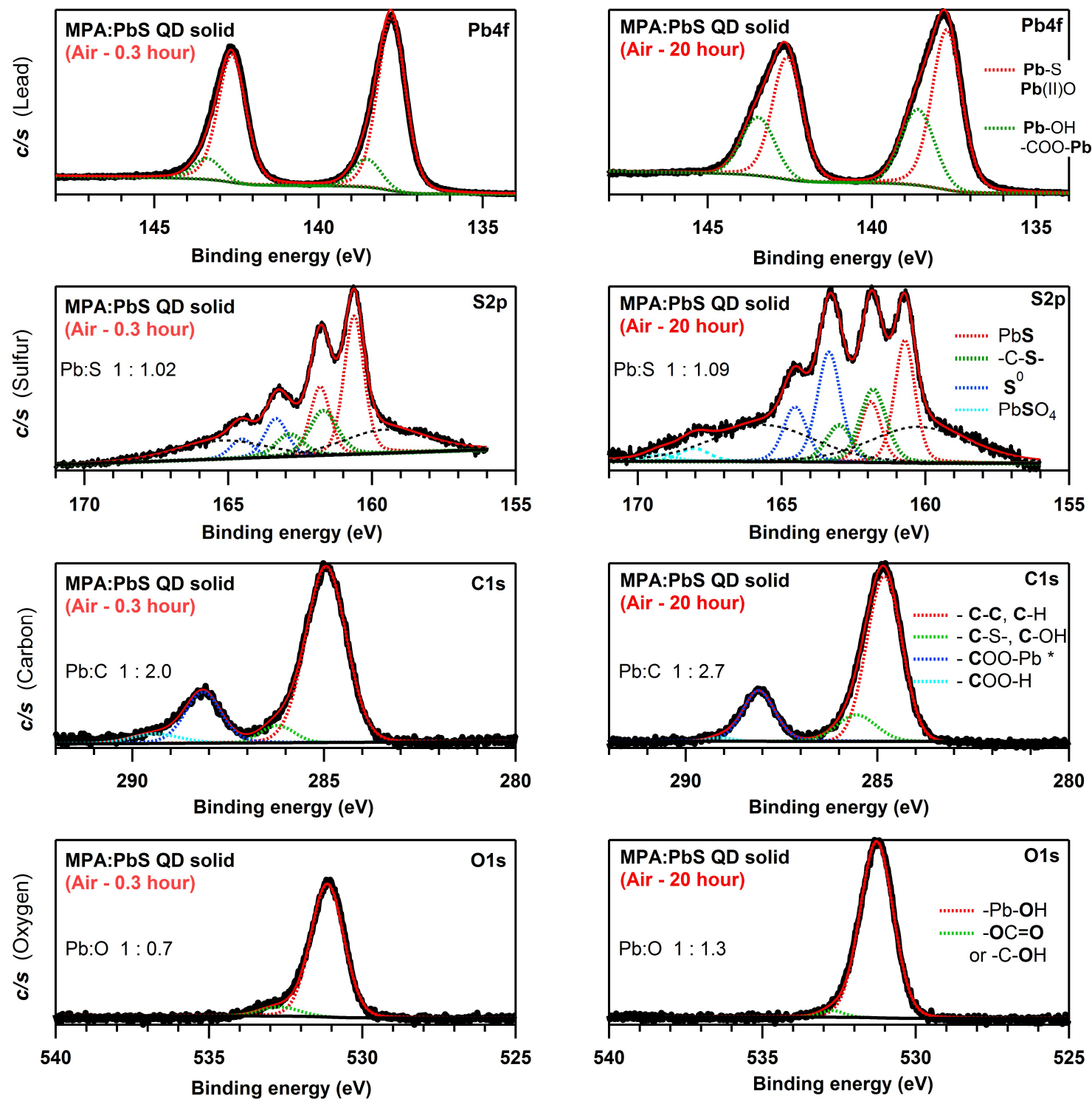

Figure 35. Elemental (Pb, S, C, and O) XPS spectra of MPA:QD solids at 0.3(left) and 20 (right) hours of air exposure.

states were minimal, however $\mathrm{C}: \mathrm{Pb}$ ratio increased by $\sim 35 \%$ due to adventitious carbon. 
Another two samples were studied with XPS, showing an effect of $\mathrm{Ar}^{+}$etching (sputter cleaning) of PbS QD solids. Ar ${ }^{+}$etching was performed within the XPS instrument, which allowed to compare XPS spectra before and after etching without exposing samples to air. Spectra were normalized to $\mathrm{Pb}$ peaks amplitude. Qualitatively, the fact that more carbon species are removed in case of 19 hour air exposed film (Figure 36) is consistent with the earlier stated fact that during air exposure, carbon species adsorb on the surface of QD solids. This suggests that in order to properly utilize the positive effect of air exposure for QD's PV performance, we might need to consider using purified (C free) oxygen, possibly humidified, as $\mathrm{Pb}-\mathrm{OH}$ peak was shown to increase during air exposure. We also notice, the qualitative disappearance of the $\mathrm{C} 1 \mathrm{~s}$ peak located at $\sim 288 \mathrm{eV}$ upon $18 \mathrm{~s}$. of $\mathrm{Ar}^{+}$etching. This peak is thought to represent carbon in carboxyl group of MPA, attached to PbS QD.
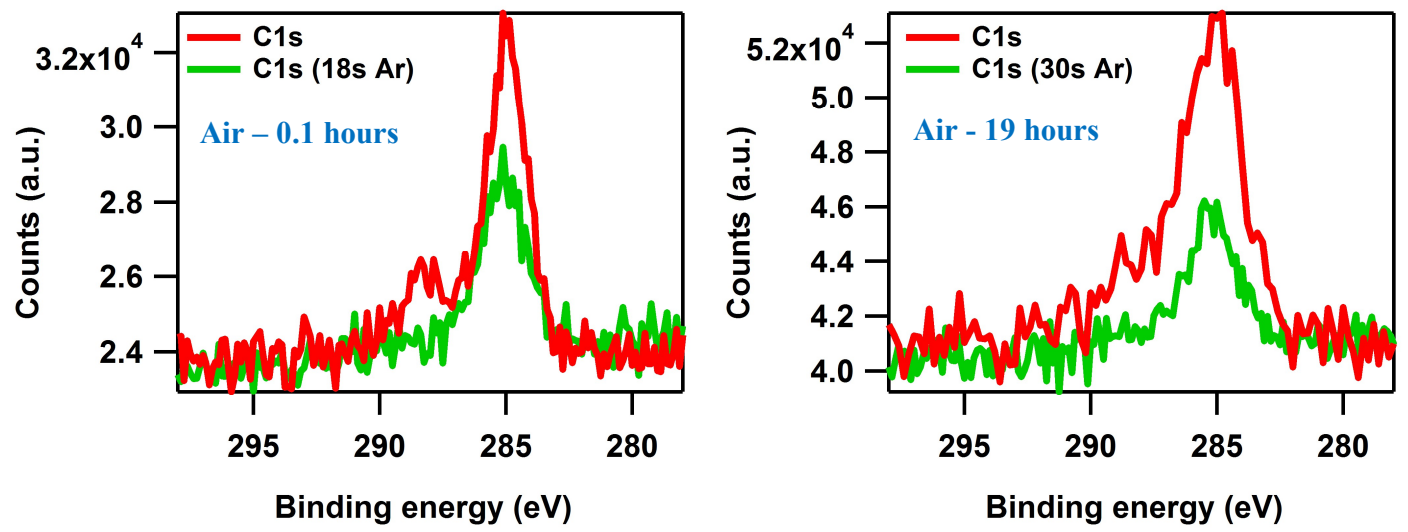

Figure 36. C1s XPS spectra of MPA:PbS QD solids deposited in the air, and air exposed for 0.1 and 19 hours respectively. Effect of $\mathrm{Ar}^{+}$etch. 
Oxygen peak located at 531-532 eV is assigned to a hydroxyl group (OH-) attached to the metal $(\mathrm{Pb}$ in $\mathrm{PbS})$ and is observed to decrease substantially for 0.1-hour air exposed film upon 18 seconds of $\mathrm{Ar}^{+}$etch. This effect is much less severe for 19-hour air exposed QD solid even after 30 seconds of $\mathrm{Ar}^{+}$etching Figure 37.
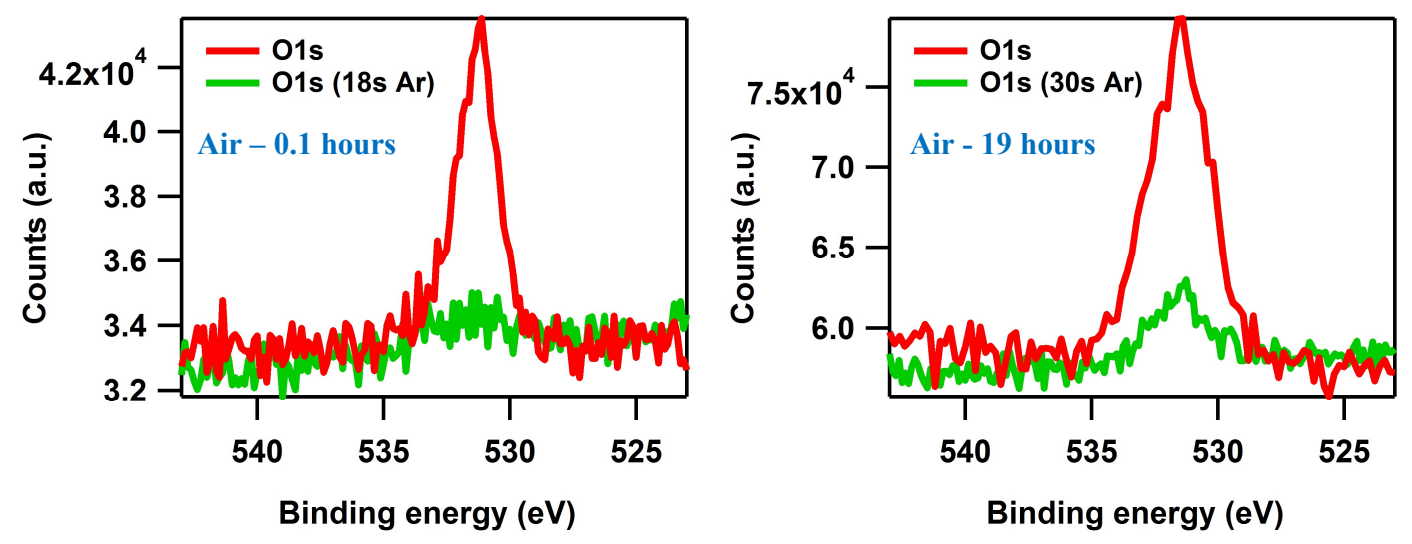

Figure 37. Elemental XPS spectra of MPA:PbS QD solid deposited in air, analyzed after 19 hours of air exposure.

In summary, XPS data suggest that chemical changes taking place on the surface of the MPA:QD solids most likely involve adsorption of water that results in the formation of $\mathrm{Pb}$ $\mathrm{OH}$ groups. However, the fact that sulfur species undergo oxidation from originally being $\mathrm{S}^{2-}$ in form of thiol groups of MPA ligand into higher oxidation states of $\mathrm{S}^{0}$ and $\mathrm{SO}_{4}{ }^{2-}$ suggest that oxygen from the air can also be involved in this process. It would be desired to perform the QD solid deposition in the oxygen-enriched atmosphere (oxygen purging of the spin coater chamber) and to expose the produced solids to oxygen, in order to investigate further extents of observed air effects on the QD PV performance. 


\section{C) Conclusions}

Work described in this chapter demonstrates that p-type MPA:PbS QD solids can be

predictably contacted using outer-sphere redox couples in form of liquid electrolytes. Successful establishment of both Ohmic and rectifying junctions was possible in this case. Electrochemical contacting was shown to be a promising method for studying the optoelectronic properties of PbS QD solids. The ideal dependence of observed open-circuit voltages on contacting energetics of the solutions is consistent with electrochemical contacting not inducing surface states at the QD solid/electrolyte interface, which is likely taking place during metal-like contacts depositions. Furthermore, photovoltages of 0.475 V were observed for QDs with $\mathbf{E}_{\mathbf{g}}=1.34 \mathrm{eV}$ (optical, for colloidal QDs). These values are comparable to those obtained for DH type devices that utilized same MPA:QDs films. Results discussed in this chapter suggest towards the importance of individual QD's and QDs solids' surface chemistry, as air exposure of such solids was shown to be responsible for consolidation of the p-type character of MPA:PbS QD solids. We showed that further studies of PV properties of QD solids using the electrochemical contacting method can warrant a better understanding of effects of QD ligands chemistries on the PV performance. 


\section{V) UNDERSTANDING THE RELATIONSHIP OF QD LIGANDS CHEMISTRY AND QD SOLIDS PV PERFORMANCE}

Previous studies have shown that ligand chemistry can directly affect the electronic properties and structure, Valence band maxima $\left(\mathbf{E}_{\mathbf{v b}}\right)$, Fermi level $\left(\mathbf{E}_{\mathbf{F}}\right)$, and Conduction band minima ( $\left.\mathbf{E}_{\mathbf{c b}}\right)$ of the QD solids. ${ }^{50,75-80}$ Additionally, by modifying surface properties of active absorber layer (QD solids) it is also possible to control charge separation and recombination processes in QD based PV devices, which allowed for improvement in the PCE efficiency. ${ }^{42}$

In this chapter, we focus on PbS QD solids prepared similarly to those discussed in the previous chapter but using new ligands that yield an n-type character of resulted QD films. Electrochemical characterization of these solids using the solution contacting method will be discussed. PV properties of Ohmic and Schottky type QD solid/liquid junctions will be compared to results of UPS spectroscopic studies of these solids. Additionally, detailed elemental XPS spectroscopy results will also be discussed to allow for an understanding of the QD ligands chemistry and how it correlates to the PV performance of n-type QD solids. 


\section{A) Results and discussions}

All photoelectrochemical studies were performed using two-electrode sandwich cells similarly to those described in the previous chapter. The construction, assembly, and structure of the test cell are described in section III)G) on page 14. Preparation of n-type QD solids is described in chapter III)D) and III)E) on page 11. Namely, n-type solids studied in this study were prepared using following ligands: benzenethiol (BT), ethanedithiol (EDT), and tetrabutylammonium iodide (TBAI) as they were previously shown to yield desired n-type QD solids. ${ }^{50}$ Using these ligands requires QD solids deposition to be performed in an inert atmosphere, with exception of TBAI. Previously we looked at the in-air deposited p-type MPA:PbS QD solids, however, we will also attempt their deposition in the $\mathrm{N}_{2}$ atmosphere in order to understand the specifics in which deposition environment affects both surface chemistry and PV performance of MPA:PbS QD solids.

\section{1) Electrochemical studies of n-type QD solids}

Photovoltaic characterization of the n-type PbS QD solids was performed using solutions of two outer-sphere, fast redox couples dissolved in anhydrous acetonitrile. Specifically, ferrocenium tetrafluoroborate/ferrocene $\left(\mathrm{Cp}_{2} \mathrm{Fe}^{+/ 0}\right)$ and cobaltocenium hexafluorophosphate/cobaltocene $\left(\mathrm{Cp}_{2} \mathrm{Co}^{+/ 0}\right)$. These redox couples were chosen for their reduction potential values being located close to $\mathbf{E}_{\mathbf{v b}}$ and $\mathbf{E}_{\mathbf{c b}}$, respectively, for $\mathrm{PbS}$ QD solids. The formal potential of $\mathrm{Cp}_{2} \mathrm{Fe}^{+/ 0}$ is reported to be $-4.982 \mathrm{eV}$ vs. vacuum ${ }^{46}$. The formal potential of $\mathrm{Cp}_{2} \mathrm{Co}^{+/ 0}$ was measured to be $-1.334 \mathrm{~V}$ vs. $\mathrm{Cp}_{2} \mathrm{Fe}^{+/ 0}$, which corresponds to $-3.648 \mathrm{eV} v s$. vacuum. 


\section{EDT:PbS QD solid/liquid junctions with $\mathrm{Cp}_{2} \mathrm{Fe}^{+/ 0}$ and $\mathrm{Cp}_{2} \mathrm{Co}^{+/ 0}$ redox couples}

Electrochemical data for EDT:PbS QD solid/liquid junctions with the respective electrolytes are shown in Figure 38 (a) and (c). Accompanying energy diagrams for each junction are provided to the right of respective I- $V$ curves, Figure 38 (b) and (d). Energies of $\mathbf{E}_{\mathbf{v b}}$, and $\mathbf{E}_{\mathbf{F}}$ for QD solid were determined using UPS spectroscopy (Figure 46, page 67). $\mathbf{E}_{\mathbf{c b}}$ was found by adding a value of $\mathbf{E}_{\mathbf{g}}$ to $\mathbf{E}_{\mathbf{v b}}$. $\mathbf{E}_{\mathbf{g}}$ value $(1.27 \mathrm{eV})$ was determined by the location of the first excitonic peak in Uv-Vis spectra for EDT:PbS QD solid (Figure 43).
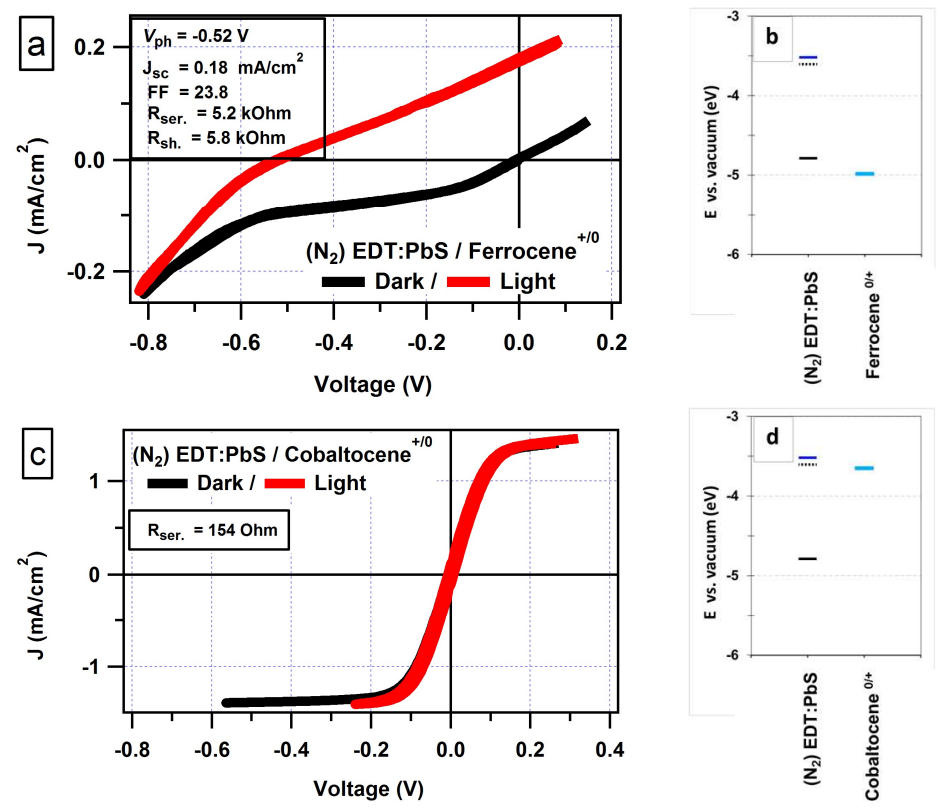

Figure 38. J-V characteristics of inertly deposited EDT:PbS QD solids contacted with $\mathrm{Cp}_{2} \mathrm{Fe}^{+/ 0}$ (a) and $\mathrm{Cp}_{2} \mathrm{Co}^{+/ 0}(\mathrm{c})$ along with corresponding energy diagrams $(\mathrm{b}, \mathrm{d})$.

Current-voltage characteristics of EDT:PbS solid and their energy band and $\mathbf{E}_{\mathbf{F}}$ alignment with reduction potentials of the electrolytes are consistent. Namely, we observe Ohmic type behavior of EDT:PbS / $\mathrm{Cp}_{2} \mathrm{Co}^{+/ 0}$ junction, which is in good agreement with the $\mathbf{E F}_{\mathbf{F}}$ and $\mathrm{q} E_{\mathrm{Cp} 2 \mathrm{Co}+/ 0}$ positions on energy scale being close to each other. Hence, we expected and observed minimal or no Schottky barrier formation (band-bending), which explains why 
photovoltage did not change upon illumination of the cell. Illumination of the cell only resulted in an insignificant decrease in cells series resistance $\left(\mathrm{R}_{\text {ser }}\right)$ from 154 to $151 \mathrm{Ohm}$. These values are very close to those observed for $\mathrm{Cp}_{2} \mathrm{Co}^{+/ 0}$ filled QD-less cell with a $20 \mu \mathrm{m}$ spacer (page 90), whereas now we used $50 \mu \mathrm{m}$ surlyn spacer in EDT cell. This suggests that EDT:PbS QD layer does not add towards $\mathrm{R}_{\text {ser }}$ of the cell and is well conductive.

Schottky type behavior was observed for EDT:PbS / $\mathrm{Cp}_{2} \mathrm{Fe}^{+/ 0}$ junctions, which agrees with the $\mathbf{E}_{\mathbf{F}}$ and $\mathrm{q} E_{\mathrm{Cp} 2 \mathrm{Fe}+/ 0}$ energetics being offset as shown in Figure 38(b). $V_{\mathrm{oc}}$ values were measured at $-0.52 \pm 0.05 \mathrm{~V}$, for QDs with the $1^{\text {st }}$ excitonic peak located at $1.44 \mathrm{eV}$ for OA:QDs in solution and $1.27 \mathrm{eV}$ in EDT:PbS films. This value is comparable to $V_{\mathrm{oc}}$ of MPA:PbS QDs solids but contacted with $\mathrm{Cp}_{2} \mathrm{Fe}^{+/ 0}$, when same Eg QDs were used (Table 2). However, $R_{\text {sh. }}$ values were measured to be significantly lower being in the range of 5-6 $\mathrm{kOhm}$ (higher values are desirable). We also note the presence of relatively high leakage currents observed for I- $V$ curve measured in non-illuminated conditions (slopes of both dark and light $\mathrm{I}-\mathrm{V}$ curves are similar near $\mathrm{V}=0$ point in Figure 38(a)). This two phenomena could potentially suggest for the presence of charge recombination centers on the surface of QDs, however, this would not be consistent with the literature, where EDT ligand when used for QDs solids preparation, resulted in lower trap state density ${ }^{81}$ by passivating the surface trap states, thus improving the QD solid's PV performance. ${ }^{42}$ For this reason, even though we were able to measure predicted photovoltage values for EDT:PbS solids, further deposition technique optimizations are required in order to quench the leakage currents (improve $\mathrm{R}_{\mathrm{sh}}$ ) and decrease series resistance of the film as discussed in the previous paragraph. 


\section{BT:PbS QD solid/liquid junctions with $\mathrm{Cp}_{2} \mathrm{Fe}^{+/ 0}$ and $\mathrm{Cp}_{2} \mathrm{Co}^{+/ 0}$ redox couples}

Results for electrochemical studies of the BT:PbS QD solids contacted with $\mathrm{Cp}_{2} \mathrm{Fe}^{+/ 0}$ and $\mathrm{Cp}_{2} \mathrm{Co}^{+/ 0}$ electrolytes are shown in Figure 39 (a) and (c), while corresponding energy diagrams for each junction are shown in Figure 39 (b) and (d). $\mathbf{E}_{\mathbf{v b}}, \mathbf{E}_{\mathbf{c b}}$, and $\mathbf{E}_{\mathbf{F}}$, were determined by UPS and Uv-Vis characterizations of QD solids, as described on page 56.
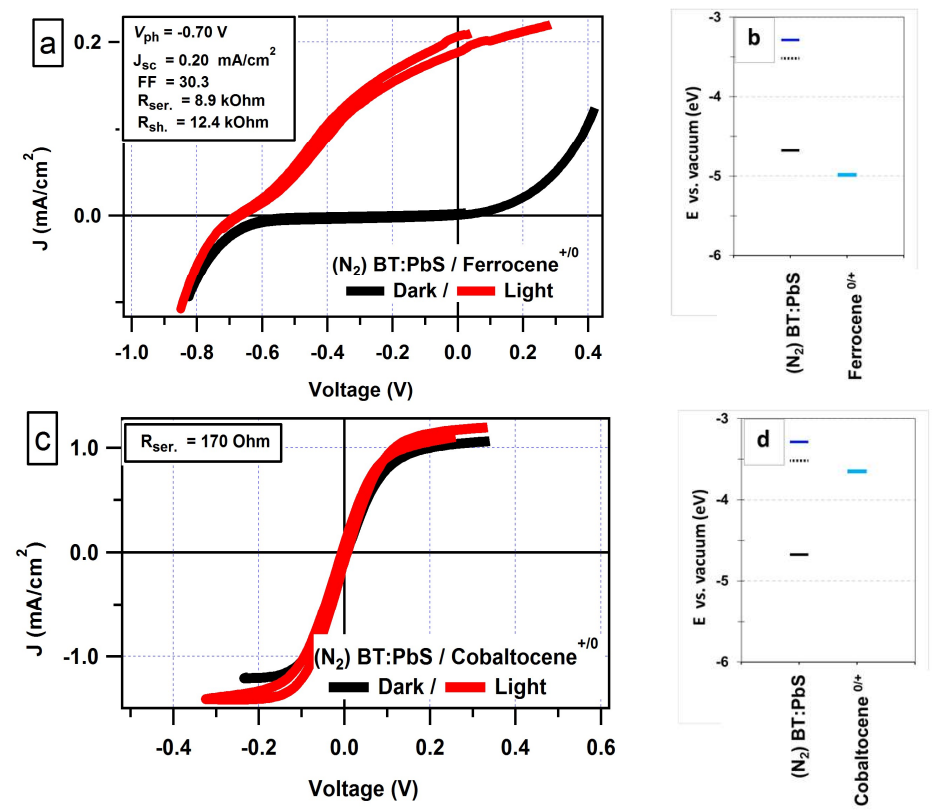

Figure 39. J-V characteristics of inertly deposited BT:PbS QD solids contacted with $\mathrm{Cp}_{2} \mathrm{Fe}^{+/ 0}$ (a) and $\mathrm{Cp}_{2} \mathrm{Co}^{+/ 0}$ (c) along with corresponding energy diagrams $(\mathrm{b}, \mathrm{d})$.

Observations of both Ohmic and Schottky junction formation are qualitatively similar to those described for EDT:PbS QD solids on page 56. As predicted according to the energy alignment of the QD solid and $\mathrm{Cp}_{2} \mathrm{Fe}^{+/ 0}$ we measured negative values for $V_{\text {oc }}$, which supports the n-type character of BT:PbS QD solids. One abnormal phenomenon, however, was observed for $\mathrm{BT}: \mathrm{PbS} \mathrm{QD} / \mathrm{Cp}_{2} \mathrm{Fe}^{+/ 0}$ junctions, namely shape of the $\mathrm{I}-V$ curve for illuminated cell appears to indicate for higher than the normal value of series resistance $\left(\mathrm{R}_{\text {ser }}=8.9 \mathrm{kOhm}\right)$. This "S" shape near $V_{\text {oc }}$ point also resembles effects of high charge 
transfer resistance $\left(\mathrm{R}_{\mathrm{ct}}\right)$ on I- $V$ curve, as described in the electrochemical literature (Electrochemical Methods, by Allen J. Bard and Larry R. Faulkner). One possible explanation for this could lie in steric hindrance of benzenethiol ligand molecules, in comparison to smaller in size ligands used to prepare EDT and MPA ligated QD solids. On the other hand, this effect could also result from the fact that reduction potential of ferrocene is located outside of the energy band-gap of BT:PbS QD solid (q $\left.E_{\mathrm{Cp} 2 \mathrm{Fe} 0 /+}<\mathbf{E}_{\mathbf{v b}}\right)$, as shown in Figure 39 (b). This could create a standing energy barrier for carriers to transfer across the interface of QD solid and the contacting solution.

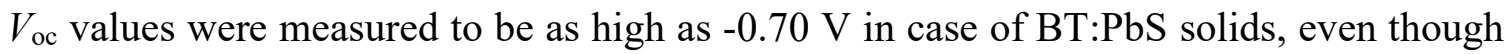
QDs with same $\mathbf{E} \mathbf{g}$ were used to prepare the MPA and EDT solids. This indeed supports that addressing the surface chemistry aspects of QD solids preparation is an important direction. 


\section{TBAI:PbS QD solid/liquid junctions with $\mathrm{Cp}_{2} \mathrm{Fe}^{+/ 0}$ and $\mathrm{Cp}_{2} \mathrm{Co}^{+/ 0}$ redox couples}

Electrochemical data for TBAI:PbS QD solid/liquid junctions with the $\mathrm{Cp}_{2} \mathrm{Fe}^{+/ 0}$ and $\mathrm{Cp}_{2} \mathrm{Co}^{+/ 0}$ electrolytes are shown in Figure 40 (a) and (c). Accompanying energy diagrams for each pair are similarly provided to the right of respective I- $V$ curves, Figure 40 (b) and (d). UPS and Uv-Vis data were used to derive the energy levels of the TBAI:PbS solids, while electrochemical measurements allowed to determine redox potentials of the electrolytes (Section III)I)). As discussed in the beginning of this chapter, TBAI based QD solids were deposited in the air, as opposed to rest of n-type solids described here that required deposition in an inert atmosphere.
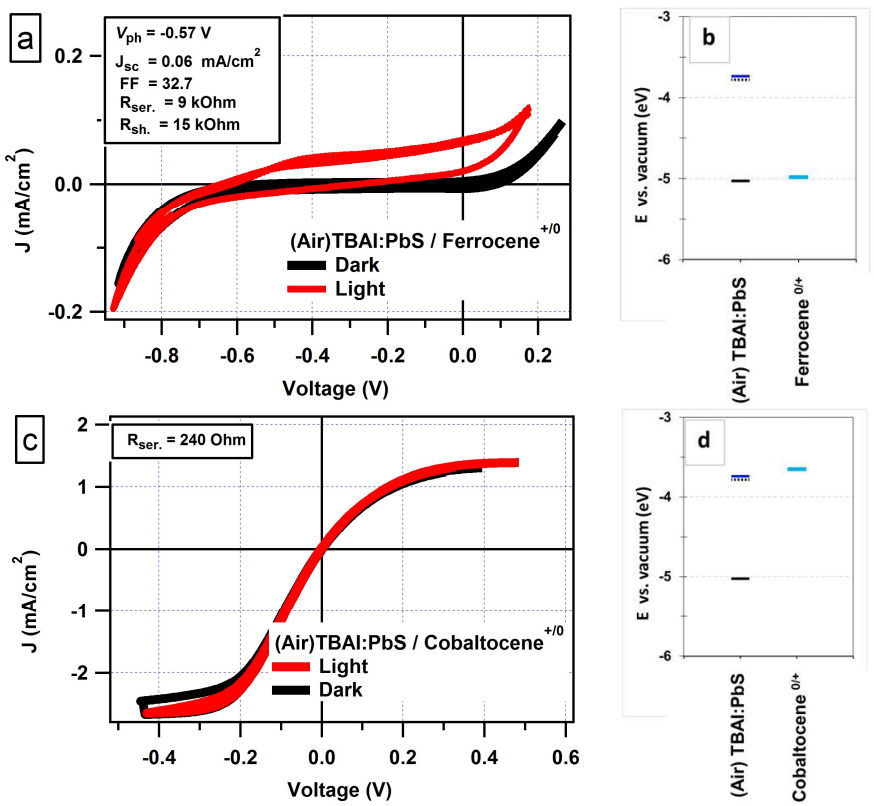

Figure 40. J-V characteristics of TBAI:PbS QD solids contacted with $\mathrm{Cp}_{2} \mathrm{Fe}^{+/ 0}$ (a) and $\mathrm{Cp}_{2} \mathrm{Co}^{+/ 0}$ (c) along with corresponding energy diagrams $(b, d)$.

As expected, the Ohmic behavior is observed in case of the junction with $\mathrm{Cp}_{2} \mathrm{Co}^{0 /+}$. Series resistance values are also comparable to those observed for cells with other ligands based QD solids. In case of $\mathrm{Cp}_{2} \mathrm{Fe}^{0 /+}$ electrolyte, we also observe photovoltages with a negative 
sign - as expected, which supports UPS data in a sense that we indeed obtained an n-type QD solid of TBAI:PbS while depositing it in the air. However, photocurrent $\left(\mathrm{J}_{\mathrm{sc}}\right)$ values obtained for this QD solids were within a factor of 3 smaller than those measured for $\mathrm{EDT}: \mathrm{PbS}$ and $\mathrm{BT}: \mathrm{PbS}$ QD solids. This is not consistent with literature reports which suggested for higher carrier diffusivity in TBAI:PbS QD solids if compared with EDT:PbS ones ${ }^{81}$. Additionally, as Figure 41 shows, photovoltage response to illumination and recovery after illumination are relatively slower than those observed for other QD solids (see Figure 13). This observation suggests that obtained TBAI:PbS films are potentially not as densely packed, and hence have higher charge transport resistance, consistent with lower photocurrent values.

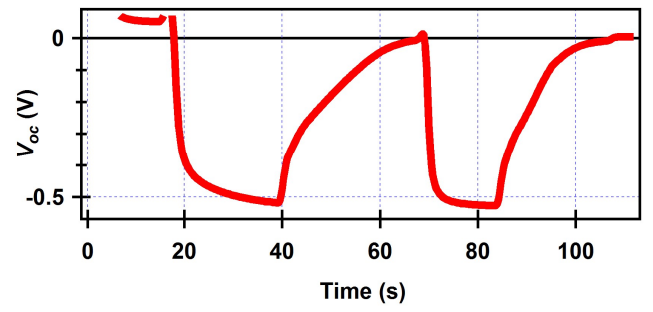

Figure 41. $V_{\text {oc }}$ change upon illumination for in-air deposited TBAI:PbS QD solid contacted with $\mathrm{Cp}_{2} \mathrm{Fe}^{+/ 0}$.

I suggest that TBAI:PbS deposition technique needs to be further optimized, potentially towards the use of sterically less obscuring counter ions than those of tetrabutylammonium in TBAI. This especially makes sense, when comparing $V_{\text {flat }}$ values of TBAI:PbS $/ \mathrm{Cp}_{2} \mathrm{Fe}^{0 /+}$ $(0.90 \mathrm{~V})$ and those of p-type MPA:PbS/Cp $2 \mathrm{Co}^{0 /+}(0.56 \mathrm{~V})$. Figure 19(a) suggests for good correlation of $V_{\text {flat }}$ values and the barrier height $\left(\varphi_{B}\right)$ of the Schottky junctions, which in turn defines maximum obtainable photovoltages. With these parallels we could expect $V_{\mathrm{ph}}$ values for TBAI:PbS exceed those observed for the rest of QD solids studied herein, 
potentially reaching values of $0.75-0.85 \mathrm{~V}$ for the QD solids with $\mathbf{E}_{\mathbf{g}}=1.29 \mathrm{eV}$ (as measured in Figure 45).

\section{n-type MPA:PbS QD solid/liquid junctions with $\mathrm{Cp}_{2} \mathrm{Fe}^{+/ 0}$ and $\mathrm{Cp}_{2} \mathrm{Co}^{+/ 0}$ redox}

\section{couples}

To further understand the surface chemistry and the effects of air-exposure on MPA:PbS QD solids, that were discussed in the chapter (IV)A)3), I prepared and electrochemically studied the MPA:PbS QD solids in the air-free environment. Electrochemical data and the respective energy diagrams for both, inertly and in-air deposited solids contacted with $\mathrm{Cp}_{2} \mathrm{Fe}^{+/ 0}$ and $\mathrm{Cp}_{2} \mathrm{Co}^{+/ 0}$ electrolytes are shown in Figure 42.
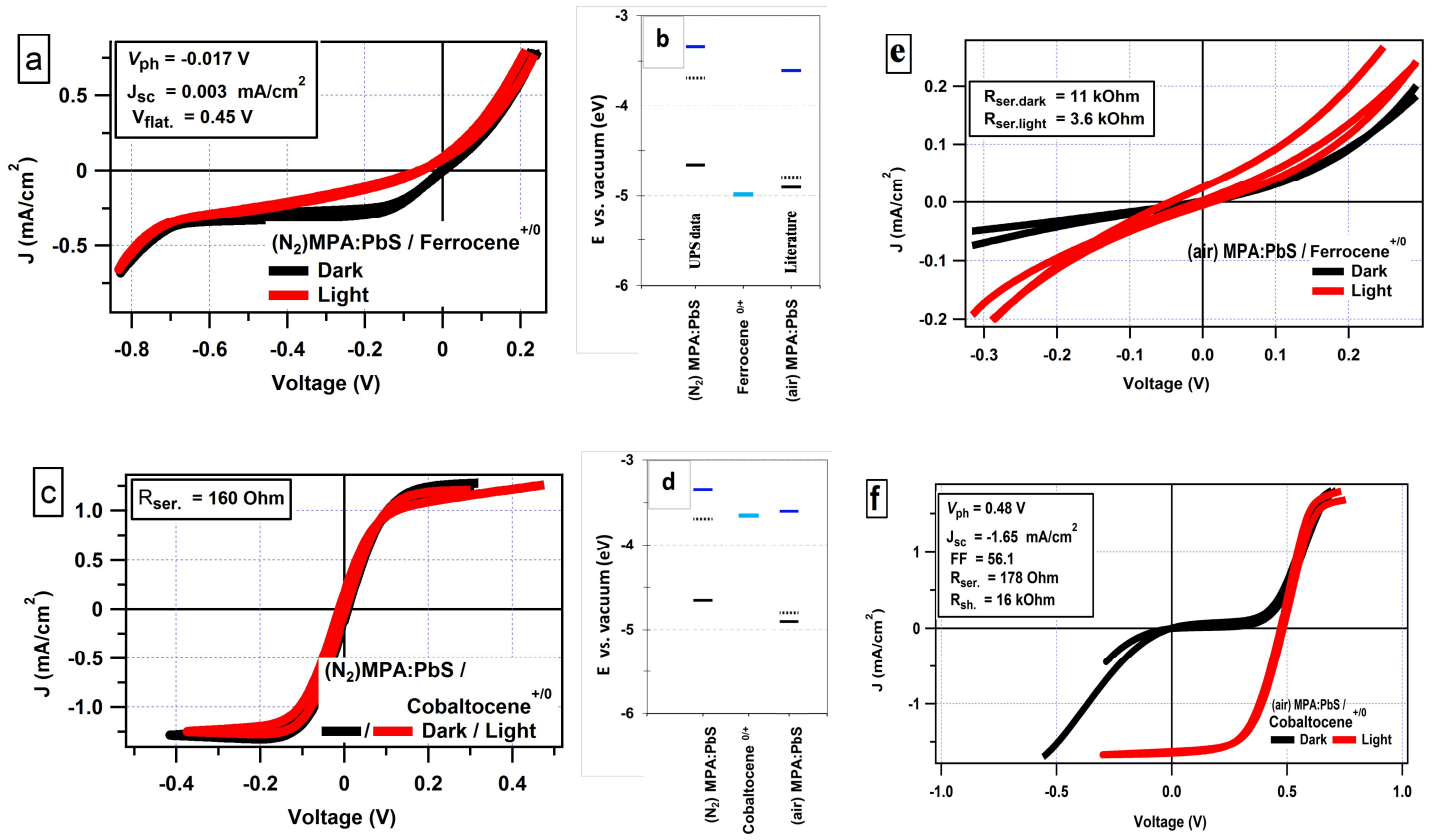

Figure 42. J-V curves for inertly and in-air deposited MPA:PbS solids contacted with $\mathrm{Cp}_{2} \mathrm{Co}^{+/ 0}$ and $\mathrm{Cp}_{2} \mathrm{Fe}^{+/ 0}$ electrolytes.

Cross-comparison of these results suggests for Ohmic J-V behavior of junction in case of (c) and (e), which is consistent with the respective energy diagrams (d and b), however 
much higher charge transfer resistances are observed in case of in-air deposited MPA:PbS solids contacted with Ferrocene/ferrocenium containing electrolyte (e). This potentially suggests that literature-based values for $\mathbf{E}_{\mathbf{F}}$ or $\mathbf{E}_{\mathbf{v b}}$ of in-air deposited solids are not indeed positioned as it is depicted in diagram (b) and would require further UPS characterization. Case (f) is consistent with same literature based energy diagrams, however the fact that barrier heights for these junctions fall in a range of $0.5-0.6 \mathrm{~V}$ (Figure 19), suggests that, indeed, the actual position of $\mathbf{E}_{\mathbf{F}}$ in these solids could be located at higher energies than it is shown in Figure $42(b, d)$.

Case (a) suggests that inertly deposited MPA:PbS QD solids are indeed of an n-type character. Higher leakage currents, however, are thought to prevent observation of significant $\mathrm{J}_{\mathrm{sc}}$ and $V_{\mathrm{ph}}$ values. This scenario somewhat resembles the earlier discussed situation in case of EDT:PbS QD solids (Figure 38) and is also consistent with the fact that $\mathbf{E}_{\mathbf{v b}}$ of the QD solid (b) is located above reduction potential of $\mathrm{Cp}_{2} \mathrm{Fe}^{+/ 0}$. It, hence, would be a more optimal choice to use a $\mathrm{Me}_{10} \mathrm{Cp}_{2} \mathrm{Fe}^{0 /+}$ electrolyte with a higher reduction potential to make strongly rectifying junctions with these solids. On the other hand, however, if these significant leakage currents will still be observed with $\mathrm{Me}_{10} \mathrm{Cp}_{2} \mathrm{Fe}^{0 /+}$, it would indicate that we have a non-ideal QD surface coverage due to insufficient ligand exchange which could lead to the presence of surface "trap" states - exciton recombination centers. This would suggest that the effects of air exposing the MPA:PbS QD solids, that improved their PV performance (section IV)A)3)), could be indeed related to additional coverage/recovery of QD surface by adsorption of hydroxyl groups, as suggested by XPS results (pages 50 - 52). 


\section{B) n-type QD solids characterization}

In order to better understand the meaning of electrochemical results I further characterized the solids of QDs described in this chapter. In order to determine key energy levels of QD solids ( $\mathbf{E}_{\mathbf{v b}}, \mathbf{E}_{\mathbf{F}}$, and $\left.\mathbf{E}_{\mathbf{c b}}\right)$ UPS and UV-Vis-NIR spectroscopies ${ }^{50}$ were used.

1) UV-Vis-NIR spectroscopy

Uv-Vis absorption (1-T) spectra for EDT:PbS QD solid is shown in the following figure.

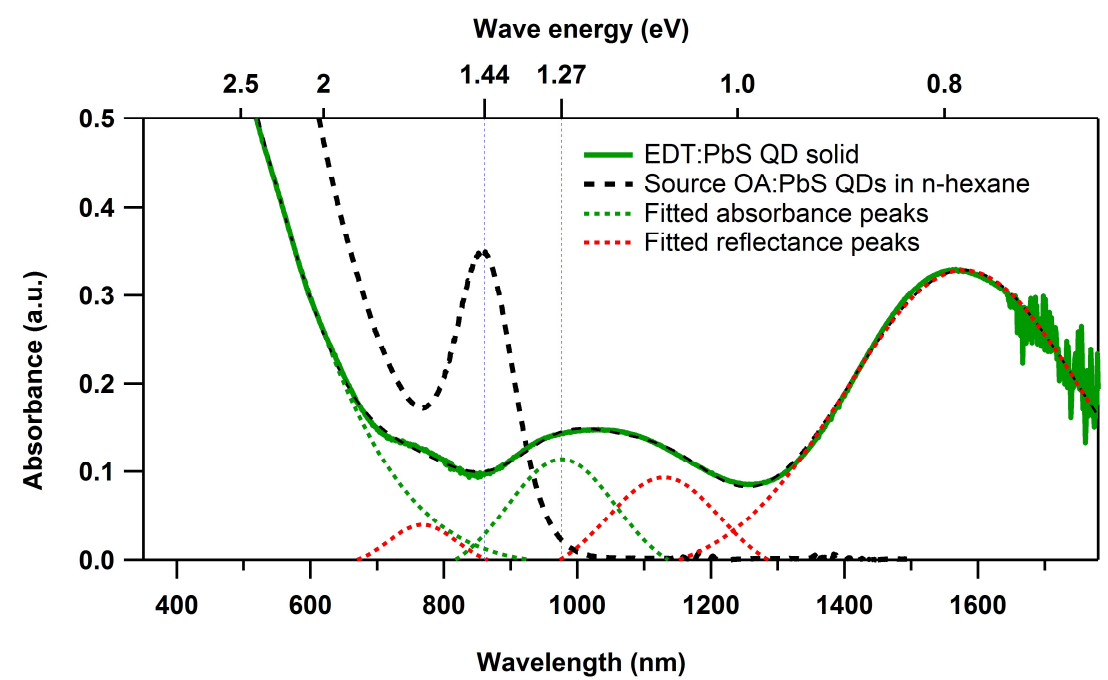

Figure 43. Absorbance spectra for EDT:PbS QD solids and of a source OA:PbS QDs in n-hexane.

Black dashed line represents absorption of 1mg/ml OA:PbS QDs suspended in n-hexane and indicates the position of the first excitonic peak at $1.44 \mathrm{eV}$, which was shifted to 1.27 eV upon ligand exchange involved QD deposition on FTO. Red dashed lines are thought to be reflectance peaks as it was discussed before in section (IV)B)4), page 44). 
Figure 44 shows similar analysis of benzenethiol exchanged PbS QD solids deposited on FTO. Interestingly, it appears that the excitonic peak is red-shifted only $0.05 \mathrm{eV}$ in case of using these ligands. This small shift is similar to that observed for OA:PbS QD solids deposited on FTO without any ligands exchange (Figure 31). This could indicate that QDs are not closely packing into the film during BT-ligand exchange, consistently with hydrophobic and steric considerations of benzenethiol ligands. Spatial separation of individual QDs in the film supports higher $\mathbf{R}_{\mathbf{c t}}$ values observed for BT:PbS QDs in Figure 39(a).

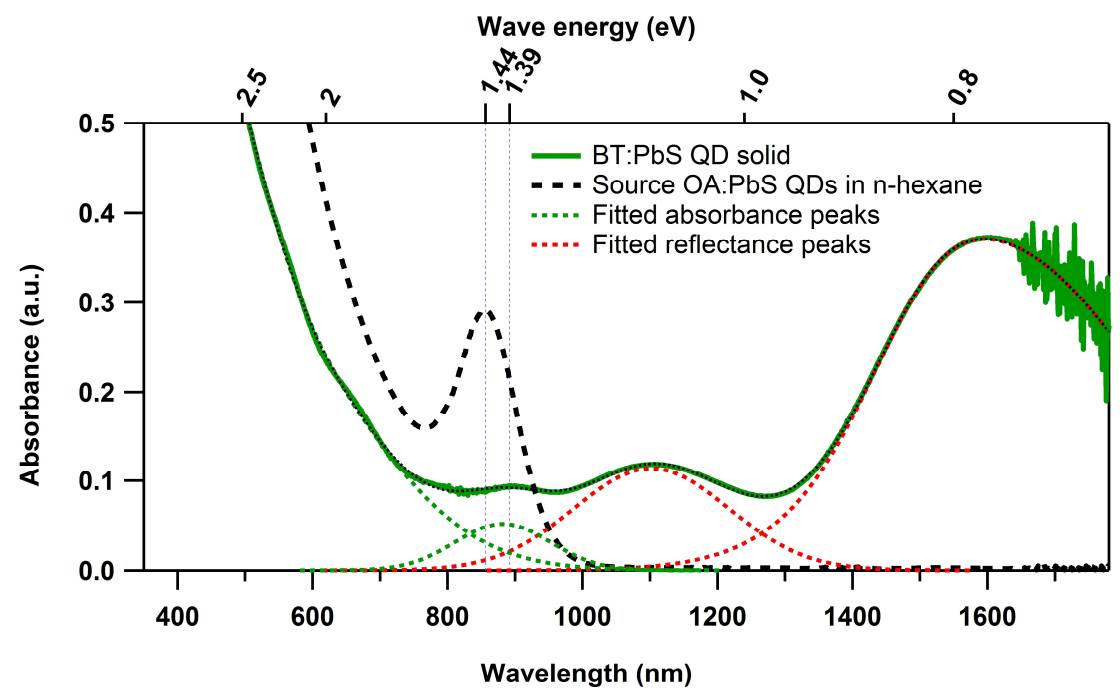

Figure 44. Absorbance spectra for BT:PbS QD solids and of source OA:PbS QDs in n-hexane. 
Figure 45 shows Uv-Vis data for TBAI:PbS QD solids, suggesting for $0.1 \mathrm{eV}$ red-shift of the first excitonic peak upon ligand exchange.

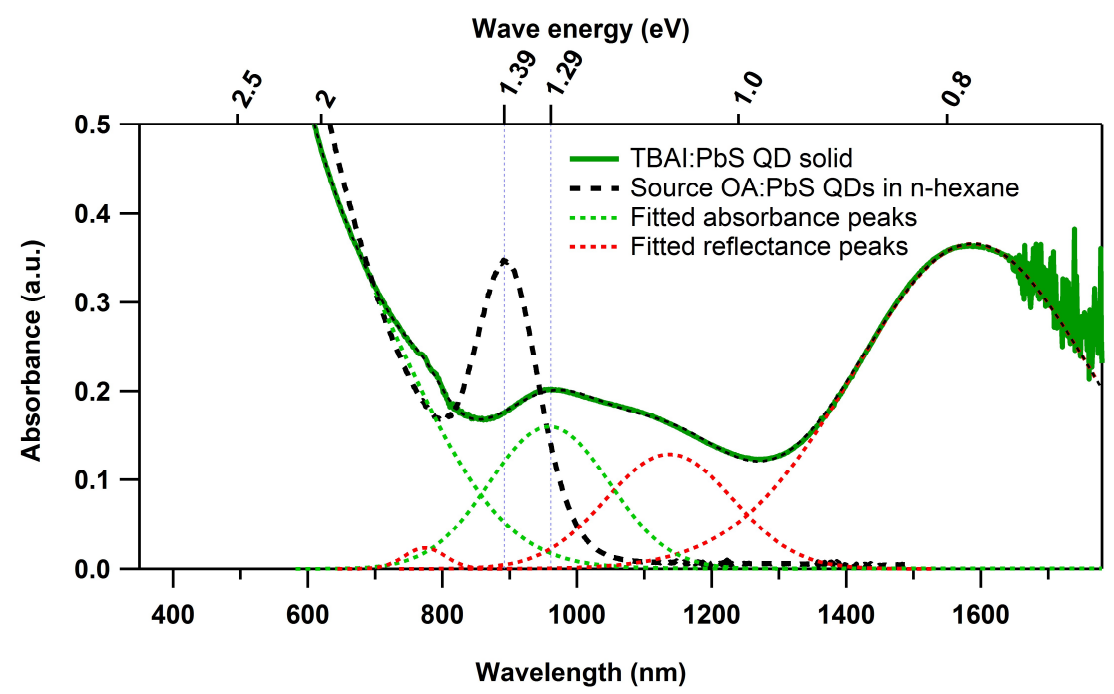

Figure 45. Absorbance spectra for TBAI:PbS QD solids and of a source OA:PbS QDs in nhexane.

Summary of observed red-shift of the first excitonic peak for all QD solids, upon their deposition and ligand exchange, is shown in the following table.

Table 3. The redshift of excitonic absorption peak for PbS QD solids as a result of ligand exchange.

\begin{tabular}{|c|c|}
\hline Ligand : QD solid & Redshift of excitonic peak (eV) \\
\hline OA:PbS & $0.02 \pm 0.01$ \\
\hline MPA:PbS & $0.09 \pm 0.01$ \\
\hline EDT:PbS & $0.17 \pm 0.01$ \\
\hline BT:PbS & $0.05 \pm 0.01$ \\
\hline TBAI:PbS & $0.10 \pm 0.01$ \\
\hline
\end{tabular}

These data suggest for biggest red-shift in case of EDT:PbS solids, which could be explained by bidentate nature of ethanedithiol ligands. However, it is hard to draw definite conclusions about ligand-QD interactions based on this data, possibly affected by 
reflectance peaks. Solid-state NMR or advanced IR spectroscopy studies would be desired to further understand this.

\section{2) UPS characterization}

Ultraviolet photoelectron spectroscopy (UPS) allows characterizing valence electron structure and energies of semiconducting samples. It is a surface sensitive technique with sample penetration depth being in the range of 2-4 $\mathrm{nm}$. UPS spectra collected for EDT, BT, and TBAI:PbS solids are shown in Figure 46.
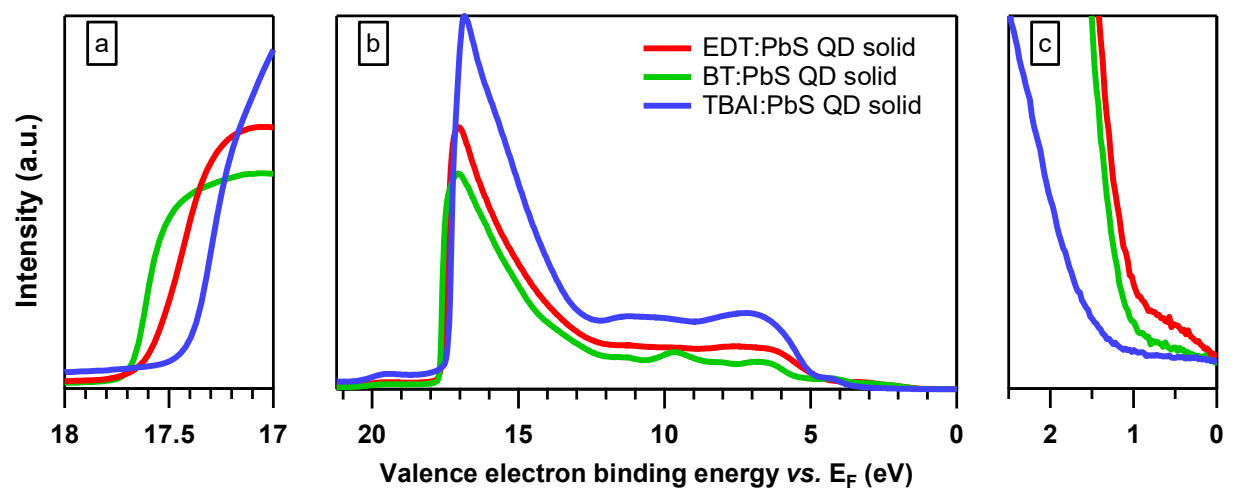

Figure 46. UPS spectra of three n-type QD solids deposited with EDT, BT, and TBAI ligands.

By looking at primary electron onset, a cross-point of two linear portions of spectra shown in (c), we can estimate the difference in energy between $\mathbf{E}_{\mathbf{v b}}$ and $\mathbf{E}_{\mathbf{F}}$. Similar analysis of secondary electron cutoff (spectra (a)), determines energy position of $\mathbf{E}_{\mathbf{F}}$ versus energy of an electron in a vacuum $\left(\mathbf{E}_{\mathbf{v a c}}\right)$. For this, $\mathbf{E}_{\mathbf{F}}=-21.22+$ [cutoff value] was used and resulting energy levels for each QD solid sample are shown in Figure 47. Evvb values were determined using Uv-Vis data, the excitonic peak position of respective QD solid. 


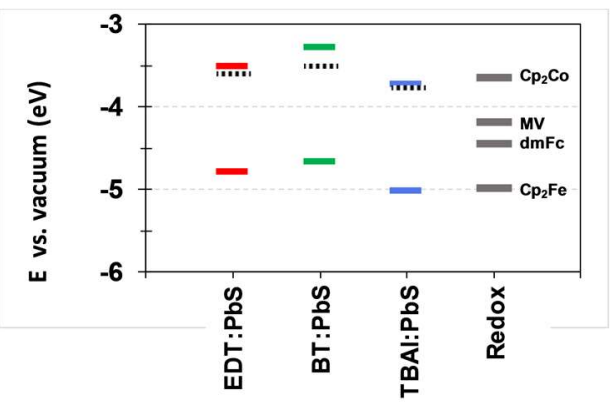

Figure 47. Energy band diagrams for the n-type QD solids (UPS), and energetics (qE) of contacting solutions (electrochemical).

\section{3) XPS characterization}

XPS is a surface sensitive technique with typical X-ray penetration depth being 7-10 nm into the sample. But since our primary goal is to modify surface (ligand) chemistry of QDs as they are deposited into solids, it can be a very beneficial one. Let us imagine a single building block of the solid of interest, $\mathrm{PbS}$ quantum dot. Its size on average is 3-3.5 $\mathrm{nm}$ as was demonstrated in Chapter (IV)B). The thickness of the solids used in this study ranges from 200 to $500 \mathrm{~nm}$. Hence even if we acquire information for chemical states of elements of the top surface of the QD solid we can better understand mechanisms of QD solids assembly and better visualize the needed routines to optimize the deposition process. Survey XPS spectra for PbS QD solids deposited in an inert atmosphere with TBAI, EDT, and BT are shown in Figure 48 - Figure 50.

EDT:PbS and BT:PbS solids XPS spectra were collected for samples deposited in an inert atmosphere ( $\mathrm{N}_{2}$ filled glovebox $)$ and were only minimally exposed to air during transfer to the XPS instrument. XPS spectra for TBAI:PbS solid will be shown for a sample that was deposited and exposed to air for 20 hours, for comparison to that of MPA:PbS sample. 


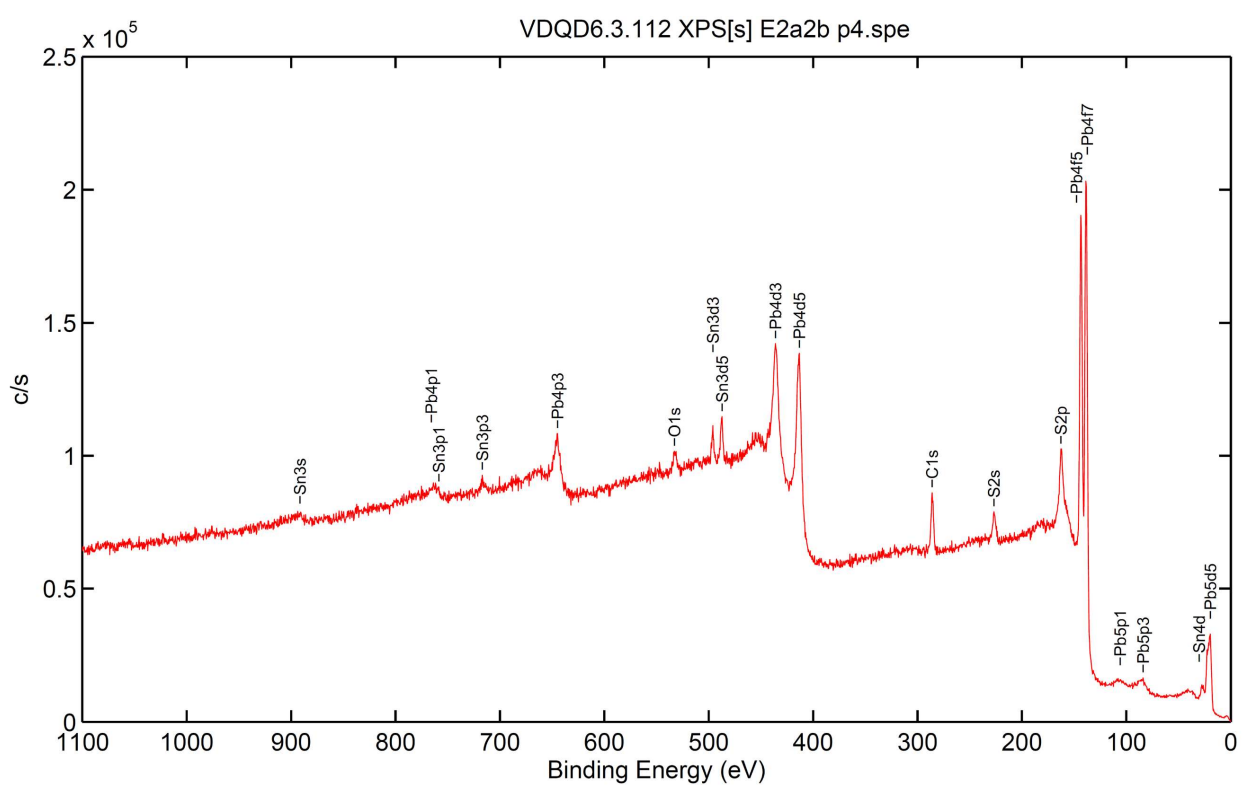

Figure 48. XPS spectra of EDT:PbS QD solid deposited in $\mathrm{N}_{2}$ atmosphere

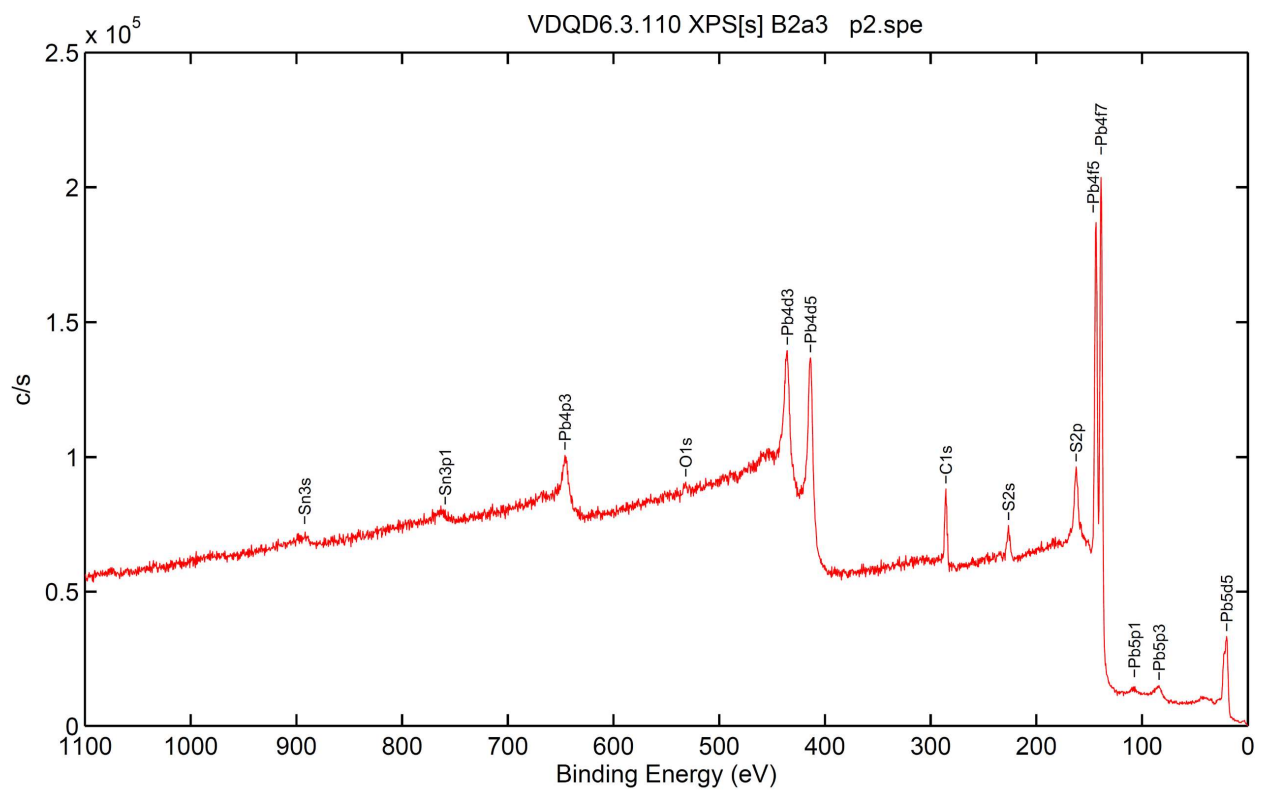

Figure 49. XPS spectra of BT:PbS QD solid deposited in $\mathrm{N}_{2}$ atmosphere 


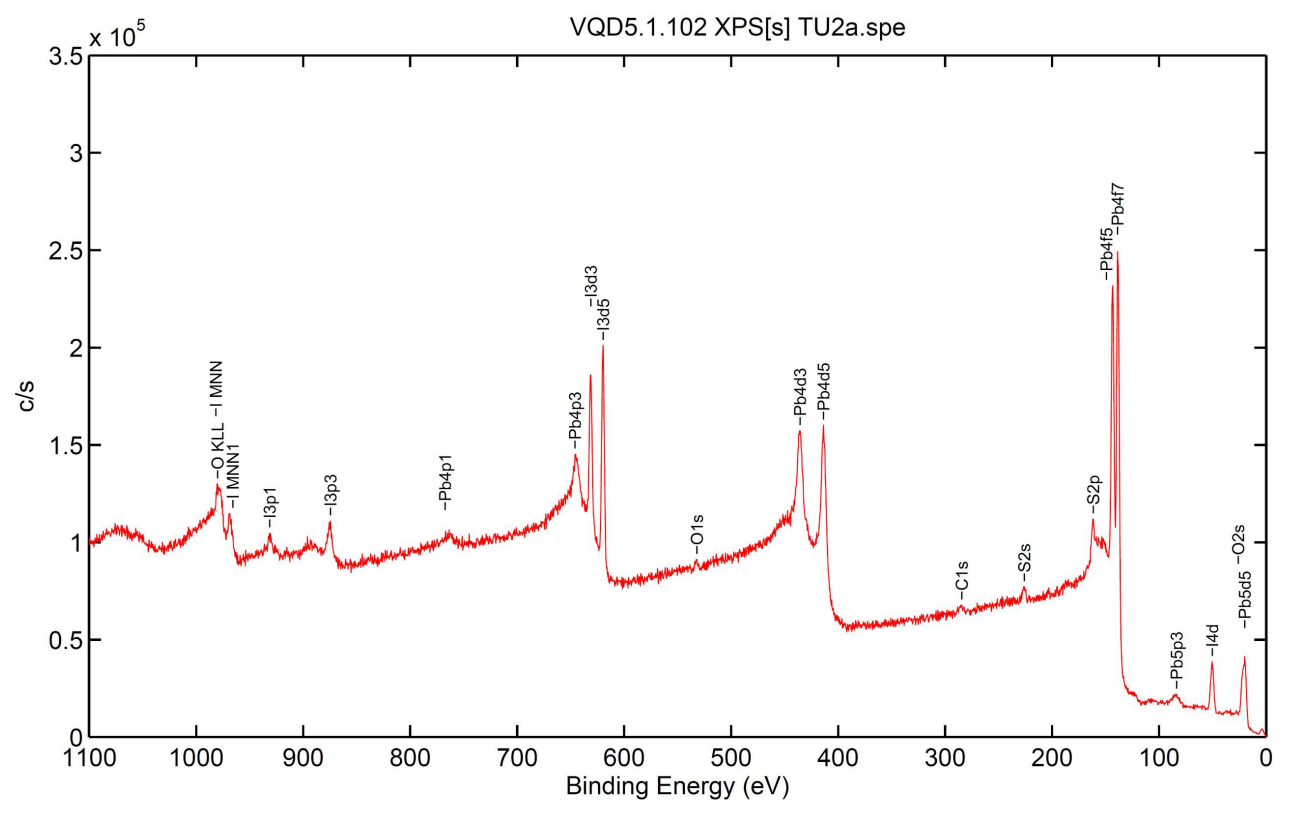

Figure 50. XPS spectra of TBAI:PbS QD solid deposited in $\mathrm{N}_{2}$ atmosphere

All elements present in each of XPS spectra above are consistent with the chemical composition of each QD solid. Presence of Sn peaks on EDT:PbS sample could signify cross-contamination of QD films surface by tin, as a possibility of observing Sn peaks from $\mathrm{SnO}_{2}$ film (of FTO substrate) in very low, considering QD films thickness of 200-300 nm. Following data contains detailed XPS elemental analysis spectra for inertly prepared EDT:PbS and BT:PbS QD solids, in-air prepared TBAI:PbS film and in-air prepared and exposed to air for 0.3 and 20 hours MPA:PbS QD solids.

Detailed lead XPS spectra for PbS QD solids deposited with different ligands is shown in Figure 51. $\mathrm{Pb} 4 \mathrm{f}^{7} / 2$ peaks at $137.8 \pm 0.2 \mathrm{eV}$ can be associated with lead in both possible chemical states: $\mathrm{PbS}^{75,82}$ and $\mathrm{PbO}^{83,84}$. However, since $\mathrm{PbO}$ is not observed in $\mathrm{O} 1 \mathrm{~s} \mathrm{XPS}$ spectra for MPA:PbS solids (Figure 54), it is most likely that $137.8 \mathrm{eV}$ peak is associated with $\mathrm{PbS}$. 

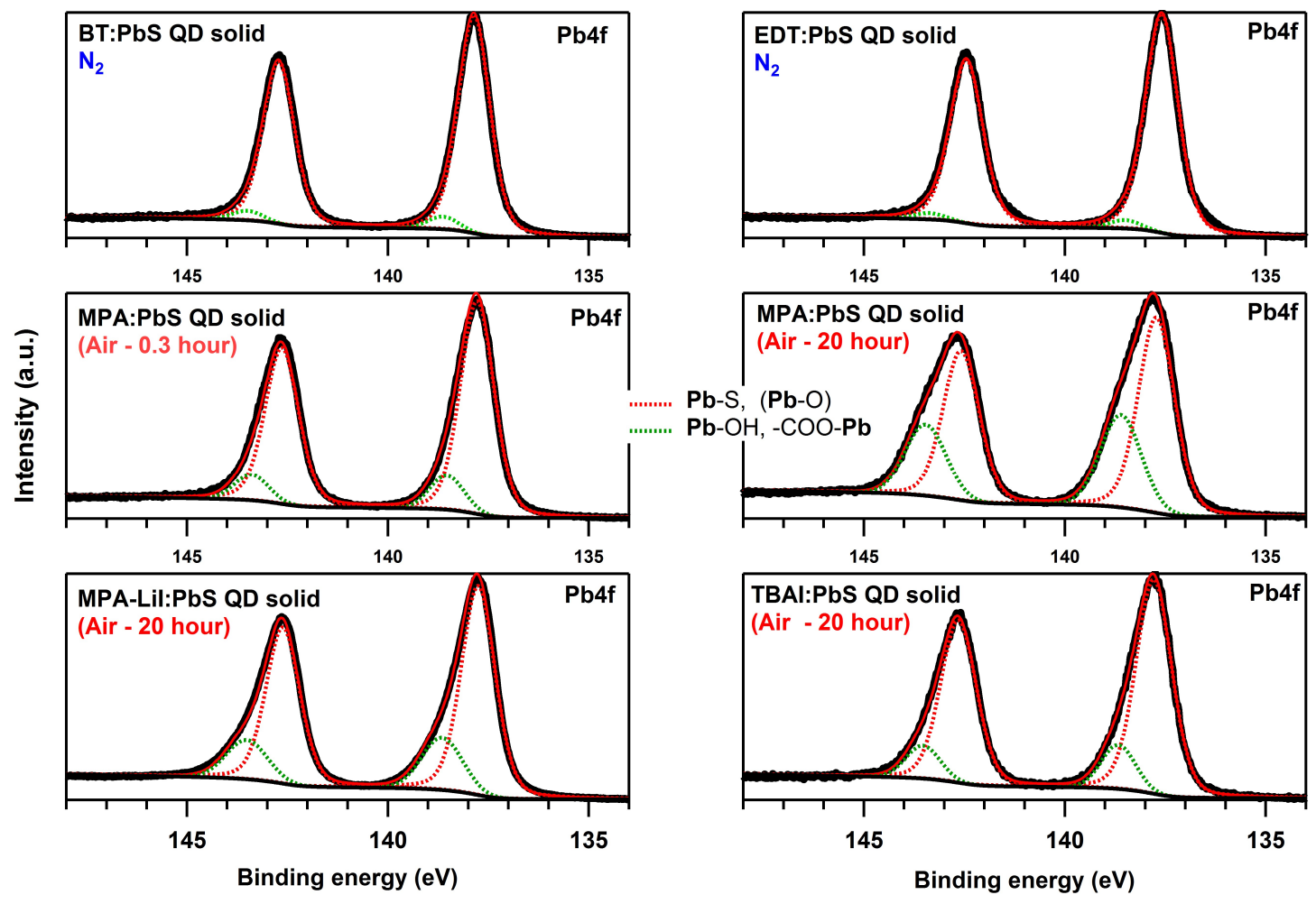

Figure 51. Lead (Pb4f) XPS spectra of QD solids deposited with different ligands

$\mathrm{Pb} 4 \mathrm{f}^{7} / 2$ peaks at $\mathbf{1 3 8 . 6} \pm \mathbf{0 . 2} \mathrm{eV}$ are consistent with both hydroxyl $(-\mathrm{OH})^{82,85}$ and carboxyl $(\mathrm{COO}-)^{75,86}$ groups attached to $\mathrm{Pb}$. Similarly, with help of O1s XPS data for MPA and $\mathrm{I}^{-}$ deposited QD solids (Figure 54), it is believed that $\mathrm{Pb}-\mathrm{OH}$ species are predominant, as carboxylic peaks in O1s spectra are smaller in comparison to metal-hydroxyl O1s peaks. The $\mathrm{PbSO}_{4}$ peak is expected to be located at $139.5-140.0 \mathrm{eV}$ but was not resolved or observed.

Detailed sulfur XPS spectra for PbS QD solids deposited with different ligands is shown in Figure 52. Sulfur S2p peaks $(\sim 160 \mathrm{eV})$ are located close to those of $\mathrm{Pb} 4 \mathrm{f}(\sim 140 \mathrm{eV})$ and hence are influenced by lead "energy loss peaks" 87 typically found $20-25 \mathrm{eV}$ towards higher binding energies of parent peaks (see Figure 50 - Figure 49 for reference). Since 
$\mathrm{Pb} 4 \mathrm{f}$ is a doublet peak originating from $\mathrm{Pb} 4 \mathrm{f} 7 / 2$ and $\mathrm{Pb} 4 \mathrm{f} 5 / 2$ lines with $4.86 \mathrm{eV}$ separation, we expect two energy loss lines with the same separation. For this reason, appropriate background peaks (shown with black dashed lines) were subtracted during S2p peak fitting and $\mathrm{Pb}: \mathrm{S}$ atomic ratio calculations. For the thiol-group containing ligands exchanged QD solids, EDT, BT and MPA, Pb:S ratio calculated based on Pb 4f and S2p XPS spectra using MultiPak software, is close to 1:1. This is consistent with the fact that PbS QD by itself is expected to be $\mathrm{Pb}$ rich (approximately 1:0.83) and the number of ligands covering each QD is expected to be proportional to the number of excess $\mathrm{Pb}$ atoms ${ }^{88}$. Interestingly, for $\mathrm{PbS}$ QD solids deposited with ligand solution with LiI : MPA in 1:1 ratio, we observed $\mathrm{Pb}: \mathrm{S}$ ratio on the solid's surface to be smaller than that for not LiI containing MPA:PbS solid.
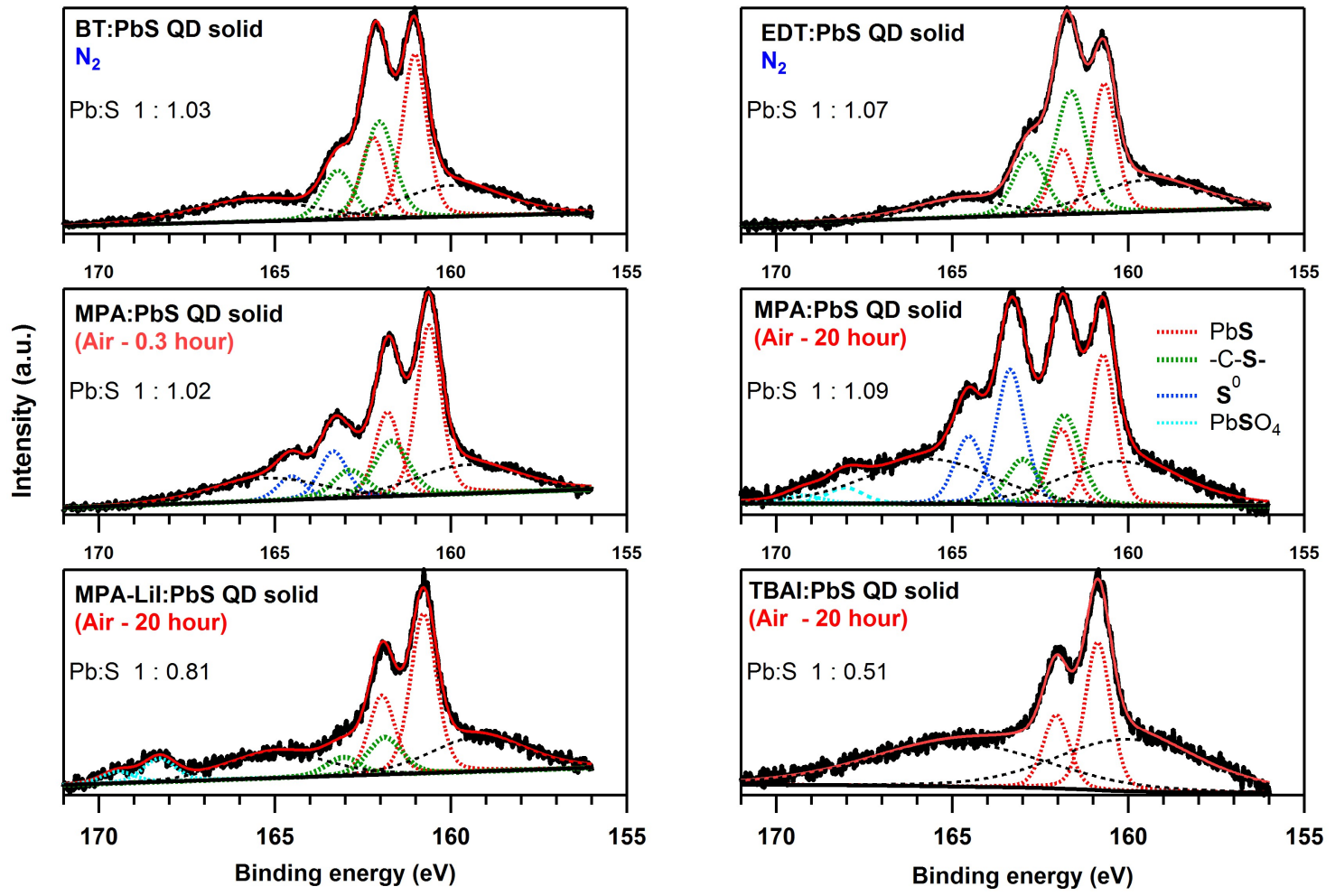

Figure 52. Sulfur (S2p) XPS spectra of QD solids deposited with varying ligands. 
Observed XPS S2p peaks for all PbS QD solids were assigned according to literature values as demonstrated in Table 4.

Table 4. The experimental S2p peak position and sulfur identity in PbS QD solids.

\begin{tabular}{|c|c|c|}
\hline Sulfur species & S2p3/2 peak $(\mathrm{eV})$ & Peak line color (Figure 52) \\
\hline $\mathrm{Pb}-\mathbf{S}^{42}$ & $160.9 \pm 0.1$ & $\cdots \cdots$ \\
\hline$-\mathrm{C}-\mathbf{S}^{42}$ & $161.9 \pm 0.1$ & $\cdots \cdots$ \\
\hline $\mathbf{S}^{0}{ }^{42}$ & $163.4 \pm 0.1$ & $\cdots \cdots$ \\
\hline $\mathrm{PbSO}_{4}{ }^{42}$ & $168.1 \pm 0.1$ & $\cdots \cdots$ \\
\hline
\end{tabular}

Detailed carbon XPS spectra for the same set of solids is shown in Figure 53.
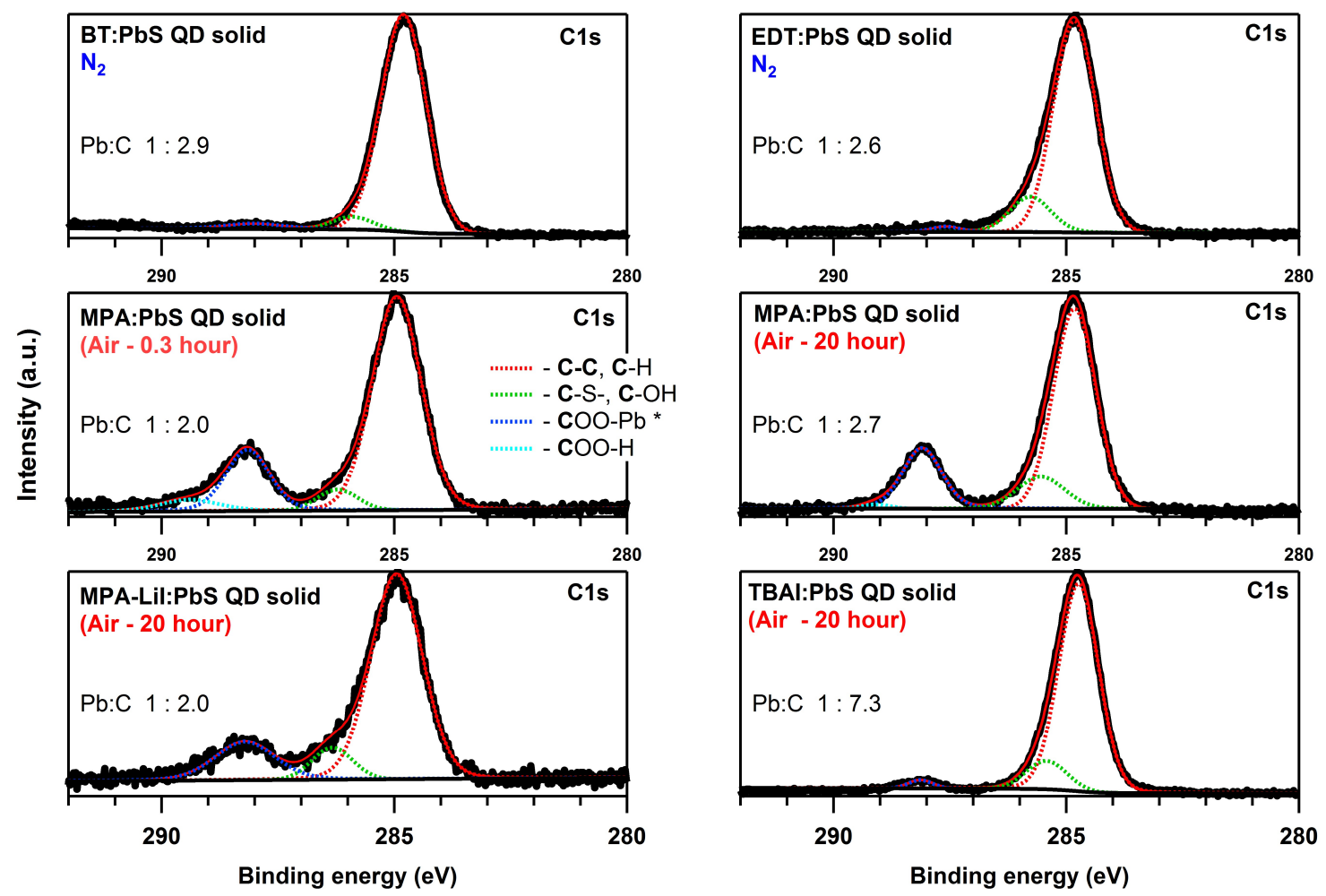

Figure 53. Carbon (C1s) XPS spectra of QD solids deposited with different ligands

The $\mathrm{C} 1 \mathrm{~s}$ peak at $288.2 \mathrm{eV}$ is associated with carbon in carboxyl groups and is only significantly observed in QD solids deposited with mercaptopropionic acid ligand exchange. Assignment of $\mathrm{C} 1 \mathrm{~s}$ peaks according to literature is presented in Table 5. 
Table 5. Experimental C1s peak position and carbon identity in PbS QD solids

\begin{tabular}{|c|c|c|}
\hline Sulfur species & C1s peak $(\mathrm{eV})$ & Peak line color \\
\hline $\mathbf{C}-\mathbf{C}, \mathbf{C}-\mathrm{H}^{89}$ & $284.9 \pm 0.1$ & $\cdots \cdots$ \\
\hline C-S-, C-OH ${ }^{89,90}$ & $286.2 \pm 0.4$ & $\cdots \cdots$ \\
\hline$-\mathrm{COO}-\mathrm{Pb}{ }^{91-93}$ & $288.2 \pm 0.4$ & $\ldots \ldots$ \\
\hline$-\mathrm{COO}-\mathrm{H}^{89,93-96}$ & $289.2 \pm 0.2$ & $\ldots$ \\
\hline
\end{tabular}

C1s XPS peak located at $289.2 \pm 0.2 \mathrm{eV}$ is considered to be related to MPA ligand molecule that is not bound to $\mathrm{Pb}$ by the carboxylic group. This was supported by an experiment where excess MPA solution was used for ligand exchange during the QD solid deposition, which resulted in $289.2 \mathrm{eV}$ peak increase.

Detailed oxygen XPS spectra for PbS QD solids is shown in Figure 54.
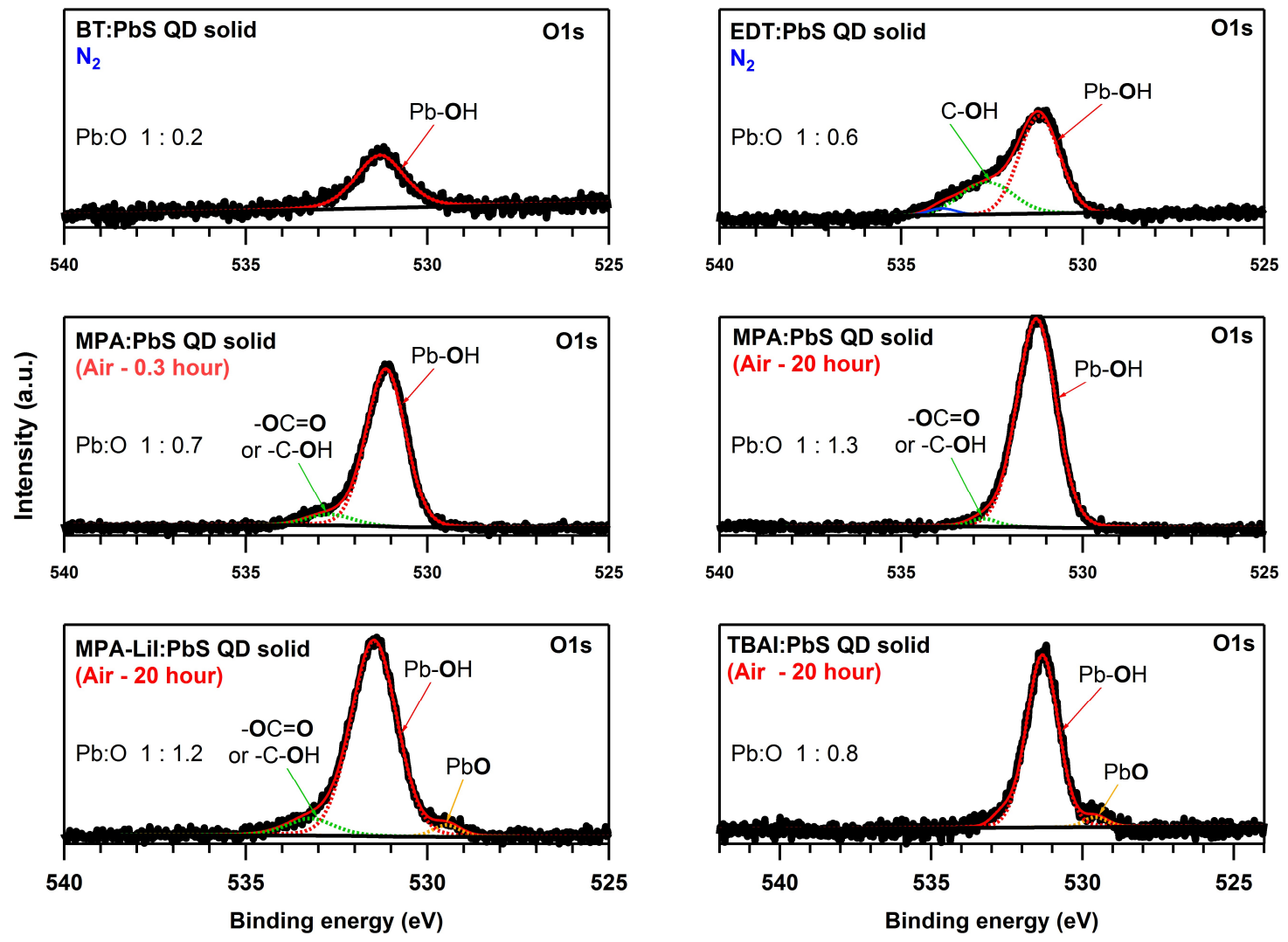

Figure 54. Oxygen (O1s) XPS spectra of QD solids deposited with different ligands 
O1s XPS peak located at $531.3 \pm 0.1 \mathrm{eV}$ is commonly associated with a hydroxyl group attached to metals (M-OH) ${ }^{97,98}$, with cases of binding directly to $\mathrm{Pb}$ in PbS QD solids with the O1s peak at $531.6 \mathrm{eV}$ were also reported ${ }^{82}$. Sulfur in $\mathrm{PbSO}_{4}$ was reported to have the O1s peak at binding energies of $531.5 \mathrm{eV}$. The O1s peak observed $533.0 \pm 0.2$ can be associated with either aliphatic hydroxyl group $(-\mathrm{C}-\mathrm{OH})(532.7-533.1 \mathrm{eV})^{99-102}$ or carboxylic group ( $\mathbf{O}=\mathrm{C}-\mathbf{O}-)(532.8-533.4){ }^{82,103}$. Hence the presence of this peak in all MPA ligand containing QD solids is expected as the carboxylic group is a part of MPA. This peak is absent in TBAI:PbS and BT:PbS QD solids which is consistent with the fact that ligands, used to deposit these solids do not contain carboxylic groups. Presence of O1s $533.0 \mathrm{eV}$ peak in EDT:PbS solids (Figure 54,b), however, cannot be assigned to oxygen in carboxylic group, as ethanedithiol does not contain one. In this case, however, it could be associated with aliphatic hydroxyl groups $(-\mathrm{C}-\mathrm{OH})^{99-102}$ or chemisorbed water ${ }^{103,104}$. Aliphatic hydroxyl groups could be a product of oxidation of $\mathrm{S}^{2-}$ in thiol groups on the surface, thus forming $\mathrm{S}^{0}$ and 2-mercaptoethanol or ethylene glycol. Formation of elemental sulfur $\left(\mathrm{S}^{0}\right)$ in this case is consistent with S2p XPS spectra changes observed for air oxidized EDT:PbS QD solids (see Figure $55(\mathrm{a}, \mathrm{b})$ and Table 6). This suggests that EDT:PbS QD solids are prone to water involved oxidation in air and are more readily susceptible to do so when compared to BT:PbS solids. This is also consistent with the fact that oxygen to lead atomic ratio is three times higher for EDT:PbS versus that of BT:EDT (see $\mathrm{Pb}: \mathrm{O}$ values in Figure 54). Both BT:PbS and EDT:PbS solids were deposited air-free, but were exposed to air for approximately 2-4 minutes during transfer process to XPS instrument. Oxygen content in these two samples is unlikely to come from other sources than air, as 
they both were deposited in $\mathrm{N}_{2}$ filled glovebox $\left(\mathrm{O}_{2}<3 \mathrm{ppm}\right)$ and using anhydrous, dry solvents (n-hexane and acetonitrile). XPS peak located at $529.8 \pm \mathbf{0 . 1}$ eV commonly associated in literature with crystalline oxides. ${ }^{82-84}$ It could potentially indicate presence of trace amounts of $\mathrm{Pb}(\mathrm{II}) \mathrm{O}$ on surface of $\mathrm{PbS}$ solids. However, since this peak is only observed for $\mathrm{PbS}$ solids deposited with iodine $\left(\mathrm{I}^{-}\right)$containing ligands, it becomes not consistent with literature cases, where iodine capped PbS QD solids have demonstrated an excellent resistance to oxidation in air. ${ }^{22}$

\section{Air exposure: surface chemistry of PbS QD solids}

Previous reports for positive effects of oxygen annealing of EDT:PbS QD solids for QD/organic bilayer solar cells have shown improvements in the electronic structure of such solids, resulting in better photovoltaic performance. ${ }^{42}$ Mainly, fill-factor values were improved due suggested suppressing of unwanted charge recombination processes within the QD layer. It was proposed that a wider band gap oxide layers (QD film oxidation products) were originated around each QD in the solid, prevent the backflow and recombination of charge carriers. Even though my QD films preparation and air treatment methods (no heat annealing) were different, it is obvious that post-depositional QD films treatments play an important role in QD solids chemistry.

In the previous section, chemical environments for each element were studied with detailed XPS analysis. In order to better understand the nature of the PbS QD solids' surface chemistry, specifically the motifs of chemical effects of air exposure on such solids and how it relates to their photovoltaic properties changes, I utilized Ar+ sputtering (used for surface cleaning) capability of the XPS instrument. For this, two samples of MPA:PbS and 
EDT:PbS QD solids were deposited in an inert atmosphere and were analyzed with XPS before and after being exposed to air. XPS data obtained for both samples produced comparably similar qualitative results. As an example, sulfur XPS data for EDT:PbS solid is shown in Figure 55. Figure 55 ( $a$ and $b$ ) shows $S 2 p$ peaks rearrangement indicating the appearance of $\mathrm{S}^{0}$ species, which is consistent with sulfur oxidation on the surface of the QD solids, as discussed earlier. Upon 30 minutes air exposure S2p peak (green-dashed line) associated with sulfur in (-C-S-) species is decreased, while $\mathrm{S}^{0}$ peak (blue-dashed line) has increased, which suggests that primarily sulfur species that undergo oxidation are (-CS-) species (originally thiol groups in QD's ligands).
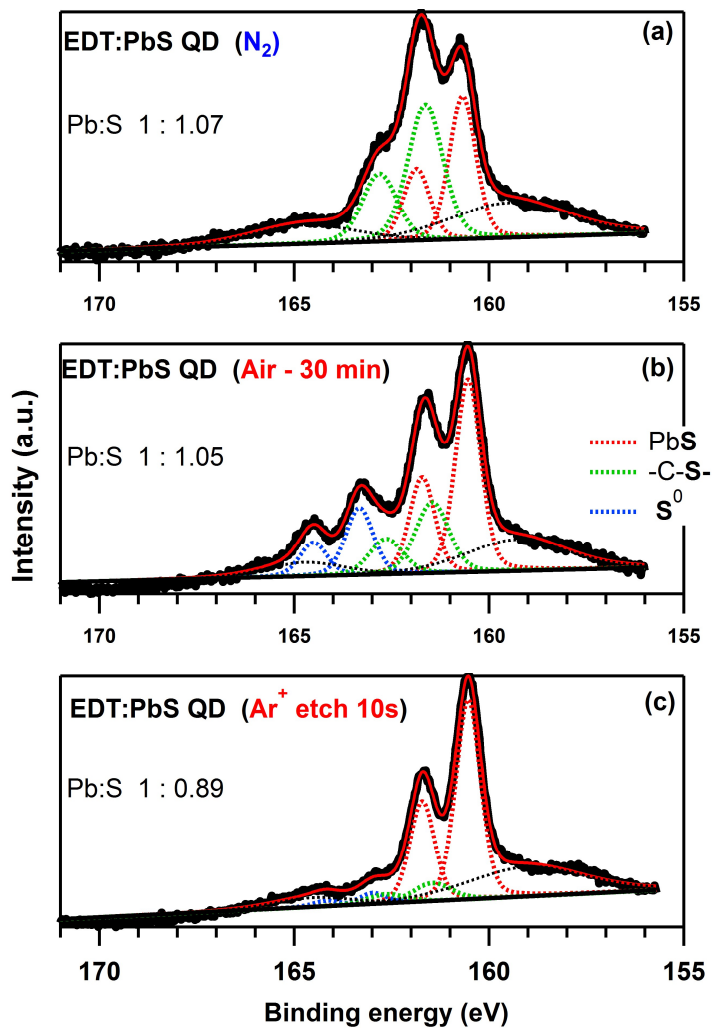

Figure 55. S2p XPS spectra of EDT:PbS QD solids (air exposure and $\mathrm{Ar}^{+}$etch effect). 
This is also shown in Table 6 that suggests that approximately $45 \%$ of (-C-S-) sulfur species are oxidized into elemental sulfur. Sulfur species in PbS are not likely being oxidized, as relative sulfur content for PbS stays about the same (44\% vs $45 \%$ ) before and after the air exposure of EDT:PbS solid ( Table 6). On the other hand, sulfur in $\mathrm{Pb}-\mathrm{S}$ bond was believed to be oxidized more readily for MPA:PbS QD solids as PbS:-C-S- peak's ratio decreased with air-oxidation, as $\mathbf{S}^{0}$ peak increased (S2p XPS in Figure 35).

Table 6. Pb:S ratio and sulfur species content analysis on the surface of EDT:PbS QD solid with respect to different treatments.

\begin{tabular}{|c|c|c|c|c|}
\hline Treatment & $\begin{array}{c}\mathrm{Pb}: \mathrm{S} \text { ratio } \\
\pm 0.3\end{array}$ & $\begin{array}{c}\% \mathbf{S}^{0} \\
\pm 3\end{array}$ & $\begin{array}{c}\% \text {-C-S- } \\
\pm 3\end{array}$ & $\begin{array}{c}\% \mathrm{PbS} \\
\pm 3\end{array}$ \\
\hline Deposited in $\mathrm{N}_{2}$ atmosphere & $1: 1.07$ & 0 & 56 & $\mathbf{4 4}$ \\
\hline 30 min. air exposed & $1: 1.05$ & 25 & 30 & $\mathbf{4 5}$ \\
\hline $10 \mathrm{~s} . \mathrm{Ar}^{+}$etched & $1: 0.89$ & 5 & 11 & 84 \\
\hline
\end{tabular}

Figure 55 (c), shows an effect of sputtering the oxidized EDT:PbS solid with $\mathrm{Ar}^{+}$ions (Argon etching available within XPS instrument). This data shows that within 10 seconds of $\mathrm{Ar}^{+}$sputtering most of the $\mathrm{S}^{0}$ and -C-S- species are being removed from the QD solids surface, leaving the sulfur in $\mathrm{PbS}$ species predominant ( $84 \%$ of all $\mathrm{S}$ atoms on the QD solid surface). First data column in Table 6 suggests that during $\mathrm{Ar}^{+}$etching $\mathrm{Pb}: \mathrm{S}$ ratio changed from being 1:1.05 to 1:0.89 ( 15\% decrease in sulfur amount). This is also consistent with removal of $\mathrm{S}^{0}$ and $-\mathrm{C}-\mathrm{S}$ - species from the surface, leaving bare QD surface, which is expected to be lead-rich $(\mathrm{Pb}: \mathrm{S}=1: 0.83) .{ }^{88}$ However it is hard to speak definitely about true $\mathrm{Pb}: \mathrm{S}$ ratio, only based on XPS data, as X-ray penetration into the QD solid, atomic XPS sensitivities differences for $\mathrm{Pb}$ and $\mathrm{S}$, and cross-sectional surficial availability of $\mathrm{Pb}$ and S atoms are not held consistent throughout the array of QDs constituting the solid. 
Changes in $\mathrm{Pb} 4 \mathrm{f}, \mathrm{C} 1 \mathrm{~s}$, and $\mathrm{O} 1 \mathrm{~s}$ spectra did not suggest any additional information to that discussed above for each of these elements.

Literature suggests that depending on the environment, oxidation products of galena $(\mathrm{PbS})$ in air include $\mathrm{PbSO}_{4}$ and $\mathrm{PbO}$, while the presence of elemental sulfur $\left(\mathrm{S}^{0}\right)$ was detected on early stages of oxidation. ${ }^{105,106}$ Hence, possible oxidation reactions taking place on the surface of PbS QD solids can be written as:

$$
\begin{gathered}
2 \mathrm{PbS}+3 \mathrm{O}_{2} \rightarrow 2 \mathrm{PbO}+2 \mathrm{SO}_{2} \\
2 \mathrm{PbO}+\mathrm{O}_{2}+\mathrm{SO}_{2} \rightarrow \mathrm{PbSO}_{4}
\end{gathered}
$$

Our XPS data did not support the formation of $\mathrm{PbO}$ on the surface of air exposed MPA:PbS QDs solids as we would expect a peak for oxygen O1s at 527.5-529.7 $\mathrm{eV}^{107}$ which was not observed Figure 35. The only possibility of formation of $\mathrm{PbO}$ was observed when $\mathrm{PbS}$ QD solids were deposited using iodine ( $\left.\mathrm{I}^{-}\right)$containing ligands (MPA-LiI mixture and TBAI) and only in case of exposing those films to air (Figure 54). However, the O1s peak observed in this case at $529.5 \mathrm{eV}$ is small indicating to trace amounts of $\mathrm{PbO}$ on the surface of QD solids. However, since we observed the formation of $\mathrm{SO}_{4}{ }^{2-}$ species in S2p spectra (Figure 52) after 20 hours air exposure of MPA:PbS solids, this supports the hypothesis that $\mathrm{PbO}$ could indeed be formed as an intermediate species, as shown in chemical equations above. Finally, we suggest that the establishment of the p-type character of the MPA:PbS QD solids with their exposure to air, as observed with the electrochemical studies (Chapter IV)A)3) on page 29), is consistent with the oxidative chemistry taking place on the surface of the QD solids. The new oxidized sulfur species bound to QDs as well as $\mathrm{Pb}-\mathrm{OH}$ species may be responsible for the creation of electron acceptor energy levels located just above 
the $\mathbf{E}_{\mathbf{v b}}$ of the QD solids, thus increasing the concentration of holes $\left(\mathrm{h}^{+}\right)$or electron vacancies in the QD solid. This, in turn, is known to result in the p-type doping of semiconducting solids ${ }^{108}$. Such explanation is consistent with literature cases, where DFT calculations were used to show that molecular oxygen, when adsorbed on the QD surface results in the creation of in-gap states located close to the $\mathbf{E}_{\mathbf{v b}} .{ }^{109}$ 


\section{C) Conclusions}

This dissertation work demonstrates series of successful electrochemical studies of the photovoltaic properties of both p-, and n-type PbS QD solids using a "soft" solution contacting method. Chapter (IV) showed that an ideal retracement of photovoltage values with respect to the changes in reduction potential of contacting electrolytes can be obtained, which suggested that electrochemical liquid contacting method does not introduce surface defects on the $\mathrm{QD} /$ /iquid junctions, as it was observed for $\mathrm{QD} /$ metal pair.

Chapter (V) extends the application of liquid contacting method to n-type PbS QD solids, while we were able to illustrate the significant effects QD ligand chemistry has on the PV performance of the QD solids. XPS studies described in this work allowed for a better understanding of relationships between the surface chemistry of QDs, surface modifications of their solids during air exposure, and their photoelectrochemical properties. Additionally, using the solution contacting method, we demonstrated that higher photovoltage values are obtainable for n-type BT:PbS and TBAI:PbS QD solids when compared to p-type MPA:PbS. However further advances in ligand exchange procedures and cell engineering are required in order to reduce charge transfer resistance and improve QD solids electronic properties. 


\section{REFERENCES}

(1) Dereviankin, V. A.; Johansson, E. Liquid Contacting as a Method to Study Photovoltaic Properties of PbS Quantum Dot Solids. J. Mater. Chem. A 2016, 4 (23), 9009-9013.

(2) Bryant, G. Excitons in Quantum Boxes: Correlation Effects and Quantum Confinement. Phys. Rev. B 1988, 37 (15), 8763-8772.

(3) Zorman, B.; Ramakrishna, M. V.; Friesner, R. A. Quantum Confinement Effects in CdSe Quantum Dots. J. Phys. Chem. 1995, 99 (19), 7649-7653.

(4) Baskoutas, S.; Terzis, A. F. Size-Dependent Band Gap of Colloidal Quantum Dots. J. Appl. Phys. 2006, 99 (1), 13708.

(5) Michalet, X.; Pinaud, F. F.; Bentolila, L. A.; Tsay, J. M.; Doose, S.; Li, J. J.; Sundaresan, G.; Wu, A. M.; Gambhir, S. S.; Weiss, S. Quantum Dots for Live Cells, in Vivo Imaging, and Diagnostics. Science 2005, 307 (5709), 538-544.

(6) Drummen, G. P. C. Quantum Dots-from Synthesis to Applications in Biomedicine and Life Sciences. Int. J. Mol. Sci. 2010, 11 (1), 154-163.

(7) Rogach, A. L.; Gaponik, N.; Lupton, J. M.; Bertoni, C.; Gallardo, D. E.; Dunn, S.; Li Pira, N.; Paderi, M.; Repetto, P.; Romanov, S. G.; O’Dwyer, C.; Sotomayor Torres, C. M.; Eychmüller, A. Light-Emitting Diodes with Semiconductor Nanocrystals. Angew. Chem. Int. Ed. Engl. 2008, 47 (35), 6538-6549.

(8) Eisler, H.-J.; Sundar, V. C.; Bawendi, M. G.; Walsh, M.; Smith, H. I.; Klimov, V. Color-Selective Semiconductor Nanocrystal Laser. Appl. Phys. Lett. 2002, 80 (24), 4614.

(9) Hoogland, S.; Sukhovatkin, V.; Howard, I.; Cauchi, S.; Levina, L.; Sargent, E. H. A Solution-Processed 1.53 Mm Quantum Dot Laser with Temperature-Invariant Emission Wavelength. Opt. Express 2006, 14 (8), 3273.

(10) Menon, V. M.; Luberto, M.; Valappil, N. V; Chatterjee, S. Lasing from InGaP Quantum Dots in a Spin-Coated Flexible Microcavity. Opt. Express 2008, 16 (24), 19535-19540.

(11) Kramer, I. J.; Sargent, E. H. Colloidal Quantum Dot Photovoltaics: A Path Forward. ACS Nano 2011, 5 (11), 8506-8514.

(12) Pattantyus-Abraham, A. G.; Kramer, I. J.; Barkhouse, A. R.; Wang, X.; Konstantatos, G.; Debnath, R.; Levina, L.; Raabe, I.; Nazeeruddin, M. K.; Grätzel, M.; Sargent, E. H. Depleted-Heterojunction Colloidal Quantum Dot Solar Cells. ACS Nano 2010, 4 (6), 3374-3380.

(13) Kamat, P. V; Tvrdy, K.; Baker, D. R.; Radich, J. G. Beyond Photovoltaics: Semiconductor Nanoarchitectures for Liquid-Junction Solar Cells. Chem. Rev. 2010, 110 (11), 6664-6688.

(14) Gerischer, H.; Lübke, M. A Particle Size Effect in the Sensitization of TiO2 Electrodes by a CdS Deposit. J. Electroanal. Chem. Interfacial Electrochem. 1986, 204 (1-2), 225-227.

(15) Vogel, R.; Pohl, K.; Weller, H. Sensitization of Highly Porous, Polycrystalline TiO2 Electrodes by Quantum Sized CdS. Chem. Phys. Lett. 1990, 174 (3-4), 241-246. 
(16) Kohtani, S.; Kudo, A.; Sakata, T. Spectral Sensitization of a TiO2 Semiconductor Electrode by CdS Microcrystals and Its Photoelectrochemical Properties. Chem. Phys. Lett. 1993, 206 (1-4), 166-170.

(17) Mora-Seró, I.; Bisquert, J. Breakthroughs in the Development of SemiconductorSensitized Solar Cells. J. Phys. Chem. Lett. 2010, 1 (20), 3046-3052.

(18) Kurtin, S.; McGill, T.; Mead, C. FUNDAMENTAL TRANSITION IN THE ELECTRONIC NATURE OF SOLIDS. Phys. Rev. Lett. 1969, 22 (26), 1433-1436.

(19) Terry, L. E. Effects of Pre- and Post-Annealing Treatments on Silicon Schottky Barrier Diodes. Proc. IEEE 1970, 58 (3), 492-494.

(20) Johnston, K. W.; Pattantyus-Abraham, A. G.; Clifford, J. P.; Myrskog, S. H.; MacNeil, D. D.; Levina, L.; Sargent, E. H. Schottky-Quantum Dot Photovoltaics for Efficient Infrared Power Conversion. Appl. Phys. Lett. 2008, 92 (15), 151115.

(21) Tang, J.; Kemp, K. W.; Hoogland, S.; Jeong, K. S.; Liu, H.; Levina, L.; Furukawa, M.; Wang, X.; Debnath, R.; Cha, D.; Chou, K. W.; Fischer, A.; Amassian, A.; Asbury, J. B.; Sargent, E. H. Colloidal-Quantum-Dot Photovoltaics Using AtomicLigand Passivation. Nat. Mater. 2011, 10 (10), 765-771.

(22) Ning, Z.; Voznyy, O.; Pan, J.; Hoogland, S.; Adinolfi, V.; Xu, J.; Li, M.; Kirmani, A. R.; Sun, J.-P.; Minor, J.; Kemp, K. W.; Dong, H.; Rollny, L.; Labelle, A.; Carey, G.; Sutherland, B.; Hill, I.; Amassian, A.; Liu, H.; Tang, J.; Bakr, O. M.; Sargent, E. H. Air-Stable N-Type Colloidal Quantum Dot Solids. Nat. Mater. 2014, 13 (8), 822828.

(23) Luther, J. M.; Gao, J.; Lloyd, M. T.; Semonin, O. E.; Beard, M. C.; Nozik, A. J. Stability Assessment on a 3\% Bilayer PbS/ZnO Quantum Dot Heterojunction Solar Cell. Adv. Mater. 2010, 22 (33), 3704-3707.

(24) Kramer, I. J.; Sargent, E. H. The Architecture of Colloidal Quantum Dot Solar Cells: Materials to Devices. Chem. Rev. 2014, 114 (1), 863-882.

(25) Labelle, A. J.; Thon, S. M.; Masala, S.; Adachi, M. M.; Dong, H.; Farahani, M.; Ip, A. H.; Fratalocchi, A.; Sargent, E. H. Colloidal Quantum Dot Solar Cells Exploiting Hierarchical Structuring. Nano Lett. 2015, 15 (2), 1101-1108.

(26) Chuang, C.-H. M.; Brown, P. R.; Bulović, V.; Bawendi, M. G. Improved Performance and Stability in Quantum Dot Solar Cells through Band Alignment Engineering. Nat. Mater. 2014, 13 (8), 796-801. NREL solar cell efficiencies chart https://www.nrel.gov/pv/assets/images/efficiency-chart.png.

(28) Shockley, W.; Queisser, H. J. Detailed Balance Limit of Efficiency of P-N Junction Solar Cells. J. Appl. Phys. 1961, 32 (3), 510.

(29) Luther, J. M.; Law, M.; Beard, M. C.; Song, Q.; Reese, M. O.; Ellingson, R. J.; Nozik, A. J. Schottky Solar Cells Based on Colloidal Nanocrystal Films. Nano Lett. 2008, 8 (10), 3488-3492.

(30) Ip, A. H.; Thon, S. M.; Hoogland, S.; Voznyy, O.; Zhitomirsky, D.; Debnath, R.; Levina, L.; Rollny, L. R.; Carey, G. H.; Fischer, A.; Kemp, K. W.; Kramer, I. J.; Ning, Z.; Labelle, A. J.; Chou, K. W.; Amassian, A.; Sargent, E. H. Hybrid Passivated Colloidal Quantum Dot Solids. Nat. Nanotechnol. 2012, 7 (9), 577-582. 
(31) Kemp, K. W.; Labelle, A. J.; Thon, S. M.; Ip, A. H.; Kramer, I. J.; Hoogland, S.; Sargent, E. H. Interface Recombination in Depleted Heterojunction Photovoltaics Based on Colloidal Quantum Dots. Adv. Energy Mater. 2013, 3 (7), 917-922.

(32) Mao, D. Open-Circuit Photovoltage and Charge Recombination at Semiconductor/Liquid Interfaces. J. Electrochem. Soc. 1994, 141 (5), 1231-1236.

(33) Kiess, H.; Rehwald, W. On the Ultimate Efficiency of Solar Cells. Sol. Energy Mater. Sol. Cells 1995, 38 (1-4), 45-55.

(34) Werner, J.; Kolodinski, S.; Queisser, H. Novel Optimization Principles and Efficiency Limits for Semiconductor Solar Cells. Phys. Rev. Lett. 1994, 72 (24), 3851-3854.

(35) Klimov, V. I. Mechanisms for Photogeneration and Recombination of Multiexcitons in Semiconductor Nanocrystals: Implications for Lasing and Solar Energy Conversion. J. Phys. Chem. B 2006, 110 (34), 16827-16845.

(36) Chuang, C.-H. M.; Maurano, A.; Brandt, R. E.; Hwang, G. W.; Jean, J.; Buonassisi, T.; Bulović, V.; Bawendi, M. G. Open-Circuit Voltage Deficit, Radiative SubBandgap States, and Prospects in Quantum Dot Solar Cells. Nano Lett. 2015, 15 (5), 3286-3294.

(37) Yuan, M.; Voznyy, O.; Zhitomirsky, D.; Kanjanaboos, P.; Sargent, E. H. Synergistic Doping of Fullerene Electron Transport Layer and Colloidal Quantum Dot Solids Enhances Solar Cell Performance. Adv. Mater. 2015, 27 (5), 917-921.

(38) Tang, J.; Liu, H.; Zhitomirsky, D.; Hoogland, S.; Wang, X.; Furukawa, M.; Levina, L.; Sargent, E. H. Quantum Junction Solar Cells. Nano Lett. 2012, 12 (9), 48894894.

(39) Yoon, W.; Boercker, J. E.; Lumb, M. P.; Placencia, D.; Foos, E. E.; Tischler, J. G. Enhanced Open-Circuit Voltage of PbS Nanocrystal Quantum Dot Solar Cells. Sci. Rep. 2013, 3, 2225.

(40) Hussain, A.; Rahman, A. Synthesis and Electrical Characteristics of $\mathrm{Al} /(\mathrm{p}) \mathrm{PbS}$ Schottky Barrier Junction. Mater. Sci. Semicond. Process. 2013, 16 (6), 1918-1924.

(41) Choi, M.-J.; Oh, J.; Yoo, J.-K.; Choi, J.; Sim, D. M.; Jung, Y. S. Tailoring of the $\mathrm{PbS} / \mathrm{metal}$ Interface in Colloidal Quantum Dot Solar Cells for Improvements of Performance and Air Stability. Energy Environ. Sci. 2014, 7 (9), 3052.

(42) Zhao, N.; Osedach, T. P.; Chang, L.-Y.; Geyer, S. M.; Wanger, D.; Binda, M. T.; Arango, A. C.; Bawendi, M. G.; Bulovic, V. Colloidal PbS Quantum Dot Solar Cells with High Fill Factor. ACS Nano 2010, 4 (7), 3743-3752.

(43) Lewis, N. S. A Quantitative Investigation of the Open-Circuit Photovoltage at the Semiconductor/Liquid Interface. J. Electrochem. Soc. 1984, 131 (11), 2496.

(44) Rosenbluth, M. L.; Lieber, C. M.; Lewis, N. S. 630-mV Open Circuit Voltage, 12\% Efficient N-Si Liquid Junction. Appl. Phys. Lett. 1984, 45 (4), 423.

(45) Rosenbluth, M. L.; Lewis, N. S. "Ideal" behavior of the Open Circuit Voltage of Semiconductor/liquid Junctions. J. Phys. Chem. 1989, 93 (9), 3735-3740.

(46) Grimm, R. L.; Bierman, M. J.; O’Leary, L. E.; Strandwitz, N. C.; Brunschwig, B. S.; Lewis, N. S. Comparison of the Photoelectrochemical Behavior of H-Terminated and Methyl-Terminated Si(111) Surfaces in Contact with a Series of One-Electron, Outer-Sphere Redox Couples in CH 3 CN. J. Phys. Chem. C 2012, 116 (44), 23569. 
(47) Kumar, A.; Lewis, N. S. Short-Wavelength Spectral Response Properties of Semiconductor/liquid Junctions. J. Phys. Chem. 1990, 94 (15), 6002-6009.

(48) Barkhouse, D. A. R.; Debnath, R.; Kramer, I. J.; Zhitomirsky, D.; PattantyusAbraham, A. G.; Levina, L.; Etgar, L.; Grätzel, M.; Sargent, E. H. Depleted Bulk Heterojunction Colloidal Quantum Dot Photovoltaics. Adv. Mater. 2011, 23 (28), 3134-3138.

(49) Labelle, A. J.; Thon, S. M.; Kim, J. Y.; Lan, X.; Zhitomirsky, D.; Kemp, K. W.; Sargent, E. H. Conformal Fabrication of Colloidal Quantum Dot Solids for Optically Enhanced Photovoltaics. ACS Nano 2015, 9 (5), 5447-5453.

(50) Brown, P. R.; Kim, D.; Lunt, R. R.; Zhao, N.; Bawendi, M. G.; Grossman, J. C.; Bulović, V. Energy Level Modification in Lead Sulfide Quantum Dot Thin Films through Ligand Exchange. ACS Nano 2014, 8 (6), 5863-5872.

(51) Zhitomirsky, D.; Voznyy, O.; Levina, L.; Hoogland, S.; Kemp, K. W.; Ip, A. H.; Thon, S. M.; Sargent, E. H. Engineering Colloidal Quantum Dot Solids within and beyond the Mobility-Invariant Regime. Nat. Commun. 2014, 5 (3803), 1-7.

(52) Manjula, A.; Nagarajan, M. Synthesis and Complexation Studies on 1,4Dinaphthocrown Ether. Arkivoc 2001, 2001 (8), 165.

(53) Wang, X.; Koleilat, G. I.; Tang, J.; Liu, H.; Kramer, I. J.; Debnath, R.; Brzozowski, L.; Barkhouse, D. A. R.; Levina, L.; Hoogland, S.; Sargent, E. H. Tandem Colloidal Quantum Dot Solar Cells Employing a Graded Recombination Layer. Nat. Photonics 2011, 5 (8), 480-484.

(54) Jähnig, F.; Bozyigit, D.; Yarema, O.; Wood, V. Research Update: Comparison of Salt- and Molecular-Based Iodine Treatments of PbS Nanocrystal Solids for Solar Cells. APL Mater. 2015, 3 (2), 20701.

(55) Choi, H.; Kwan Kim, J.; Hoon Song, J.; Kim, Y.; Jeong, S. Increased Open-Circuit Voltage in a Schottky Device Using PbS Quantum Dots with Extreme Confinement. Appl. Phys. Lett. 2013, 102 (19), 193902.

(56) Szendrei, K.; Gomulya, W.; Yarema, M.; Heiss, W.; Loi, M. A. PbS Nanocrystal Solar Cells with High Efficiency and Fill Factor. Appl. Phys. Lett. 2010, 97 (20), 203501.

(57) Hyun, B.-R.; Choi, J. J.; Seyler, K. L.; Hanrath, T.; Wise, F. W. Heterojunction PbS Nanocrystal Solar Cells with Oxide Charge-Transport Layers. ACS Nano 2013, 7 (12), 10938-10947.

(58) Guijarro, N.; Lana-Villarreal, T.; Gómez, R. Modulating the N- and P-Type Photoelectrochemical Behavior of Zinc Copper Indium Sulfide Quantum Dots by an Electrochemical Treatment. Chem. Commun. (Camb). 2012, 48 (62), 7681-7683.

(59) Wang, C. Electrochromic Nanocrystal Quantum Dots. Science (80-. ). 2001, 291 (5512), 2390-2392.

(60) Engel, J. H.; Surendranath, Y.; Alivisatos, A. P. Controlled Chemical Doping of Semiconductor Nanocrystals Using Redox Buffers. J. Am. Chem. Soc. 2012, 134 (32), 13200-13203.

(61) Koh, W.; Koposov, A. Y.; Stewart, J. T.; Pal, B. N.; Robel, I.; Pietryga, J. M.; Klimov, V. I. Heavily Doped N-Type PbSe and PbS Nanocrystals Using GroundState Charge Transfer from Cobaltocene. Sci. Rep. 2013, 3, 2004. 
(62) Kirmani, A. R.; Carey, G. H.; Abdelsamie, M.; Yan, B.; Cha, D.; Rollny, L. R.; Cui, X.; Sargent, E. H.; Amassian, A. Effect of Solvent Environment on ColloidalQuantum-Dot Solar-Cell Manufacturability and Performance. Adv. Mater. 2014, 26 (27), 4717-4723.

(63) Boehme, S. C.; Wang, H.; Siebbeles, L. D. A.; Vanmaekelbergh, D.; Houtepen, A. J. Electrochemical Charging of CdSe Quantum Dot Films: Dependence on Void Size and Counterion Proximity. ACS Nano 2013, 7 (3), 2500-2508.

(64) Rosenbluth, M. L.; Lewis, N. S. Kinetic Studies of Carrier Transport and Recombination at the N-Silicon Methanol Interface. J. Am. Chem. Soc. 1986, 108 (16), 4689-4695.

(65) Hu, L.; Mandelis, A.; Lan, X.; Melnikov, A.; Hoogland, S.; Sargent, E. H. Imbalanced Charge Carrier Mobility and Schottky Junction Induced Anomalous Current-Voltage Characteristics of Excitonic PbS Colloidal Quantum Dot Solar Cells. Sol. Energy Mater. Sol. Cells 2016, 155, 155-165.

(66) Lan, X.; Voznyy, O.; Kiani, A.; García de Arquer, F. P.; Abbas, A. S.; Kim, G.-H.; Liu, M.; Yang, Z.; Walters, G.; Xu, J.; Yuan, M.; Ning, Z.; Fan, F.; Kanjanaboos, P.; Kramer, I.; Zhitomirsky, D.; Lee, P.; Perelgut, A.; Hoogland, S.; Sargent, E. H. Passivation Using Molecular Halides Increases Quantum Dot Solar Cell Performance. Adv. Mater. 2016, 28 (2), 299-304.

(67) Reinhart, C. C.; Johansson, E. Colloidally Prepared 3-Mercaptopropionic Acid Capped Lead Sulfide Quantum Dots. Chem. Mater. 2015, 27 (21), 7313-7320.

(68) Mora-Sero, I.; Bertoluzzi, L.; Gonzalez-Pedro, V.; Gimenez, S.-S.; FabregatSantiago, F.; Kemp, K. W.; Sargent, E. H.; Bisquert, J. Selective Contacts Drive Charge Extraction in Quantum Dot Solids via Asymmetry in Carrier Transfer Kinetics. Nat. Commun. 2013, 4, 2272.

(69) Williams, K. J.; Tisdale, W. A.; Leschkies, K. S.; Haugstad, G.; Norris, D. J.; Aydil, E. S.; Zhu, X.-Y. Strong Electronic Coupling in Two-Dimensional Assemblies of Colloidal PbSe Quantum Dots. ACS Nano 2009, 3 (6), 1532-1538.

(70) Wolcott, A.; Doyeux, V.; Nelson, C. A.; Gearba, R.; Lei, K. W.; Yager, K. G.; Dolocan, A. D.; Williams, K.; Nguyen, D.; Zhu, X.-Y. Anomalously Large Polarization Effect Responsible for Excitonic Red Shifts in PbSe Quantum Dot Solids. J. Phys. Chem. Lett. 2011, 2 (7), 795-800.

(71) Moreels, I.; Lambert, K.; Smeets, D.; De Muynck, D.; Nollet, T.; Martins, J. C.; Vanhaecke, F.; Vantomme, A.; Delerue, C.; Allan, G.; Hens, Z. Size-Dependent Optical Properties of Colloidal PbS Quantum Dots. ACS Nano 2009, 3 (10), 30233030.

(72) Gaponenko, M. S.; Lutich, A. A.; Tolstik, N. A.; Onushchenko, A. A.; Malyarevich, A. M.; Petrov, E. P.; Yumashev, K. V. Temperature-Dependent Photoluminescence of PbS Quantum Dots in Glass: Evidence of Exciton State Splitting and Carrier Trapping. Phys. Rev. B - Condens. Matter Mater. Phys. 2010, 82 (12).

(73) Ullrich, B.; Xi, H.; Wang, J. S. Photoluminescence Limiting of Colloidal PbS Quantum Dots. Appl. Phys. Lett. 2016, 108 (8).

(74) Moreels, I.; Kruschke, D.; Glas, P.; Tomm, J. W. The Dielectric Function of PbS Quantum Dots in a Glass Matrix. Opt. Mater. Express 2012, 2 (5), 496. 
(75) Hwang, G. W.; Kim, D.; Cordero, J. M.; Wilson, M. W. B.; Chuang, C.-H. M.; Grossman, J. C.; Bawendi, M. G. Identifying and Eliminating Emissive SubBandgap States in Thin Films of PbS Nanocrystals. Adv. Mater. 2015, 27 (30), 4481-4486.

(76) Kim, D.; Kim, D.-H.; Lee, J.-H.; Grossman, J. C. Impact of Stoichiometry on the Electronic Structure of PbS Quantum Dots. Phys. Rev. Lett. 2013, 110 (19), 196802.

(77) Voznyy, O.; Zhitomirsky, D.; Stadler, P.; Ning, Z.; Hoogland, S.; Sargent, E. H. A Charge-Orbital Balance Picture of Doping in Colloidal Quantum Dot Solids. ACS Nano 2012, 6 (9), 8448-8455.

(78) Voznyy, O.; Thon, S. M.; Ip, A. H.; Sargent, E. H. Dynamic Trap Formation and Elimination in Colloidal Quantum Dots. J. Phys. Chem. Lett. 2013, 4 (6), 987-992.

(79) Giansante, C.; Infante, I.; Fabiano, E.; Grisorio, R.; Suranna, G. P.; Gigli, G. "Darker-than-Black" PbS Quantum Dots: Enhancing Optical Absorption of Colloidal Semiconductor Nanocrystals via Short Conjugated Ligands. J. Am. Chem. Soc. 2015, 137 (5), 1875-1886.

(80) Yuan, M.; Liu, M.; Sargent, E. H. Colloidal Quantum Dot Solids for SolutionProcessed Solar Cells. Nat. Energy 2016, 1 (3), 16016.

(81) Hu, L.; Mandelis, A.; Melnikov, A.; Lan, X.; Hoogland, S.; Sargent, E. H. Study of Exciton Hopping Transport in PbS Colloidal Quantum Dot Thin Films Using Frequency- and Temperature-Scanned Photocarrier Radiometry. Int. J. Thermophys. 2017, $38(1)$.

(82) Maulu, A.; Rodríguez-Cantó, P. J.; Navarro-Arenas, J.; Abargues, R.; Sánchez-Royo, J. F.; García-Calzada, R.; Martínez Pastor, J. P. Strongly-Coupled PbS QD Solids by Doctor Blading for IR Photodetection. RSC Adv. 2016, 6 (83), 80201-80212.

(83) Baker, J. M.; Johnson, R. W.; Pollak, R. A. Surface Analysis of Rf Plasma Oxidized In and PbInAu Films Using ESCA. J. Vac. Sci. Technol. 1979, 16 (5), 1534-1541.

(84) Gökağaş, G.; Kennedy, B. J. Potential-Dependent Surface Segregation in Lead + Ruthenium Pyrochlore Pb2Ru2O7-Y. J. Electroanal. Chem. 1993, 353 (1-2), 7180 .

(85) Nefedov, V. I.; Salyn, Y. V.; Solozhenkin, P. M.; Pulatov, G. Y. X-Ray Photoelectron Study of Surface Compounds Formed during Flotation of Minerals. Surf. Interface Anal. 1980, 2 (5), 170-172.

(86) Pederson, L. R. Two-Dimensional Chemical-State Plot for Lead Using XPS. $J$. Electron Spectros. Relat. Phenomena 1982, 28 (2), 203-209.

(87) Moulder, J. F.; Stickle, W. F.; Sobol, P. E.; Bomben, K. D. Handbook of X-Ray Photoelectron Spectroscopy; Chastain, Jill; Roger C. King, J., Ed.; ULVAC-PHI, Inc, 1995.

(88) Zherebetskyy, D.; Scheele, M.; Zhang, Y.; Bronstein, N.; Thompson, C.; Britt, D.; Salmeron, M.; Alivisatos, P.; Wang, L.-W. Hydroxylation of the Surface of PbS Nanocrystals Passivated with Oleic Acid. Science (80-. ). 2014, 344 (6190), 13801384.

(89) G. Beamson, D. B. High Resolution XPS of Organic Polymers. Sci. ESCA300 Database Wiley Intersci. 1992. 
(90) Electrochemistry of Hemoglobin I fromLucina Pectinata Immobilized on a Modified Gold Electrode with 3-Mercaptopropionic Acid. Int. J. Anal. Bioanal. Chem. 2012, 2 (4), 218-227.

(91) Hammond, J. S.; Holubka, J. W.; DeVries, J. E.; Dickie, R. a. The Application of XRay Photo-Electron Spectroscopy to a Study of Interfacial Composition in Corrosion-Induced Paint de-Adhesion. Corros. Sci. 1981, 21 (3), 239-253.

(92) Nefedov V.I., Salyn Y.V., K. X. No Title. Zh. Neorg. Khimii 1979, 24 (2564).

(93) Burns, F. C.; Swalen, J. D. X-Ray Photoelectron Spectroscopy of Cadmium Arachidate Monolayers on Various Metal Surfaces. J. Phys. Chem. 1982, 86 (26), 5123-5127.

(94) Gelius, U.; Hedén, P. F.; Hedman, J.; Lindberg, B. J.; Manne, R.; Nordberg, R.; Nordling, C.; Siegbahn, K. Molecular Spectroscopy by Means of ESCA: III Carbon Compounds. Phys. Scr. 1970, 2 (1-2), 70-80.

(95) Jung D.R., C. A. W. No Title. J. Vac. Sci. Technol. A 1995, 13 (1337).

(96) Nefedov V.I., Salyn Y.V., Majorova A.G., Nazarova L.A., B. I. B. No Title. $Z h$. Neorg. Khimii 1974, 19, 1353.

(97) Venezia, A. M.; Bertoncello, R.; Deganello, G. X-ray Photoelectron Spectroscopy Investigation of Pumice-supported Nickel Catalysts. Surf. Interface Anal. 1995, 23 (4), 239-247.

(98) Verhoeven, J. A. T.; Van Doveren, H. An XPS Investigation of the Interaction of $\mathrm{CH} 4, \mathrm{C} 2 \mathrm{H} 2, \mathrm{C} 2 \mathrm{H} 4$ and C2H6 with a Barium Surface. Surf. Sci. 1982, 123 (2-3), 369-383.

(99) Xu, X.; Friend, C. M. The Role of Coverage in Determining Adsorbate Stability: Phenol Reactivity on rhodium(111). J. Phys. Chem. 1989, 93 (24), 8072-8080.

(100) J.M., B. -. J. Vac. Sci. Technol. 1979, 16, 363.

(101) Beamson, G. Briggs, D. High Resolution XPS of Organic Polymers: The Scienta ESCA300 Database (Beamson, G.; Briggs, D.). J. Chem. Educ. 1993, 70 (1), A25.

(102) Beamson, G.; Briggs, D. High Resolution XPS of Organic Polymers, The Scienta ESCA 300 Database John Wiley \& Sons; 1992; Vol. 15.

(103) Wagner, C. D.; Zatko, D. A.; Raymond, R. H. Use of the Oxygen KLL Auger Lines in Identification of Surface Chemical States by Electron Spectroscopy for Chemical Analysis. Anal. Chem. 1980, 52 (9), 1445-1451.

(104) Nefedov V.I., Gati D., Dzhurinskii, B.F., Sergushin N.P., S. Y. V. -. Zh. Neorg. Khimii 1975, 20, 2307.

(105) Manocha, A. S.; Park, R. L. Flotation Related ESCA Studies on PbS Surfaces. Appl. Surf. Sci. 1977, 1 (1), 129-141.

(106) Zingg, D. S.; Hercules, D. M. Electron Spectroscopy for Chemical Analysis Studies of Lead Sulfide Oxidation. J. Phys. Chem. 1978, 82 (18), 1992-1995.

(107) Kim, K. S.; O’Leary, T. J.; Winograd, N. X-Ray Photoelectron Spectra of Lead Oxides. Anal. Chem. 1973, 45 (13), 2214-2218.

(108) Neamen, D. A. Semiconductor Physics and Devices. Mater. Today 2006, 9 (5), 57.

(109) Zhang, Y.; Zherebetskyy, D.; Bronstein, N. D.; Barja, S.; Lichtenstein, L.; Alivisatos, A. P.; Wang, L.-W.; Salmeron, M. Molecular Oxygen Induced in-Gap States in PbS Quantum Dots. ACS Nano 2015, 9 (10), 10445-10452. 


\section{Appendix A) "Sandwich" cell optimizations for QD solids studies}

As mentioned earlier, the proximity of $\mathrm{WE}$ and $\mathrm{CE}$ in the proposed cell geometry is important. I optimized the Surlyn spacer's thickness and other complementary aspects of the cell, in order to eliminate unwanted resistance or redox species diffusion limitations when liquid contacting will be used. For this study, a test cell was made as illustrated in Figure 56. Area of contacting electrolyte was kept constant $\left(0.45 \mathrm{~cm}^{2}\right)$.

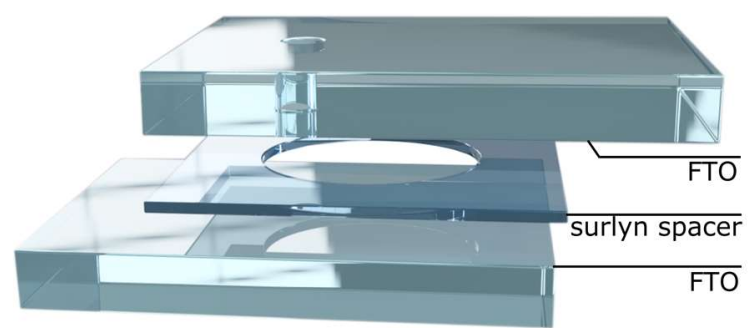

Figure 56. Test cell used for the cell optimizations studies.

As demonstrated in Figure 57, the series resistance of the test cell is linearly proportional to the spacer thickness which is explained by definition of resistivity $\rho$.

$$
\rho=R \frac{A}{l}
$$

Where $\mathrm{R}$ is the resistance of a uniform specimen of material, $l$ is length (thickness) of the material, and $\mathrm{A}$ is a cross-sectional area of the specimen. 

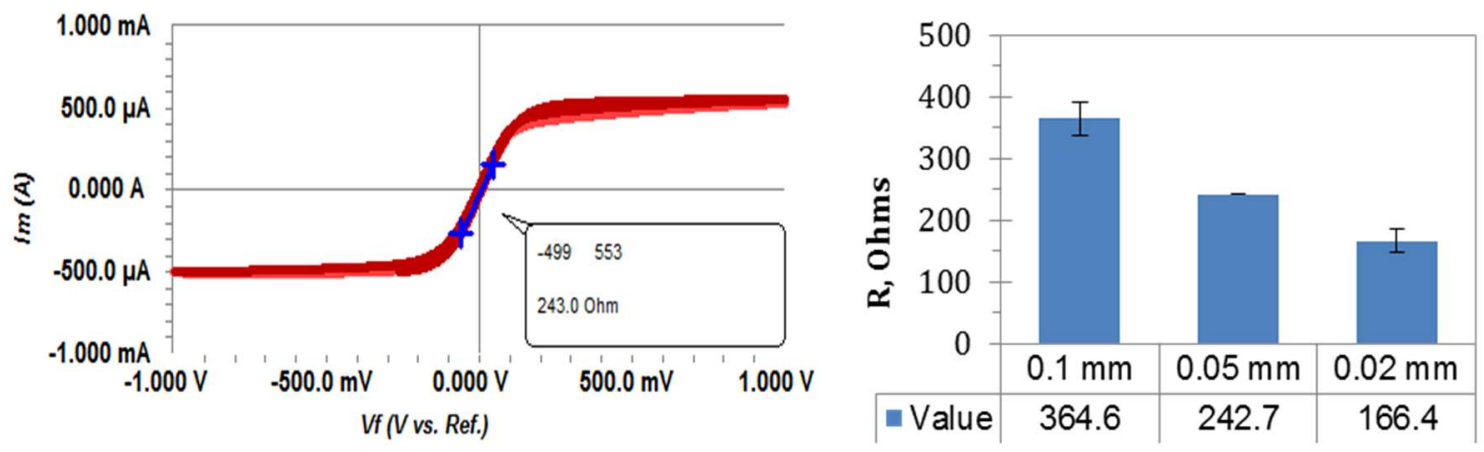

Figure 57. Effect of spacer's thickness on series resistance of the test cell filled with $\mathrm{Cp}_{2} \mathrm{Co}^{+/ 0}$ electrolyte.

Importance of reduced thickness of the spacer was also noticeably observed on improved diffusion-limited anodic and cathodic currents (Figure 58) of the devices.

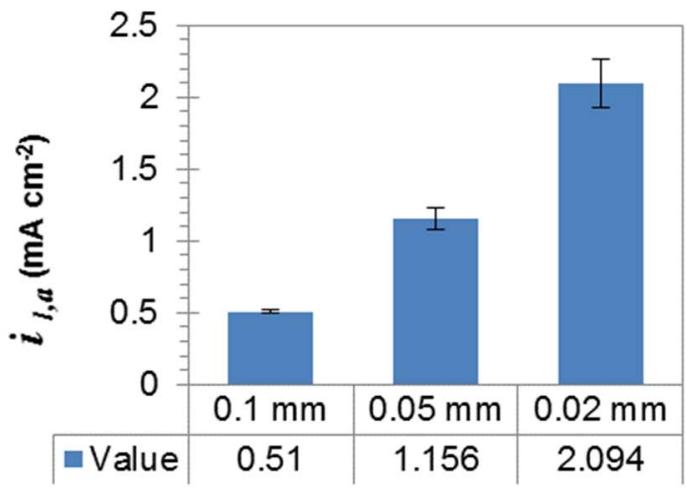

Figure 58. Effect of spacer's thickness on limiting current of the test cell filled with $\mathrm{Cp}_{2} \mathrm{Co}^{+/ 0}$ electrolyte.

Since the end-use of the device-optimized herein is to study photovoltaic properties of QD solids, and the fact that series resistance does limit the PCE of such devices, it is of high interest to use as thin spacer as practically possible. Additionally, with thicker spacers, like parafilm $(0.11 \mathrm{~mm})$ or $0.1 \mathrm{~mm}$ Elastosil, another characteristic feature of the $i-V$ curve is observed. Figure 59 illustrates the presence of so-called duck-shape and an emergence of 
the associated hysteresis, which is desired to be avoided in $i$ - $V$ curves when a more defined shape of such curve is necessary (FF and $V_{\mathrm{oc}}$ measurements).

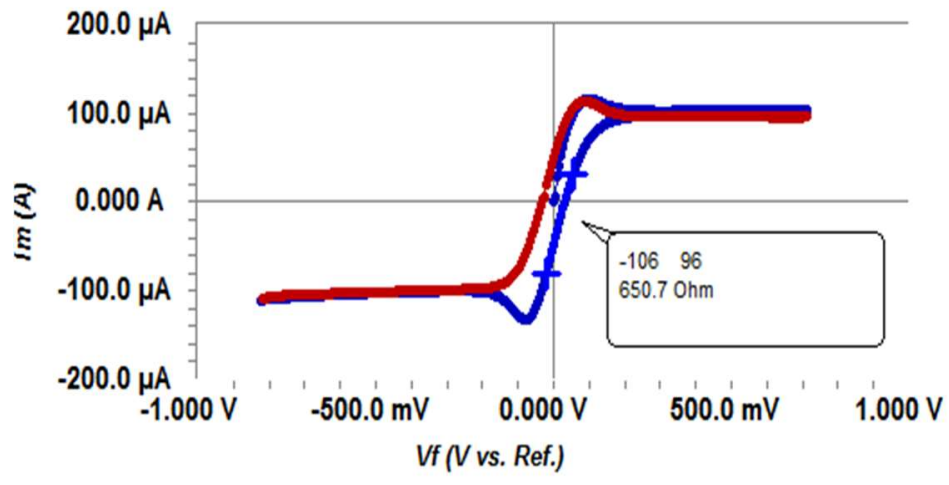

Figure 59. The I- $V$ curve obtained with Sandwich cell (FTO/Cp $\left.\mathrm{Co}^{+/ 0} / \mathrm{FTO}\right)$ that used a thick $(0.1 \mathrm{~mm})$ spacer.

Two spacer materials were found promising in the application of this kind; the thermoplastic sealant (Surlyn) (TPS 065096-30, Dyesol) and "Elastosil" (by Wacker). Surlyn films are harder than Elastosil and require heat-assisted softening and sealing, while Elastosil films are soft and flexible and can be used in a mechanical clamping (Figure 60) applications, where, for example, a cell will need to be disassembled after electrochemical testing for QD films characterization on a different instrument.

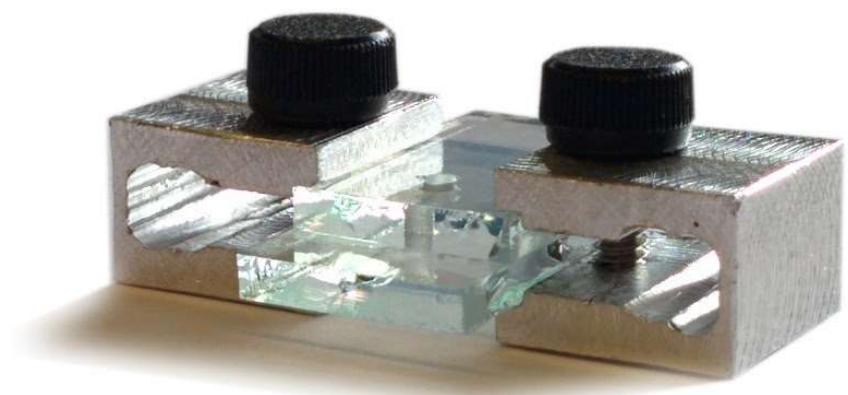

Figure 60. Mechanically clamped test cell with a soft spacer (Elastosil) 
It should be mentioned, however, that Elastosil films are harder to apply, due to its softness and electrostatic properties that result in easy film folding. This becomes an issue, especially if a cell needs to be assembled in a glovebox. Most of the studies were performed using 30um thick heat sealing Surlyn spacer.

An additional two features of the "sandwich" cell engineering were also explored. Adhesive aluminum is known to be used on contacting areas to assist connection and proper contacting between alligator clip and the solar cell. Also, metallic coverage of counter FTO electrode with gold $(\sim 50-80 \mathrm{~nm} \mathrm{Au})$ was believed to reduce resistance and hence improve the cell performance. However, after these two effects were studied, it was found that depositing $\mathrm{Au}$ on $\mathrm{CE}$ has a negligible effect on such improvement, while the particular brand of $\mathrm{Al}$ adhesive that was used, had a negative effect on cells performance. Hence, optimal conditions for test cell assembly were found and consistently followed throughout the studies. 


\section{Appendix B) Automated programmable spin coater}

During the work described here, a need for an improved reproducibility and cleanliness of deposited QD solids raised, as this was a challenge to achieve with the manual spin coating. Another critical point was the question of portability of the commercially available spin coating machines. This was important for spin coat deposition of QD solids in an inert atmosphere glovebox, with space limitations of glovebox itself and the transfer chambers attached to them. Additionally, the average cost of an automated spin coating machine reaches well over $\$ 4,000-\$ 6,000$ USD.

Hence, I designed, prototyped and built a compact, portable spin coater with automatic liquid injection feature (Figure 61). It is powered by 12 VDC, is actuated by one brushless and three servo motors, and is controlled by an Atmega328 microcontroller, remotely communicating to a keypad (input) and directly connected to an LCD screen (output).

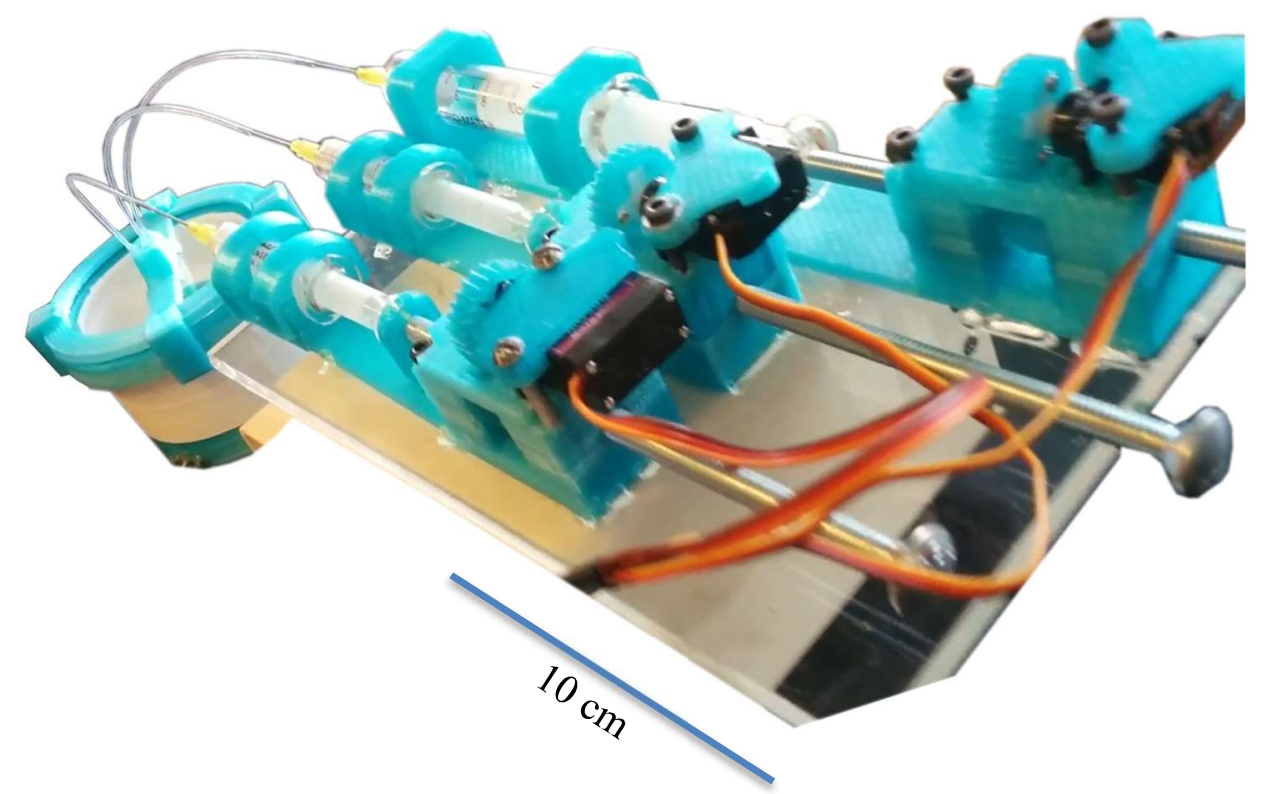

Figure 61. A photograph of the automated injection system and the spin coater chamber. 
The chamber contains an insulated brushless motor and an insert for leftover liquid collection, as well as the customized sample holder. The replaceable sample holder is 3D printed and is designed to work without a need for vacuum (Figure 62).

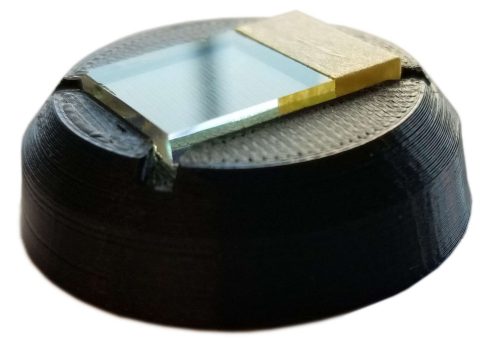

Figure 62. Spin coater's sample holder.

The controls and user parameters are entered via IR-remote keypad and are displayed on the controller's LCD screen shown in Figure 63.
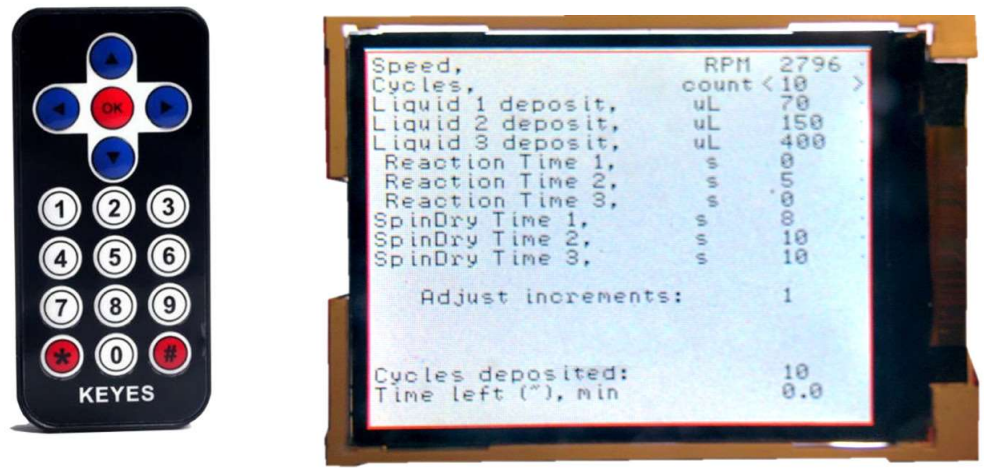

Figure 63. Remote controller and parameters display of the spin coater.

Since most of the parts for the described spin coater were 3D printed using plastic filament materials; polylactic acid (PLA) or acrylonitrile butadiene styrene (ABS), one important aspect should be emphasized. Deposition of chemically stabilized QD solids requires the use of appropriate solvents, hence compatibility of those solvents and the plastic used to manufacture solvents collecting compartment and the sample holder must be considered. 
For example, PLA works great with most alcohol solvents, while will only last for 7-10 minutes with acetonitrile and $\sim 15$ minutes with acetone as later can dissolve PLA. Similarly, ABS is not compatible with acetone. Solvents such as n-hexane were proven to be compatible with PLA. As an alternative though, in case of incompatibility, a Teflon material can be used to machine the parts that are to be exposed to the solvents.

With the use of the automated spin coater, not only the reproducibility in PV performance of QD based devices was improved, but also the film quality as shown in Figure 64. This was mainly achieved due to more precisely timed solution injections and reaction times, and reduced chamber volume which allows for easier control of solvent vapors and inner gas quality.
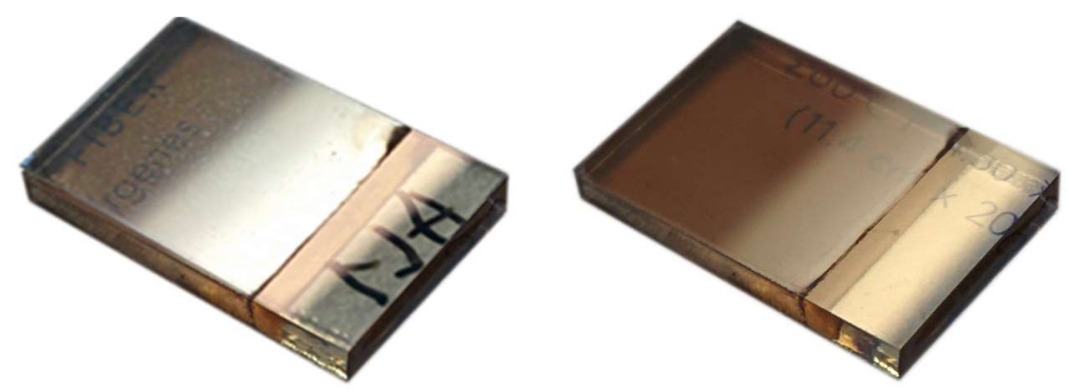

Figure 64. Differences in quality of PbS QD solid films deposited on FTO manually (left), and with use of automated spin coater (right). 